\title{
Stereo-Selective and Atom-Economic Alkenyl C-H Allylation/Alkenylation in Aqueous Media by Iridium Catalysis
}

Yinhua Huang,${ }^{\dagger *}$ Liangyao Xu, ${ }^{\dagger}$ Feifei Yu, ${ }^{\dagger}$ Wenzhou Shen,${ }^{\dagger}$ Xiunan Lu, ${ }^{\dagger}$ Liyuan Ding, ${ }^{\dagger}$ Liangjun Zhong, ${ }^{\ddagger *}$ Guofu Zhong, ${ }^{\dagger}$ and Jian Zhang ${ }^{\dagger *}$

${ }^{\dagger}$ College of Materials, Chemistry and Chemical Engineering, Hangzhou Normal University, Hangzhou 311121, China.

*Department of Stomatology, The Affiliated Hospital of Hangzhou Normal University, Hangzhou Normal University, Hangzhou, 310015, China.

E-mail:yhhuang@hznu.edu.cn; zymdxx@163.com; zhangjian@hznu.edu.cn

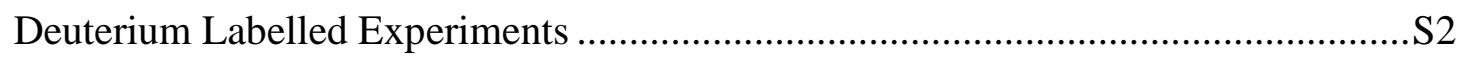

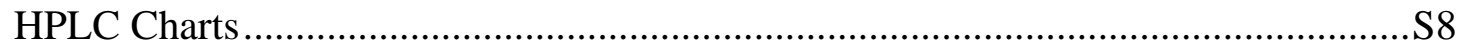

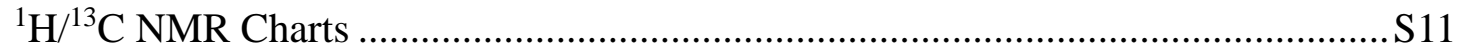


Ir-Catalyzed H/D Exchange
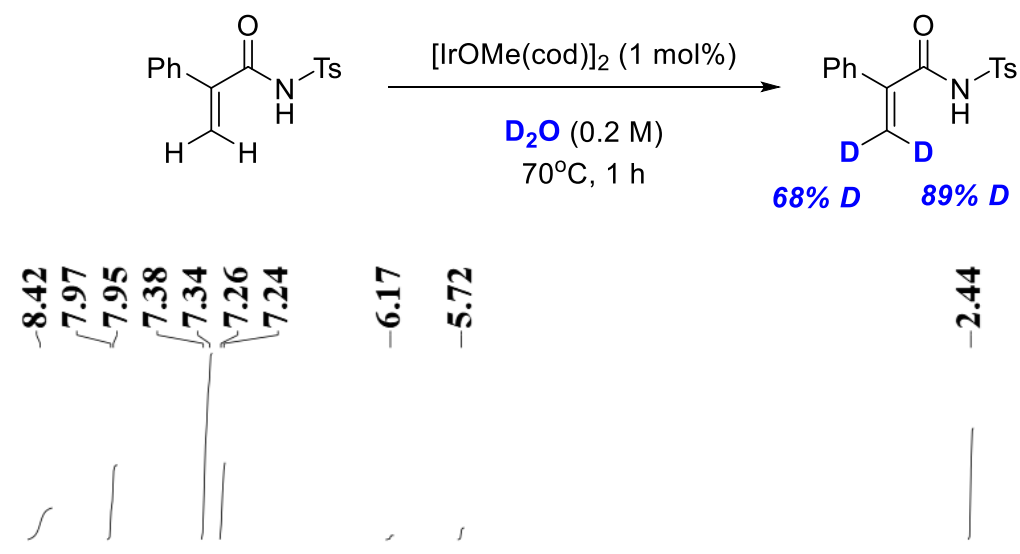

${ }^{1} \mathrm{H}$ NMR $\left(\mathrm{CDCl}_{3}, 500 \mathrm{MHz}\right)$

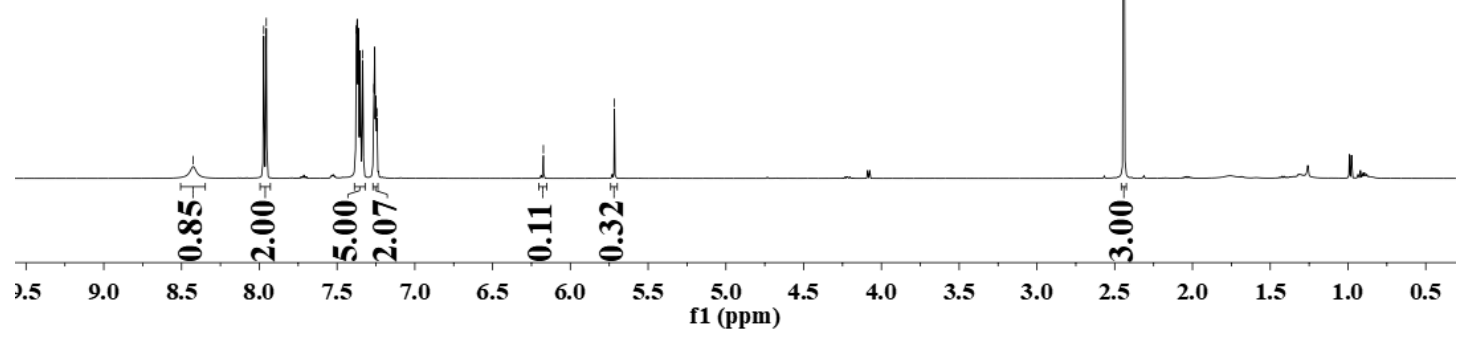



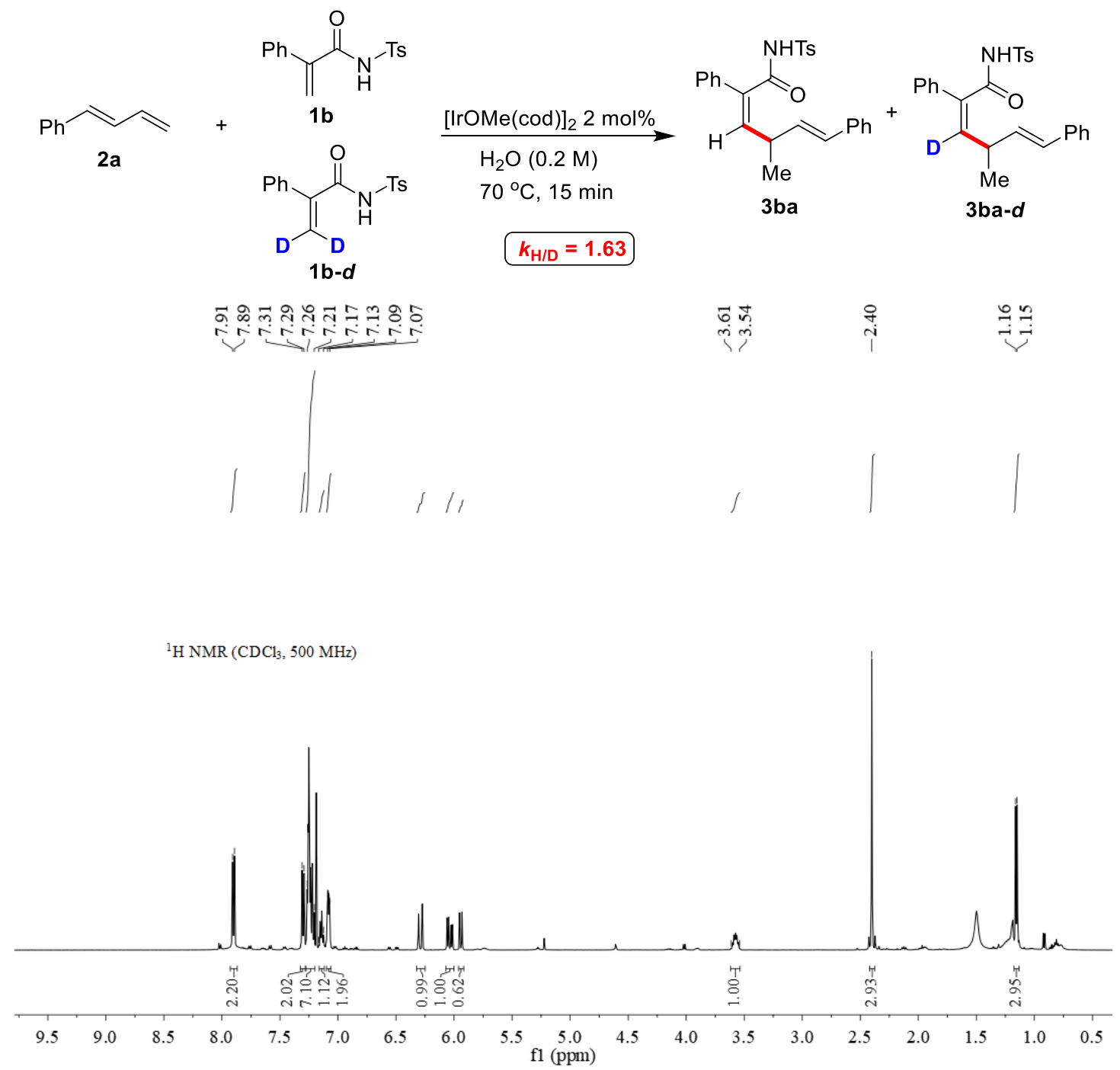


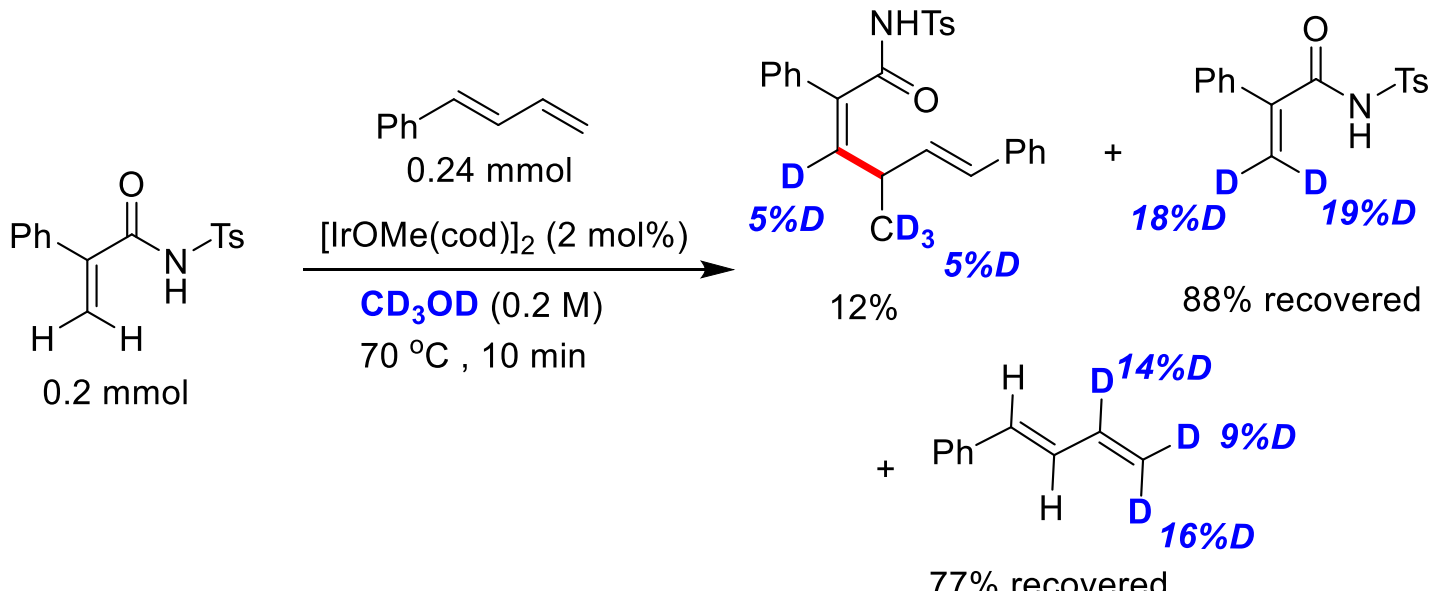

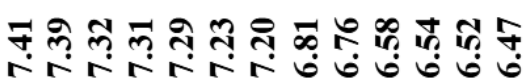

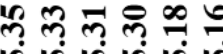

vi in in in

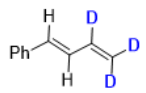

${ }^{1} \mathrm{H} \mathrm{NMR}\left(\mathrm{CDCl}_{3}, 500 \mathrm{MHz}\right)$

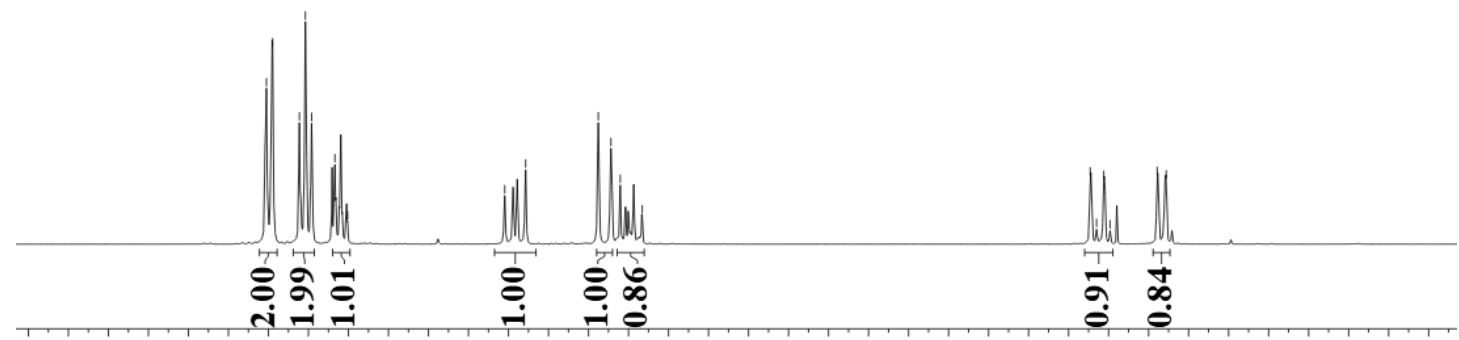

B.0 7.9 7.8 7.7 7.6 7.5 7.4 7.3 7.2 7.1 7.0 6.9 6.8 6.7 6.6 6.5 6.4 6.3 6.2 6.1 6.0 5.9 5.8 5.7 5.6 5.5 5.4 5.3 5.2 5.1 5.0 4.9 4.8 4.7 4.6 4.5 f1 (ppm) 


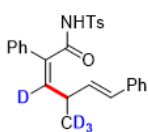

${ }^{1} \mathrm{H} \mathrm{NMR}\left(\mathrm{CDCl}_{3}, 500 \mathrm{MHz}\right)$

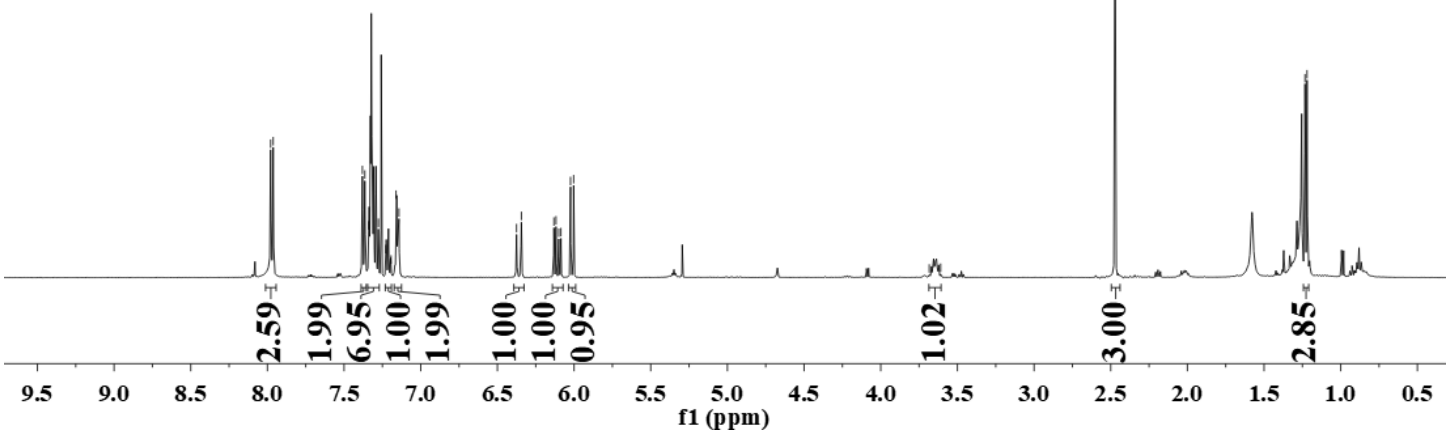

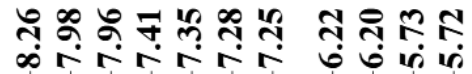

$\frac{10}{8}$

$$
\overbrace{D}^{2} \overbrace{N^{-T s}}^{O}
$$

${ }^{1} \mathrm{H} \mathrm{NMR}\left(\mathrm{CDCl}_{3}, 500 \mathrm{MHz}\right)$

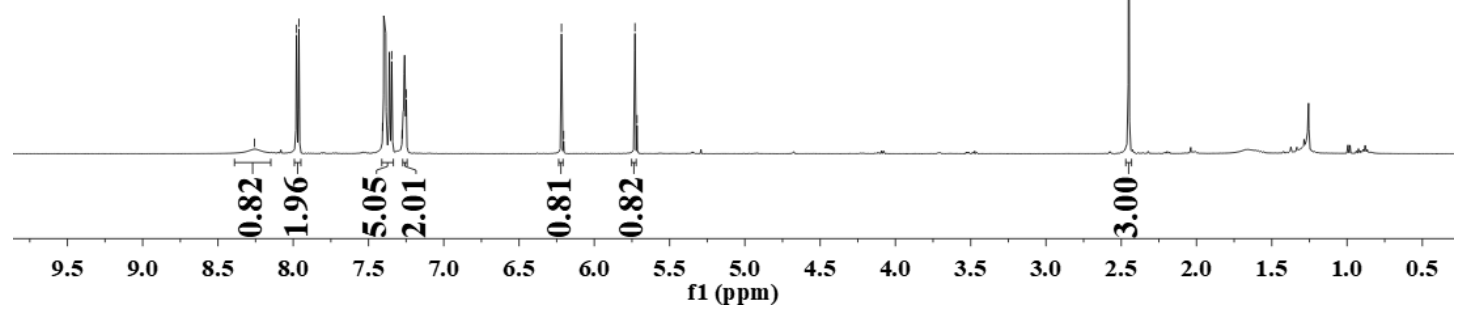




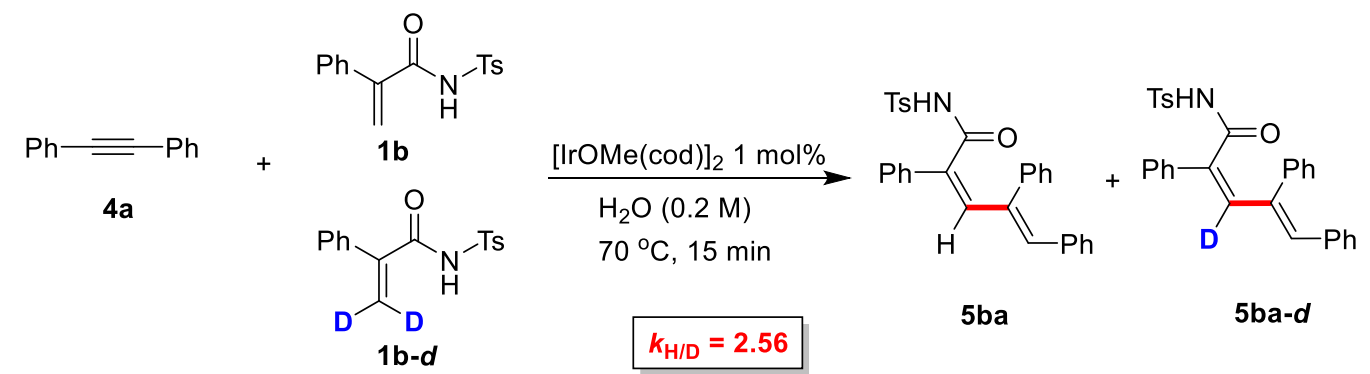

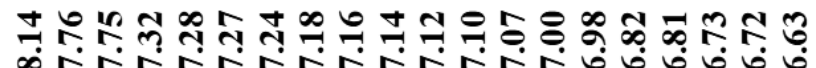

กิ

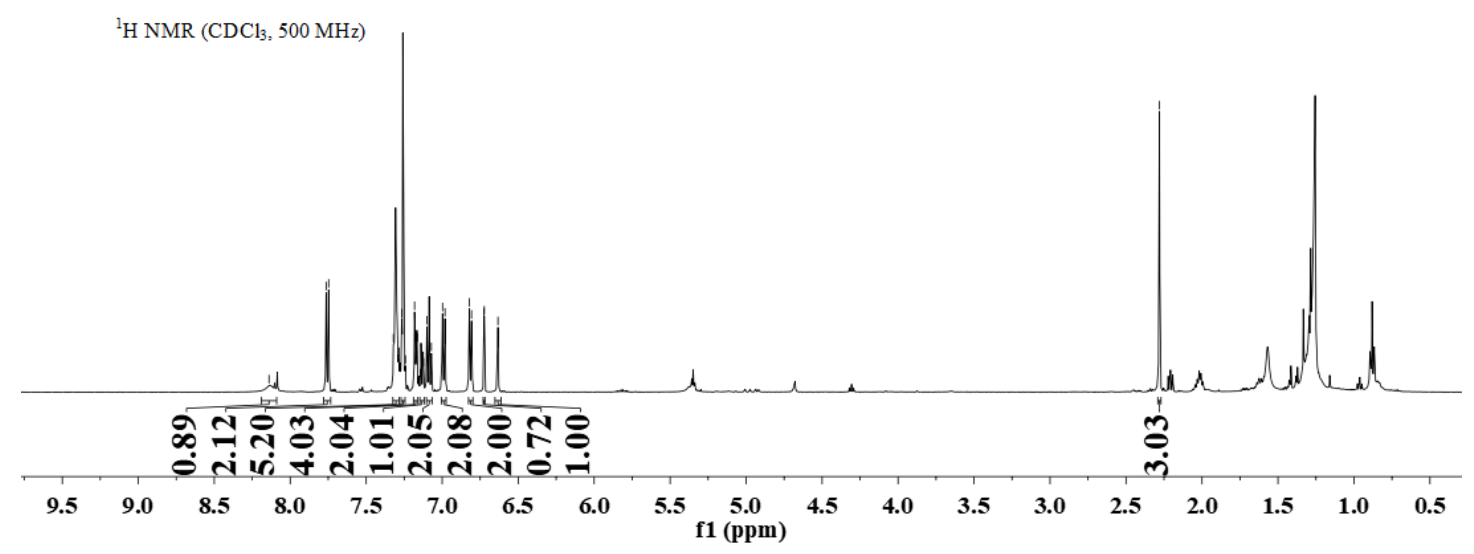




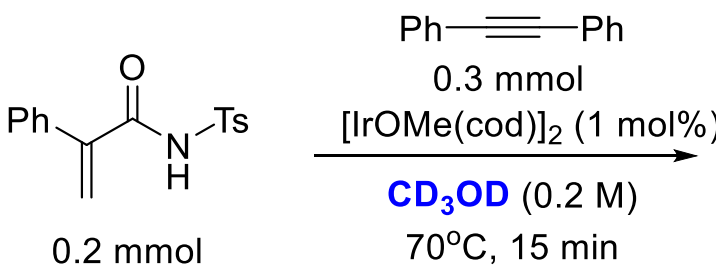

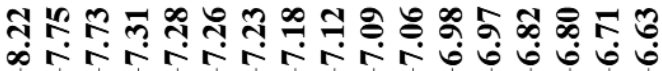

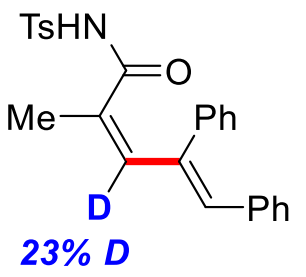

$15 \%$

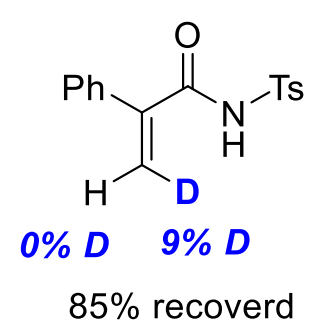

กิ
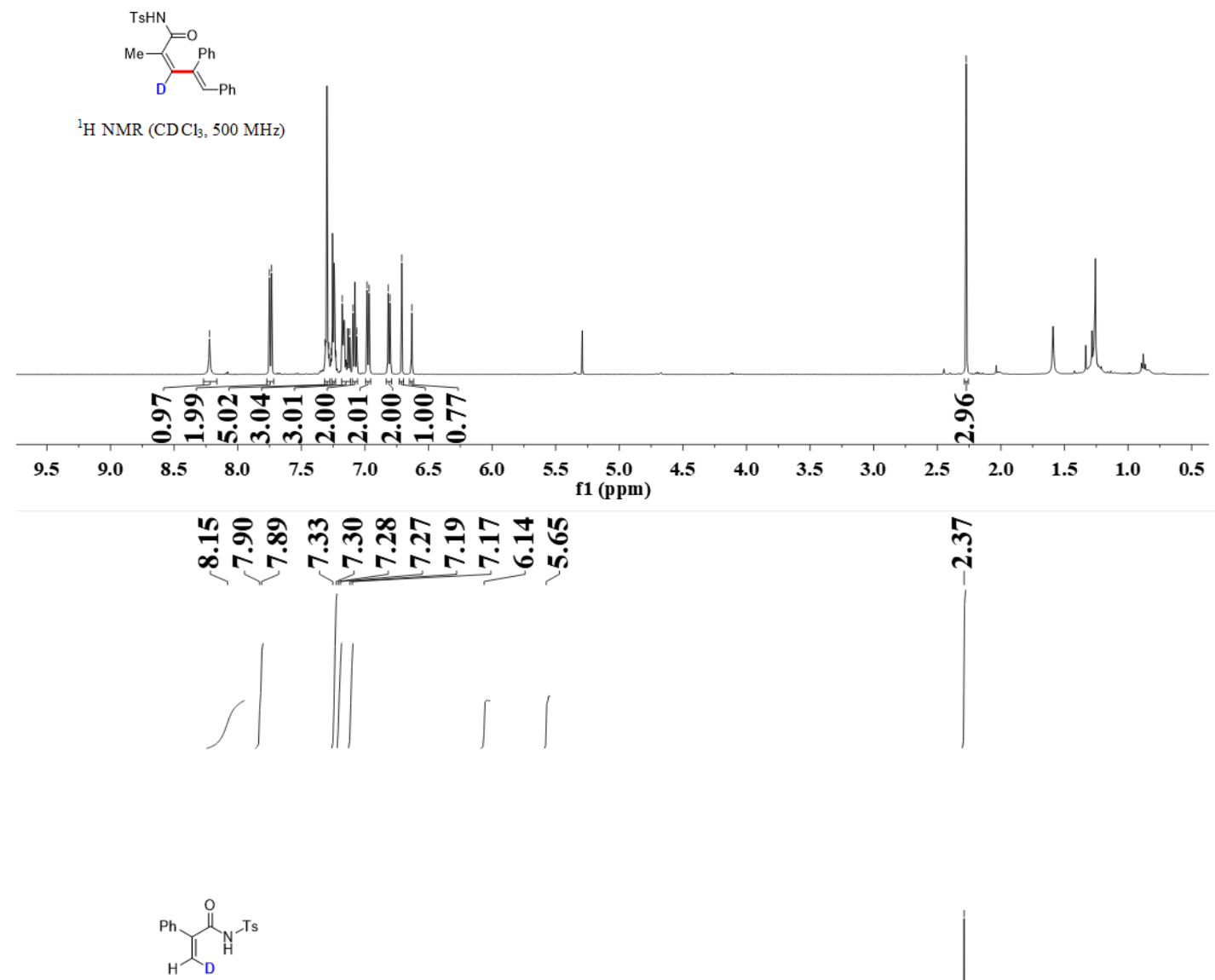

${ }^{1} \mathrm{H} \mathrm{NMR}\left(\mathrm{CDCl}_{3}, 500 \mathrm{MHz}\right)$

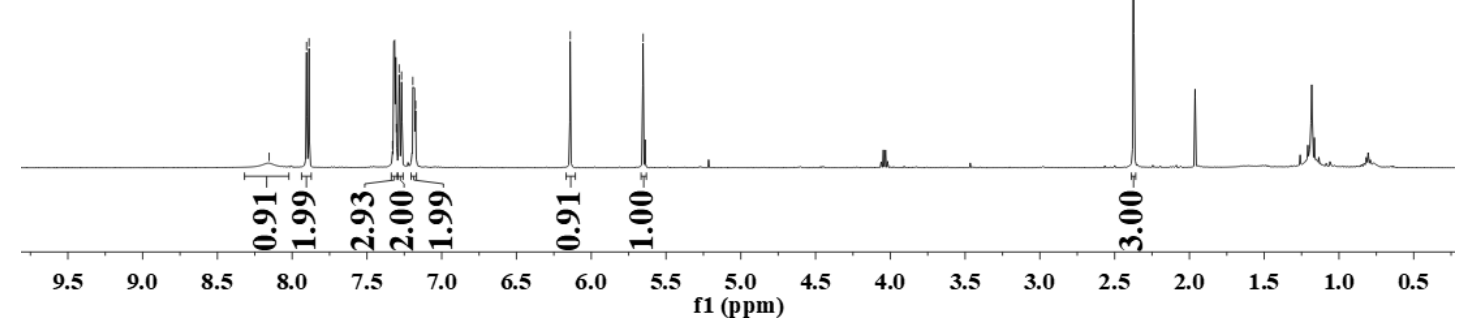




\section{HPLC Charts}

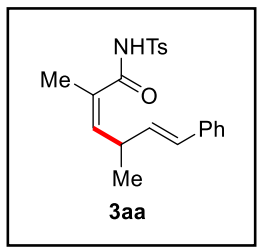

HPLC: Chiralcel IA (n-hexane/i-PrOH, 90/10, flow rate $1.0 \mathrm{~mL} / \mathrm{min}$,

$\lambda=254 \mathrm{~nm}), \mathrm{t}_{\mathrm{R}}($ major $)=29.6 \mathrm{~min}, \mathrm{t}_{\mathrm{R}}($ minor $)=27.1 \mathrm{~min} ; 79 \%$ ee.

$[\alpha]_{\mathrm{D}}{ }^{25}+56.6\left(c 0.25, \mathrm{CHCl}_{3}\right)$.

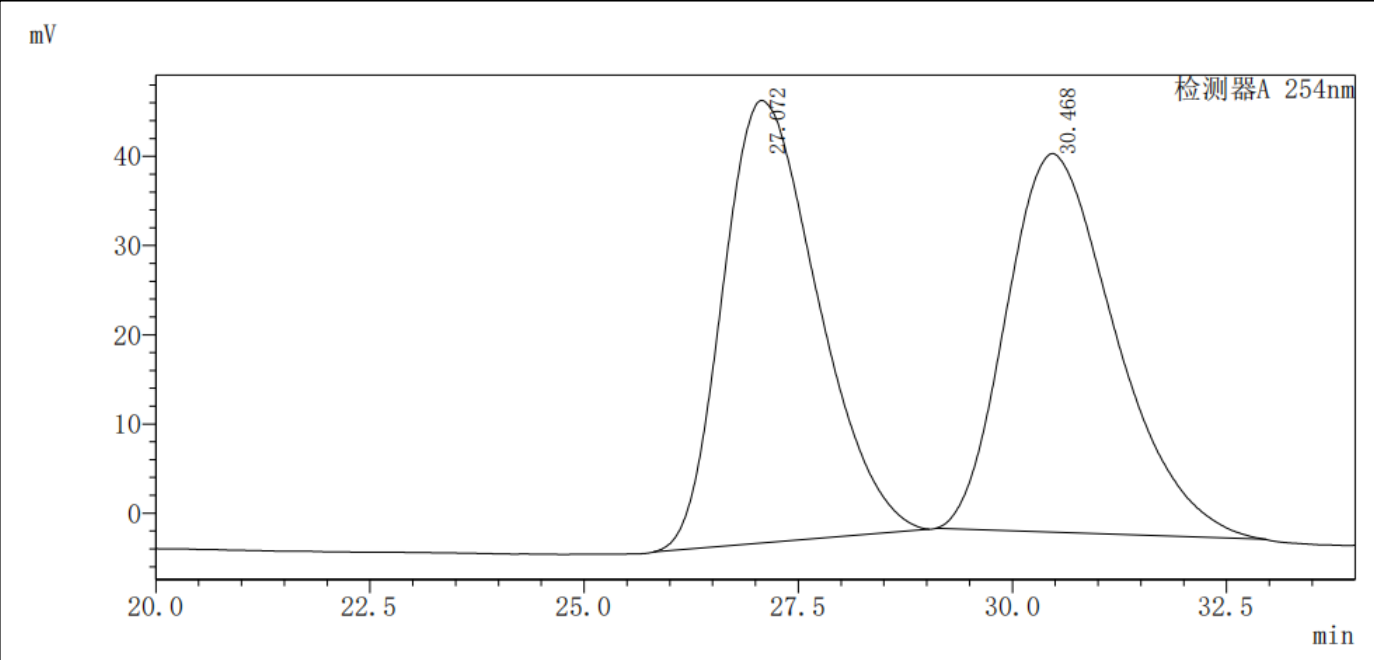

<Peak Table>

Detector A 254nm

\begin{tabular}{|c|l|l|l|l|}
\hline Peak\# & Ret. Time & Area & Hight & Conc. \\
\hline 1 & 27.072 & 3815980 & 49605 & 50.334 \\
\hline 2 & 30.468 & 3765344 & 42458 & 49.666 \\
\hline Total & & 7581324 & 92062 & \\
\hline
\end{tabular}

$\mathrm{mV}$

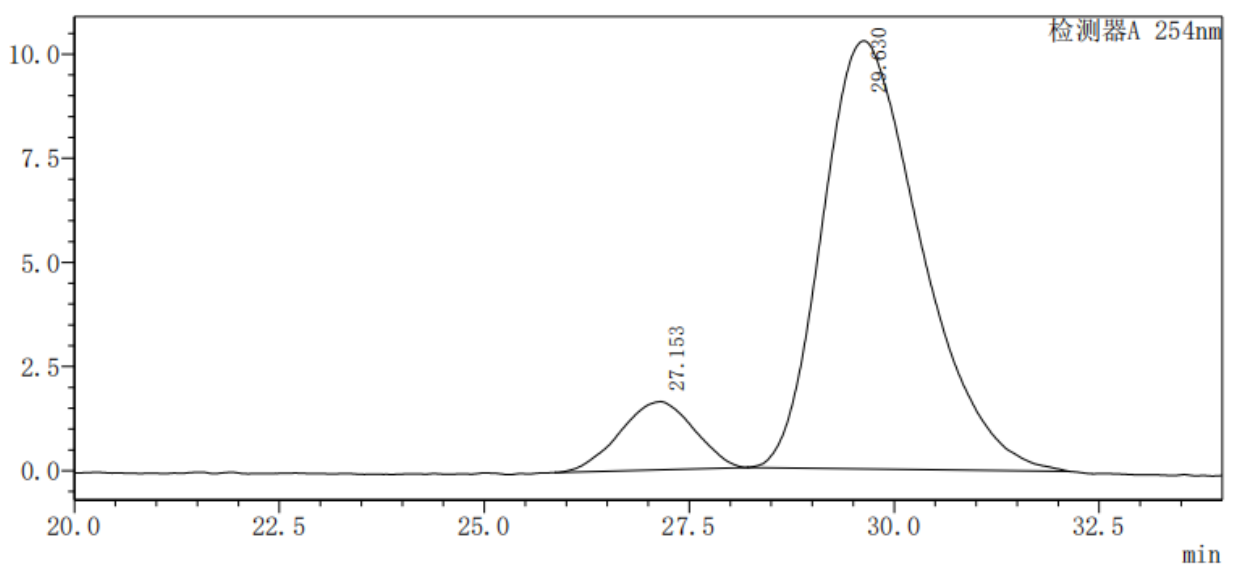

$<$ Peak Table>

Detector A 254nm

\begin{tabular}{|c|l|l|l|l|}
\hline Peak\# & Ret. Time & Area & Hight & Conc. \\
\hline 1 & 27.153 & 103150 & 1639 & 10.705 \\
\hline 2 & 29.630 & 860426 & 10278 & 89.295 \\
\hline Total & & 963577 & 11916 & \\
\hline
\end{tabular}




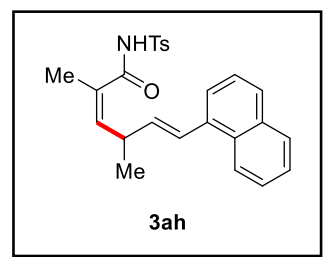

HPLC: Chiralcel IA (n-hexane/i-PrOH, 90/10, flow rate 1.0 $\mathrm{mL} / \mathrm{min}, \lambda=254 \mathrm{~nm}), \mathrm{t}_{\mathrm{R}}($ major $)=31.6 \mathrm{~min}, \mathrm{t}_{\mathrm{R}}($ minor $)=25.9$ $\min ; 79 \%$ ee. $[\alpha]_{\mathrm{D}}{ }^{25}+46.6\left(c 0.25, \mathrm{CHCl}_{3}\right)$.

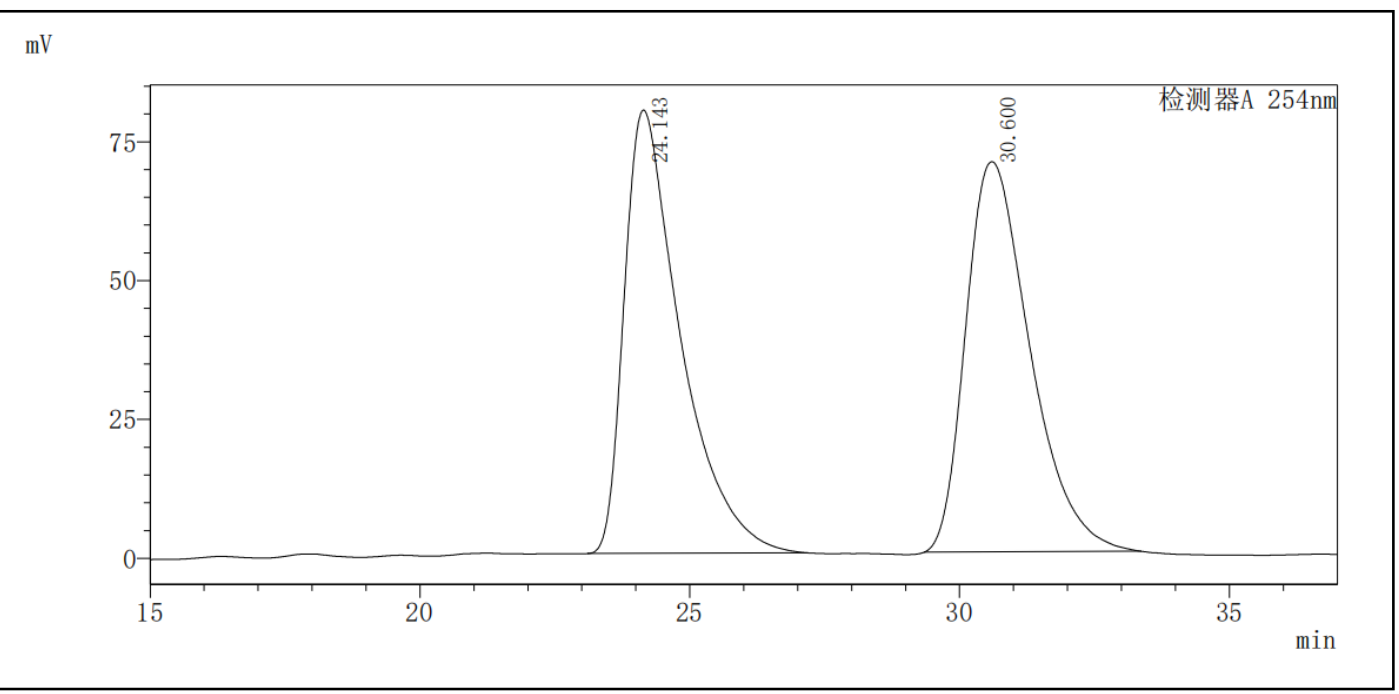

\section{$<$ Peak Table $>$}

Detector A $254 \mathbf{n m}$

\begin{tabular}{|c|l|l|l|l|}
\hline Peak\# & Ret. Time & Area & Hight & Conc. \\
\hline 1 & 24.143 & 5783635 & 79820 & 49.855 \\
\hline 2 & 30.600 & 5817217 & 70242 & 50.145 \\
\hline Total & & 11600852 & 150062 & \\
\hline
\end{tabular}

<Peak Table>

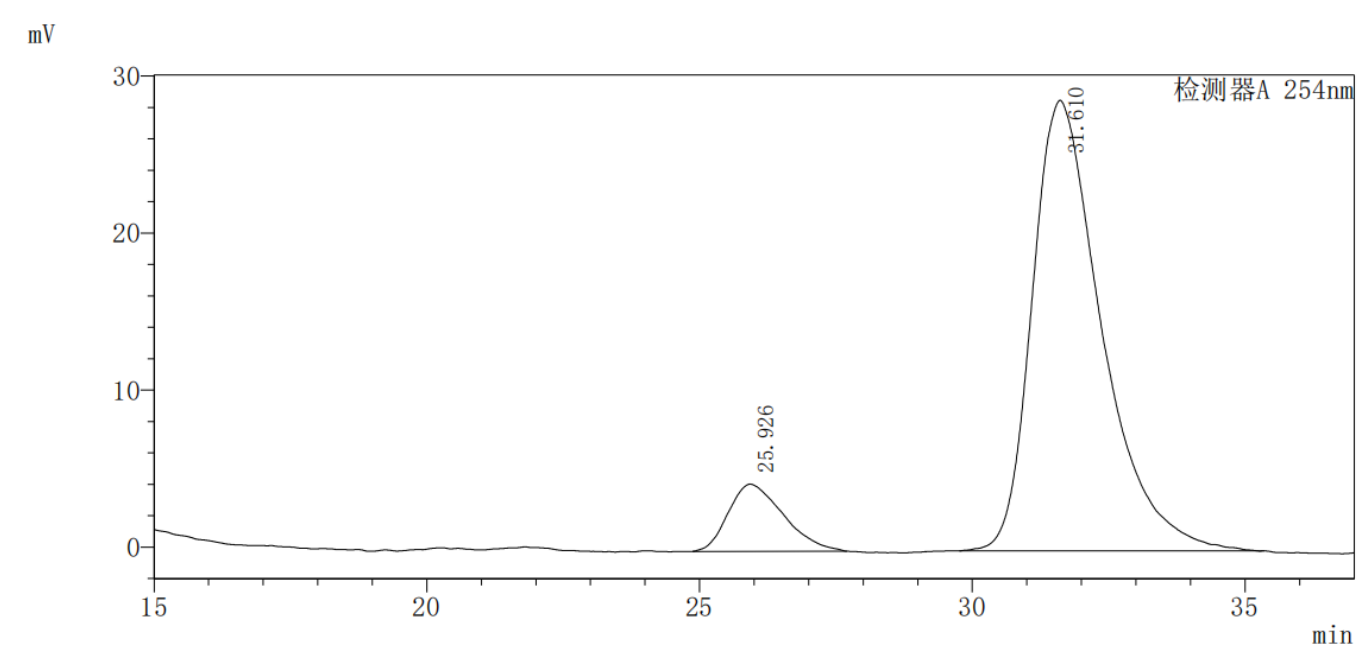

Detector A $254 \mathrm{~nm}$

\begin{tabular}{|c|l|l|l|l|}
\hline Peak\# & Ret. Time & Area & Hight & Conc. \\
\hline 1 & 25.926 & 299324 & 4277 & 10.547 \\
\hline 2 & 31.610 & 1538599 & 28695 & 89.453 \\
\hline Total & & 2837923 & 32972 & \\
\hline
\end{tabular}


Other ligands $\mathrm{L}_{1-8}$ (as shown below) were tested for this reaction, however all of them gave racemic product 3aa.<smiles>c1ccc(-c2ccc3ccccc3c2-c2c(P(c3ccccc3)c3ccccc3)ccc3ccccc23)cc1</smiles>

$\mathrm{L}_{1}$<smiles>CC(C)(C1=NC(c2ccccc2)CO1)C1=NC(c2ccccc2)CO1</smiles><smiles>c1ccc(Cc2cccc(C3=NC(Cc4ccccc4)CO3)n2)cc1</smiles>

$L_{2}$

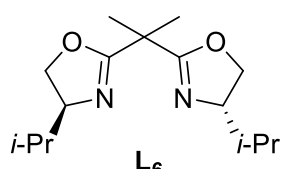<smiles>CC(C)(C)[C@H]1COC(c2cccc(C3=N[C@H](C(C)(C)C)CO3)n2)=N1</smiles>

$\mathrm{L}_{3}$

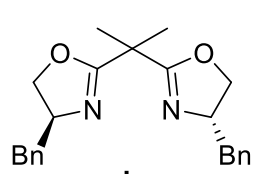

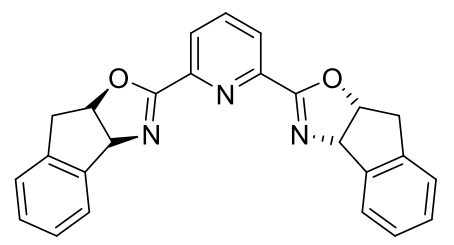

$\mathrm{L}_{4}$<smiles>CC(C)(C)[C@H]1COC(C2(C3=N[C@H](C(C)(C)C)CO3)CCCC2)=N1</smiles> 


\section{${ }^{1} \mathrm{H} /{ }^{13} \mathrm{C}$ NMR Charts}<smiles>CC(/C=C/c1ccccc1)C(=O)N[Sb]</smiles>

3aa

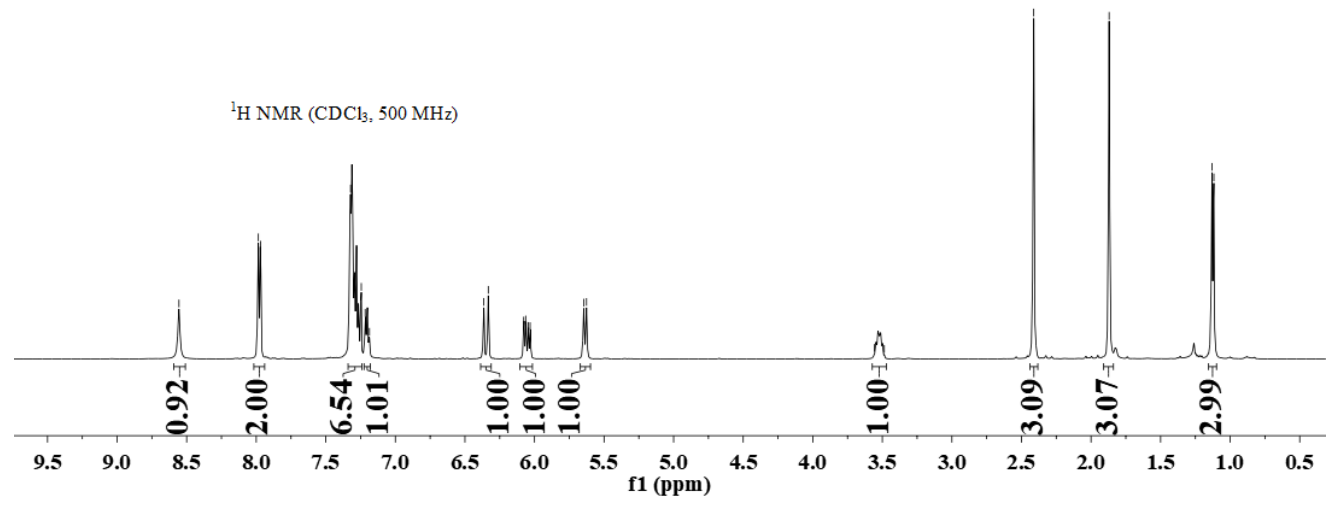

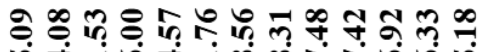

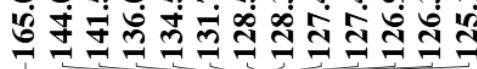

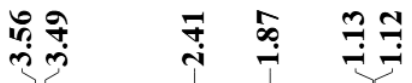
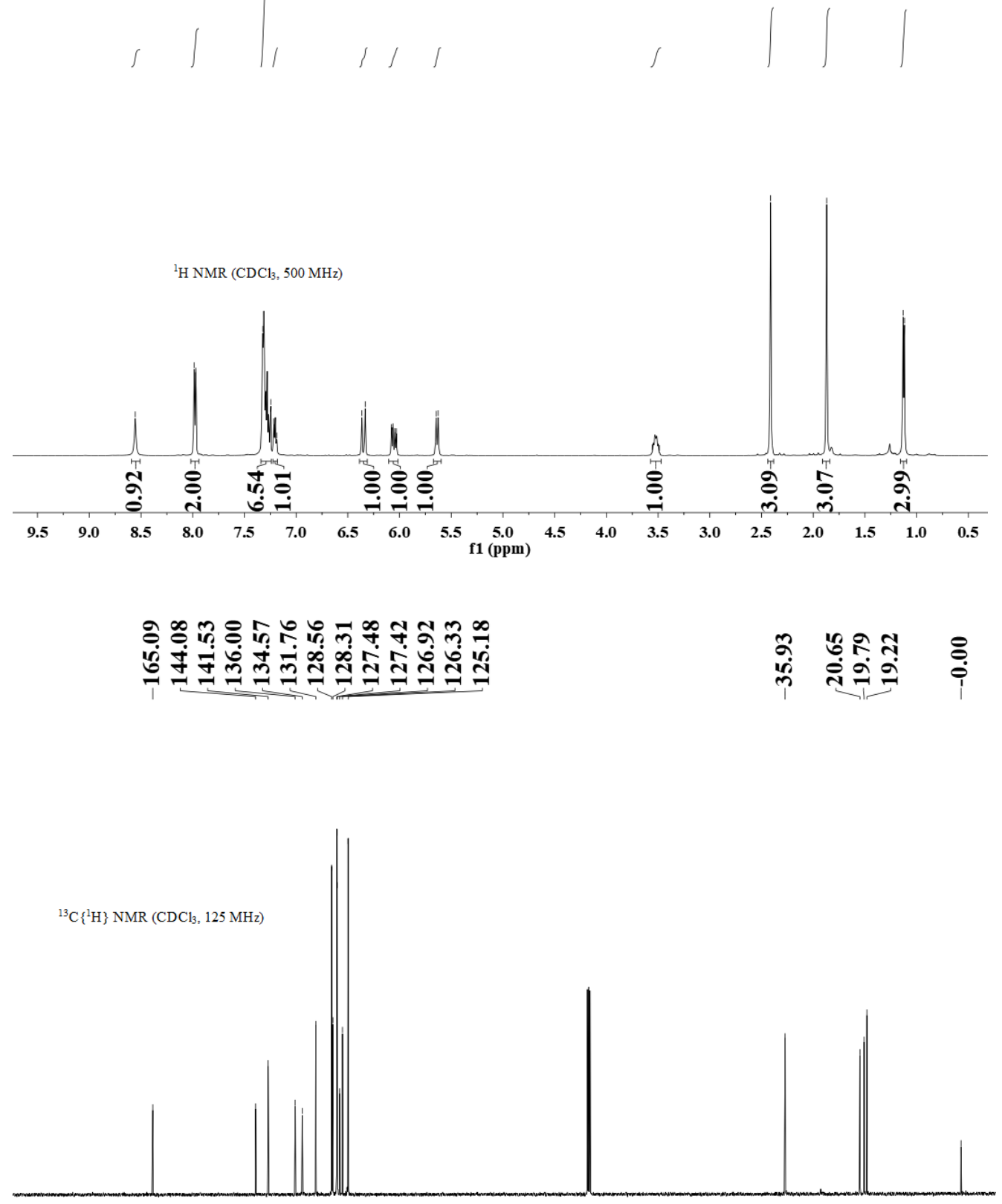

$\begin{array}{lllllllllllllllllllllllll}190 & 180 & 170 & 160 & 150 & 140 & 130 & 120 & 110 & 100 & 90 & 80 & 70 & 60 & 50 & 40 & 30 & 20 & 10 & 0\end{array}$ 
<smiles>CCCCCCCCCNC(=O)C(C)=CC(C)C=Cc1ccc(F)cc1</smiles>

$3 a b$

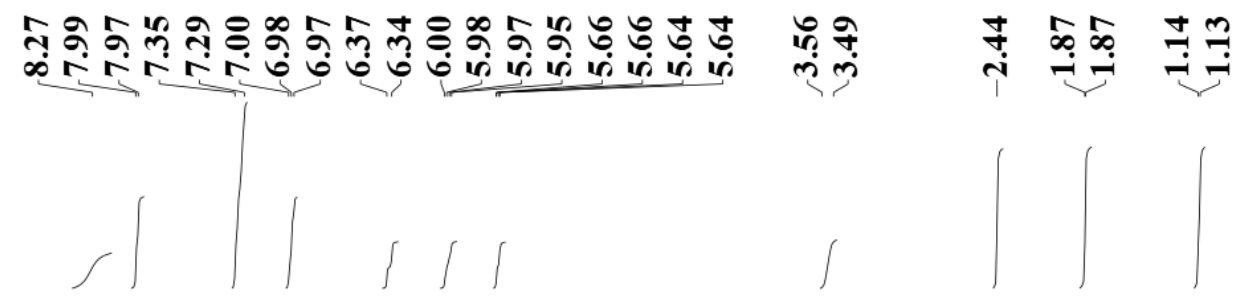

${ }^{1} \mathrm{H} \mathrm{NMR}\left(\mathrm{CDCl}_{3}, 500 \mathrm{MHz}\right)$

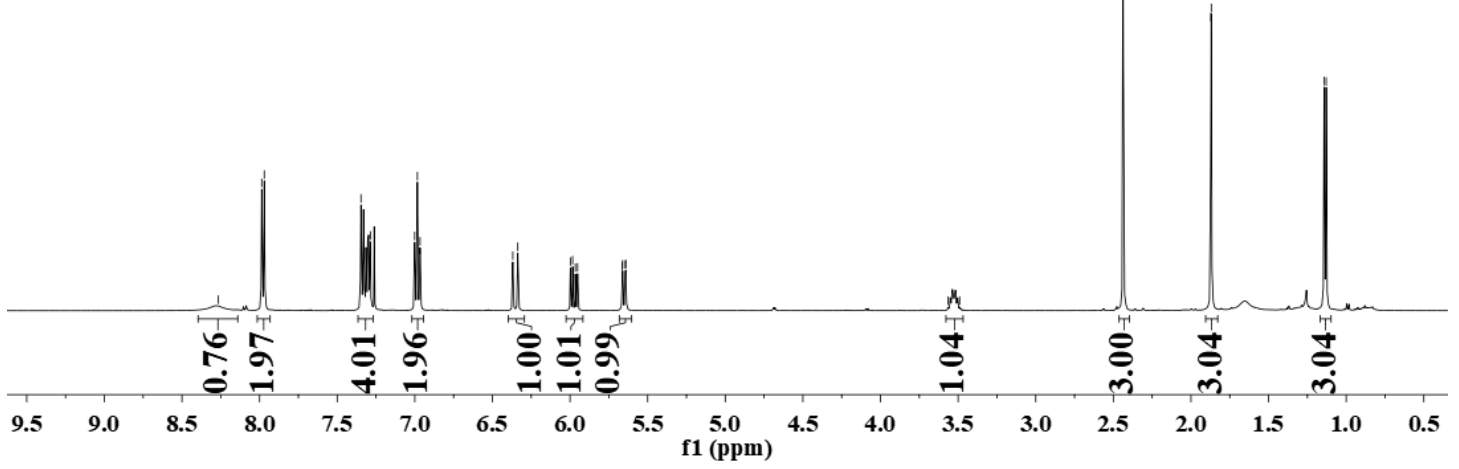

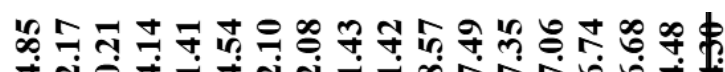

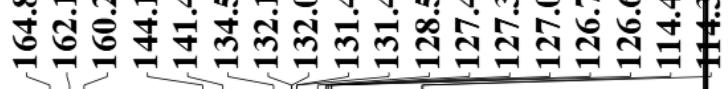

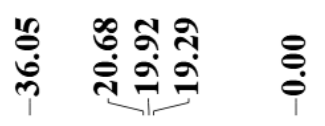

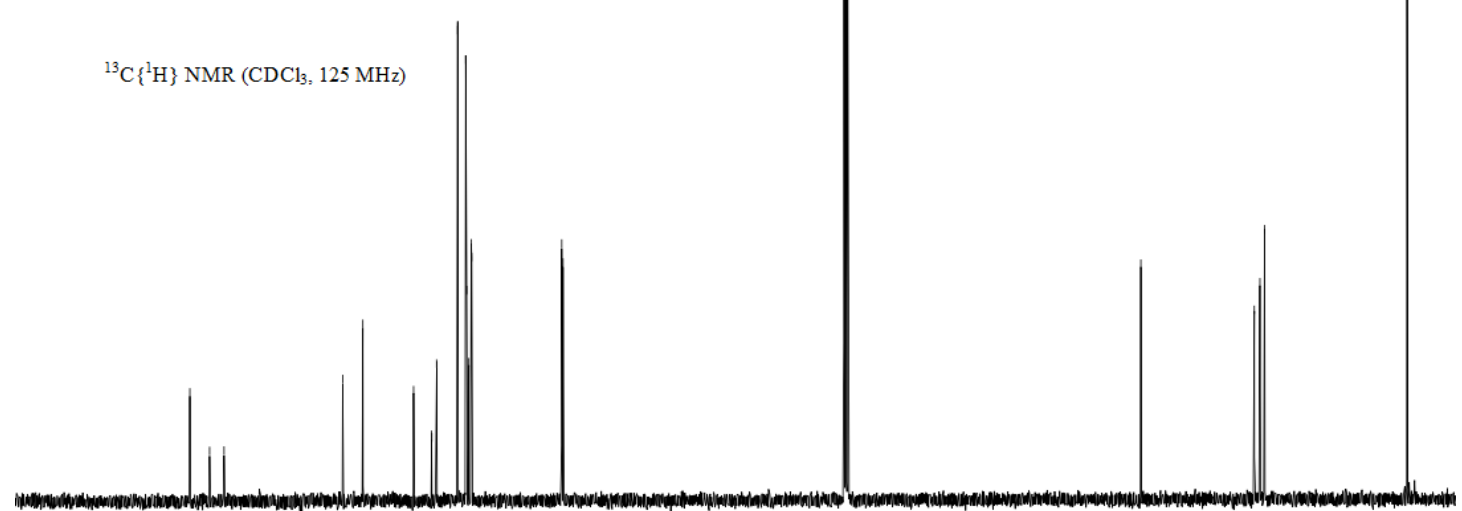

$\begin{array}{lllllllllllllllllll}180 & 170 & 160 & 150 & 140 & 130 & 120 & 110 & 100 & \underset{\mathrm{f} 1}{(\mathrm{ppm})} & 80 & 70 & 60 & 50 & 40 & 30 & 20 & 10 & 0\end{array}$ 
<smiles>CC(=CC(C)C)C(=O)N[SH3+]</smiles>

仓ิ

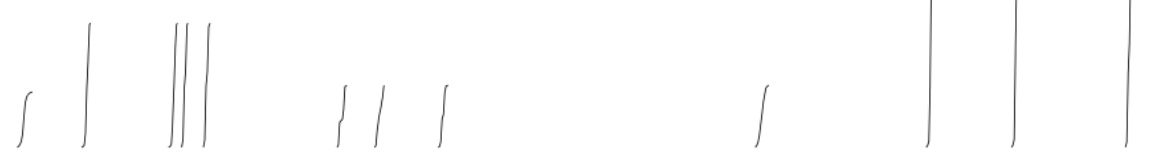

${ }^{1} \mathrm{H} \mathrm{NMR}\left(\mathrm{CDCl}_{3}, 500 \mathrm{MHz}\right)$

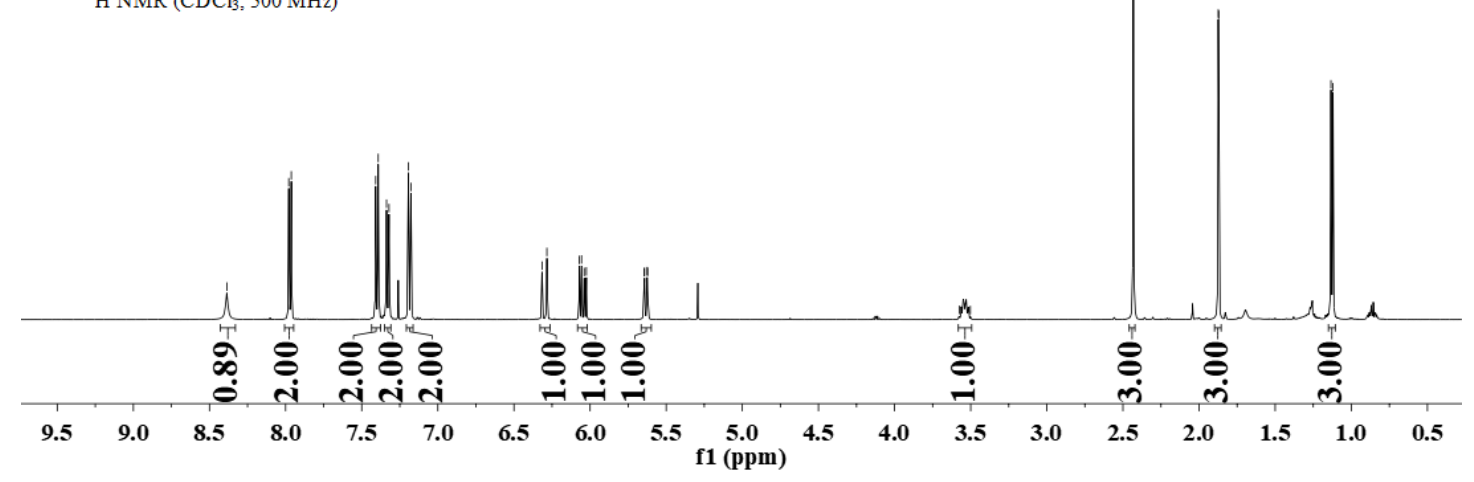

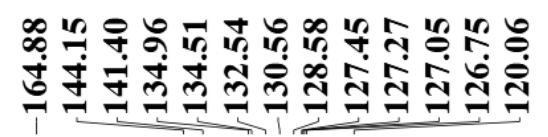

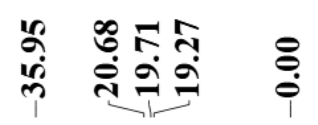

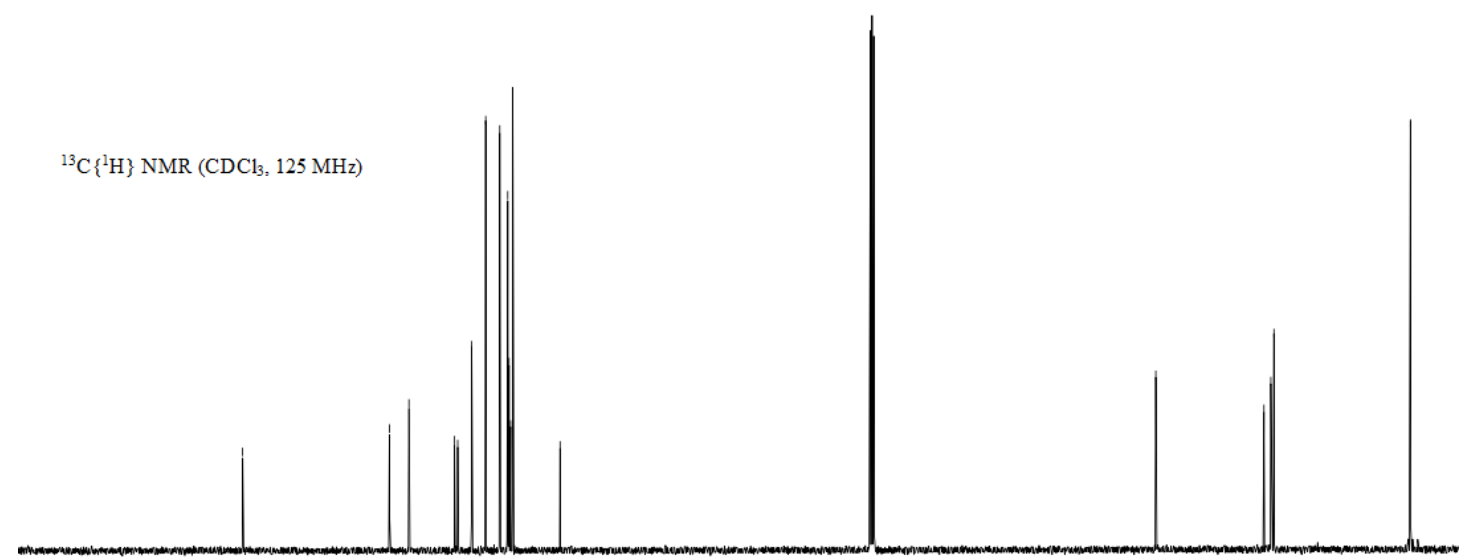

$\begin{array}{lllllllllllllllllll}190 & 180 & 170 & 160 & 150 & 140 & 130 & 120 & 110 & \begin{array}{r}100 \\ \text { f1 }(\mathrm{ppm})\end{array} & 80 & 70 & 60 & 50 & 40 & 30 & 20 & 10 & 0\end{array}$ 


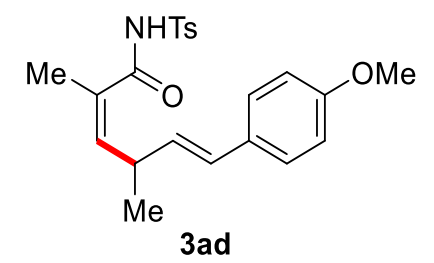

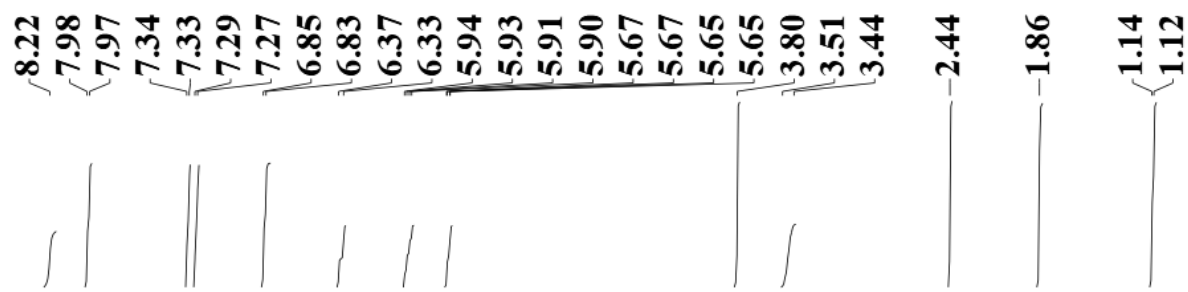

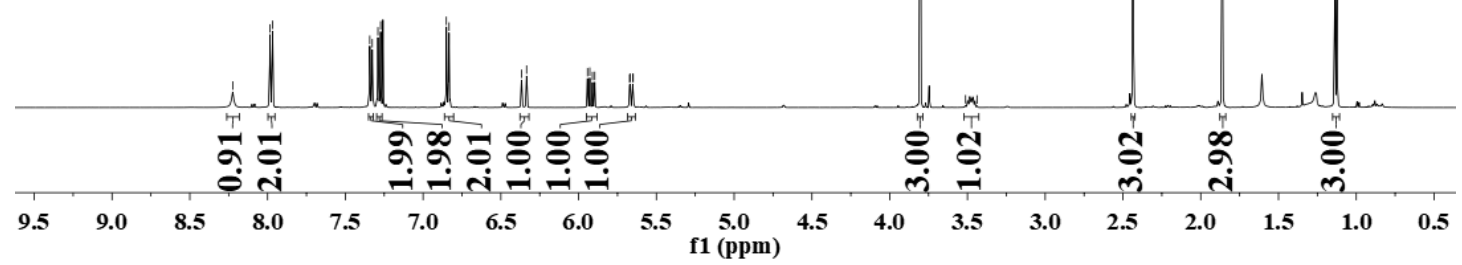

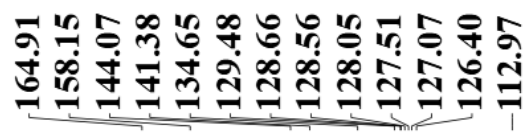

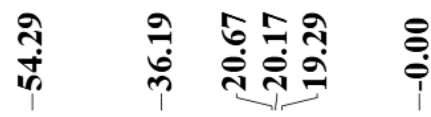

${ }^{13} \mathrm{C}\left\{{ }^{1} \mathrm{H}\right\}$ NMR $\left(\mathrm{CDCl}_{3}, 125 \mathrm{MHz}\right)$

$\begin{array}{llllllllll}190 & 180 & 170 & 160 & 150 & 140 & 130 & 120 & 110 & \begin{array}{c}100 \\ \text { f1 (ppm) }\end{array}\end{array}$ 
<smiles>CCNC(=O)/C(C)=C\C(C)/C=C/c1ccccc1OC</smiles>

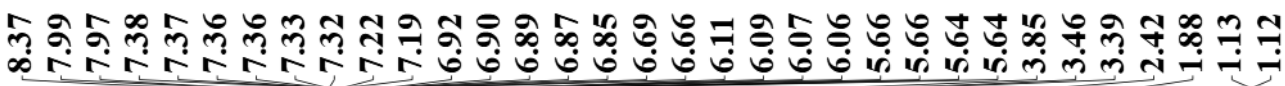

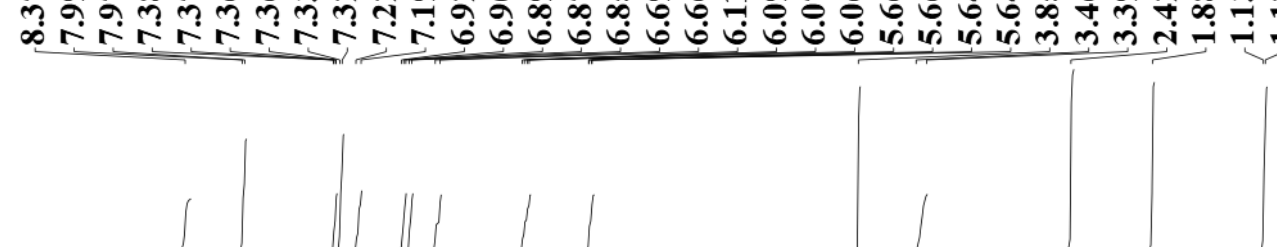

${ }^{1} \mathrm{H}$ NMR $\left(\mathrm{CDCl}_{3}, 500 \mathrm{MHz}\right)$

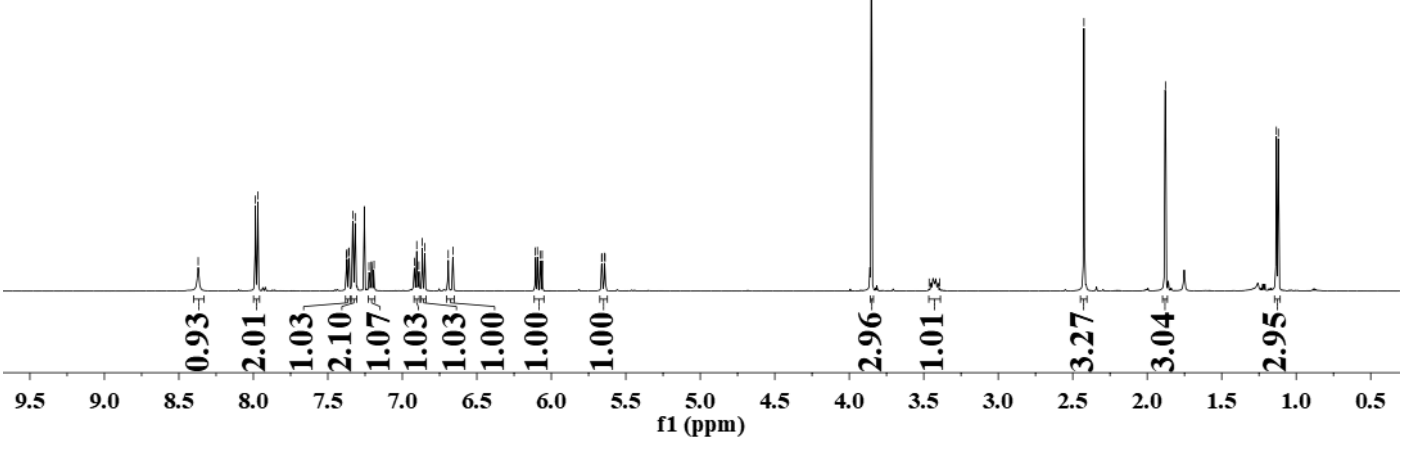

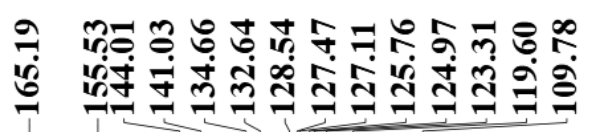

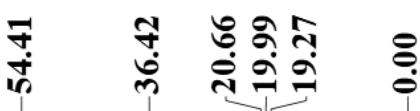

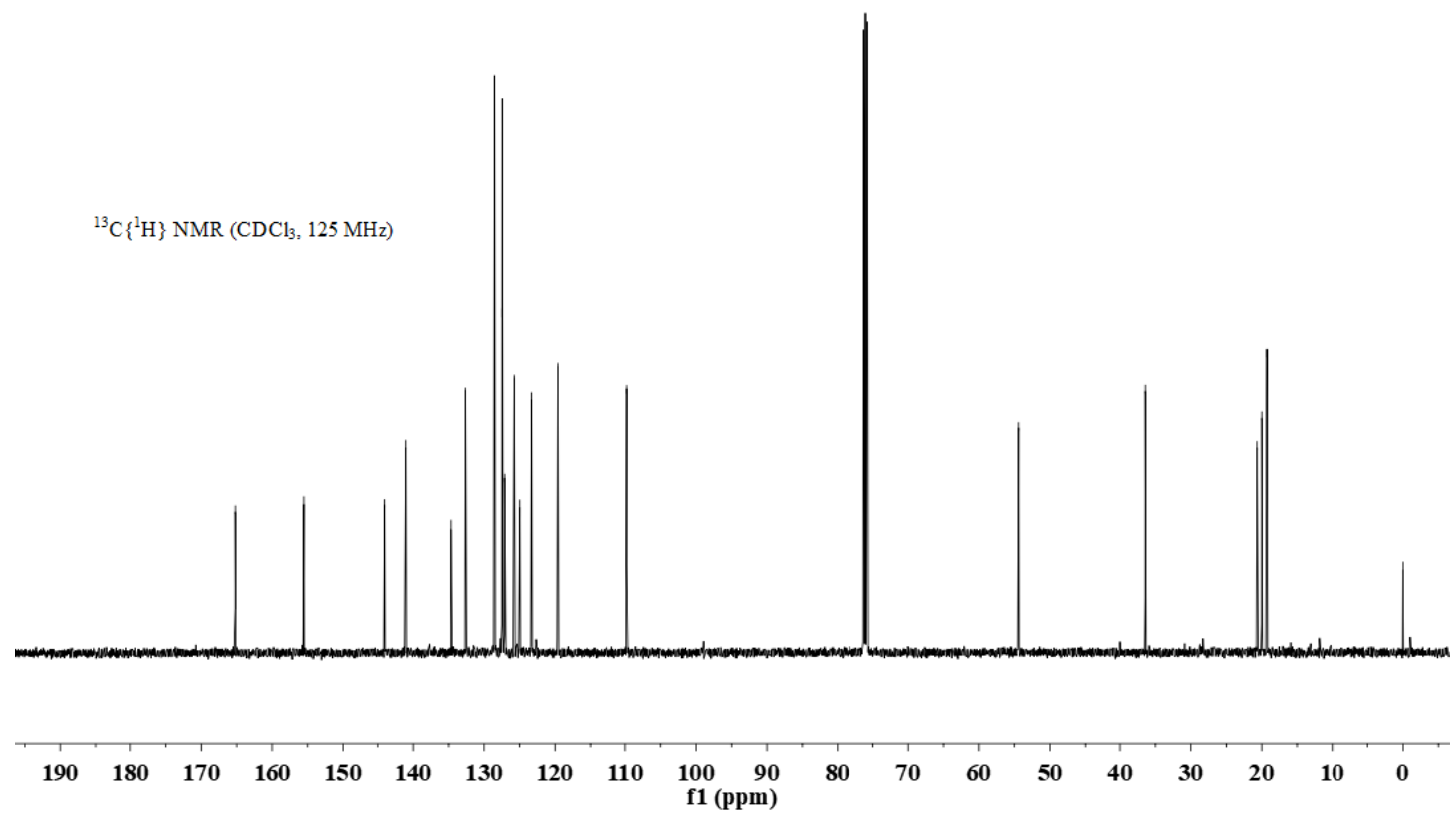


<smiles>CC(=CC(C)C(C)=Cc1ccccc1)C(=O)N[As]</smiles>

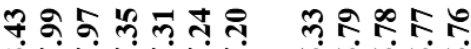

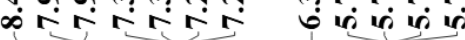

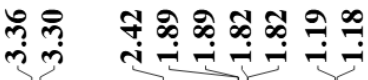

$\left(\mathrm{CDCl}_{3}, 500 \mathrm{MH}\right.$

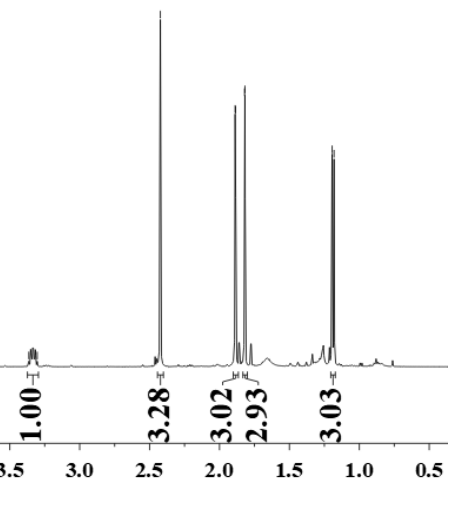

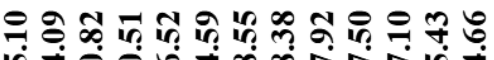

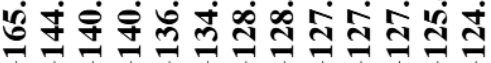

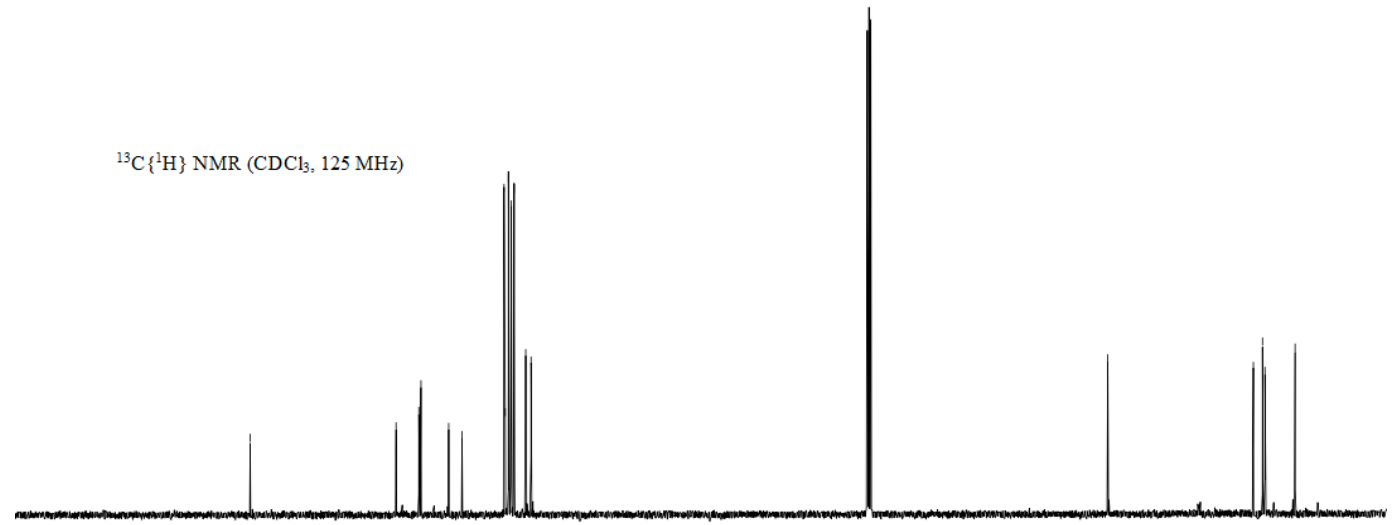

$\begin{array}{lllllllllllllllllll}190 & 180 & 170 & 160 & 150 & 140 & 130 & 120 & 110 & 100 & 90 & 80 & 70 & 60 & 50 & 40 & 30 & 20 & 10\end{array}$ 
<smiles>C/C(=C/C(C)C)C(=O)N[I-]</smiles>

3ag

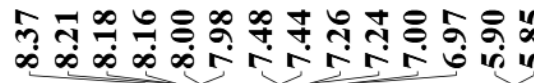

ஸ̆ळ
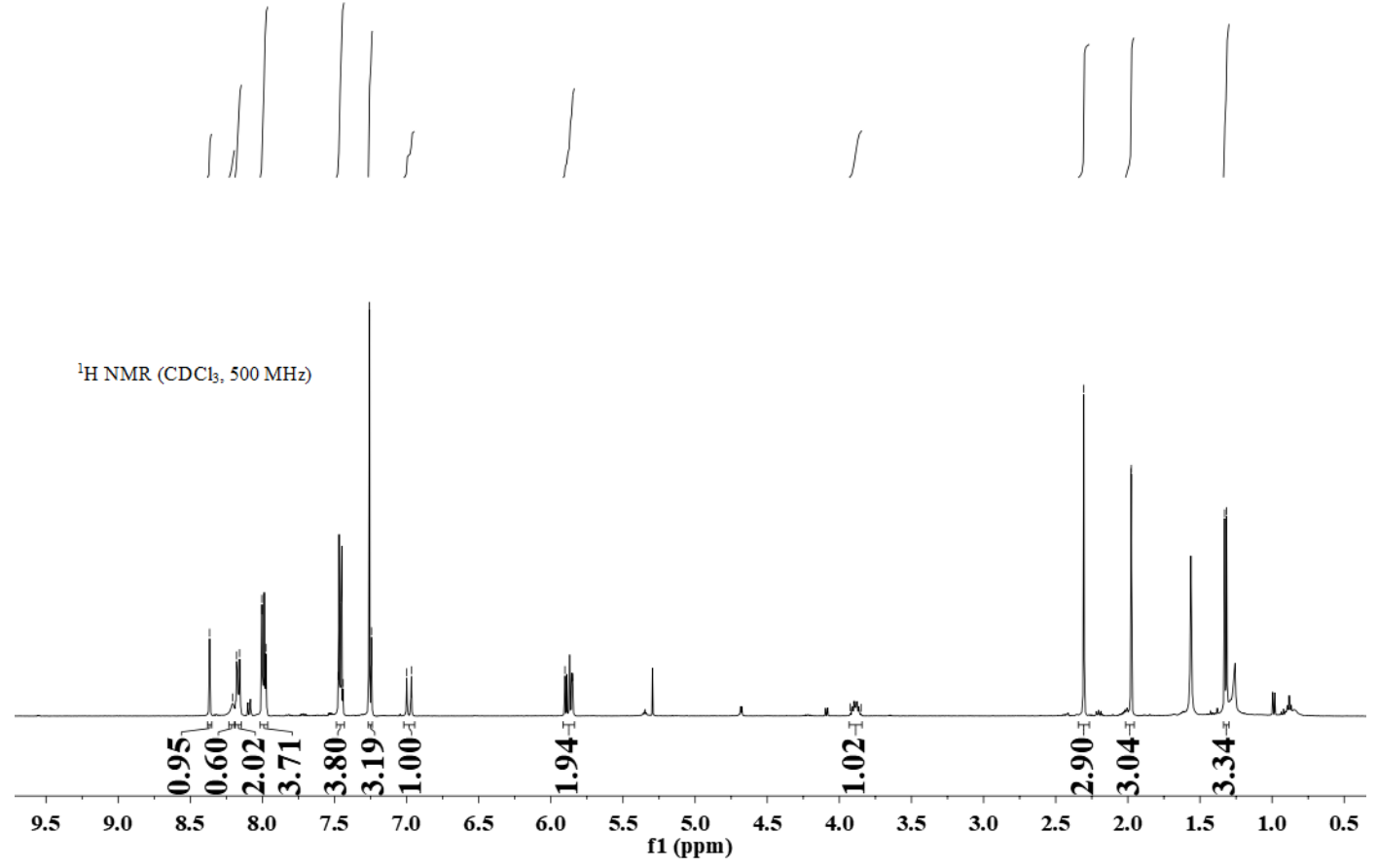

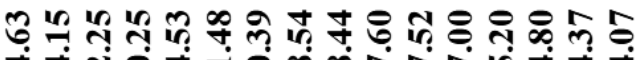

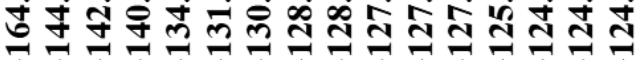

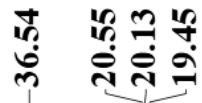

${ }^{13} \mathrm{C}\left\{{ }^{1} \mathrm{H}\right\}$ NMR $\left(\mathrm{CDCl}_{3}, 125 \mathrm{MHz}\right)$

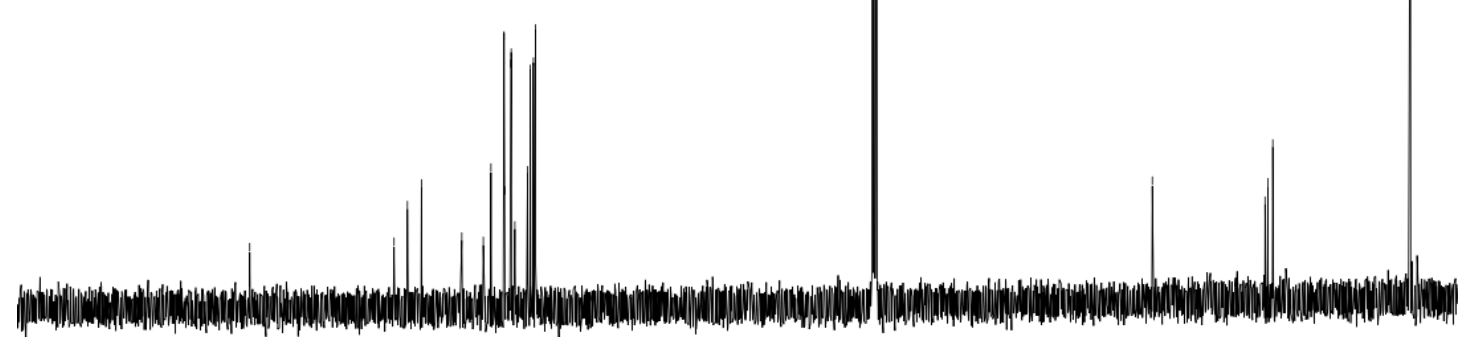

$\begin{array}{llllllllllllllllllll}190 & 180 & 170 & 160 & 150 & 140 & 130 & 120 & 110 & 100 & 90 & 80 & 70 & 60 & 50 & 40 & 30 & 20 & 10 & 0\end{array}$ 
<smiles>[GeH2]=[Te]</smiles>

3 ba

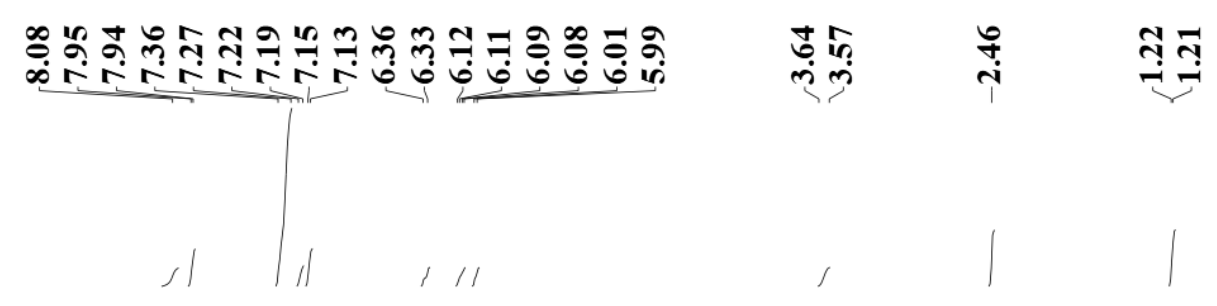

${ }^{1} \mathrm{H} \mathrm{NMR}\left(\mathrm{CDCl}_{3}, 500 \mathrm{MHz}\right)$

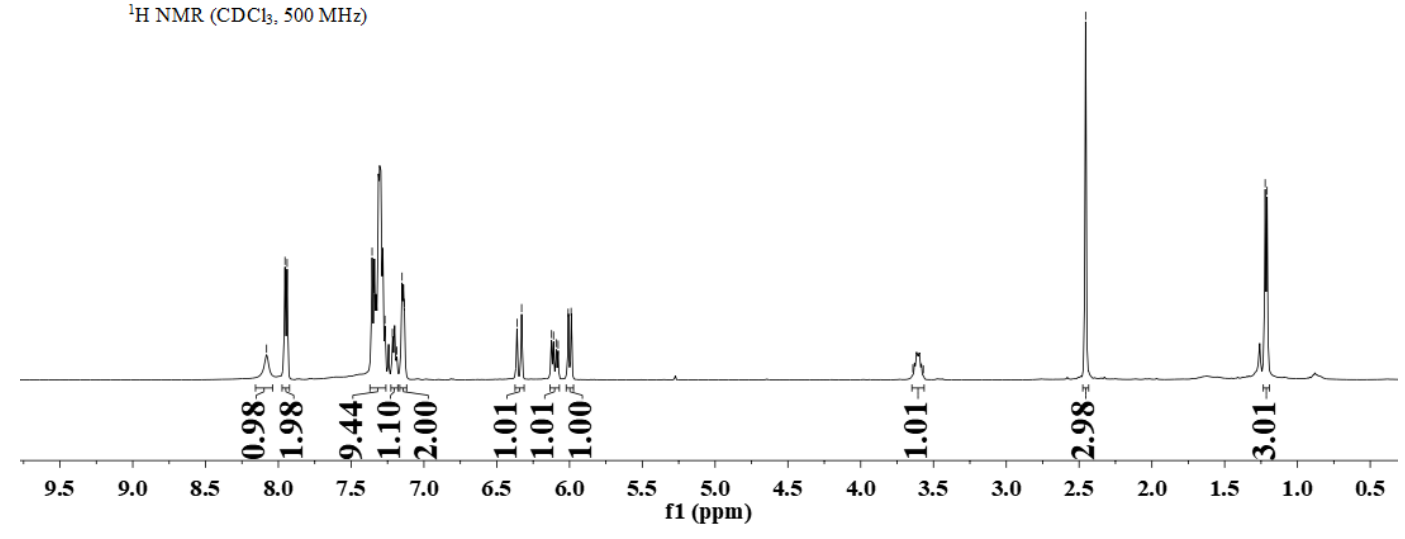

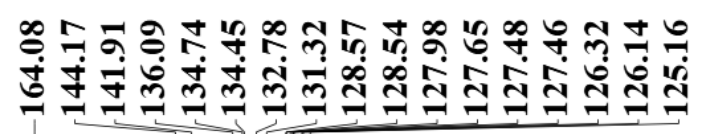

ت

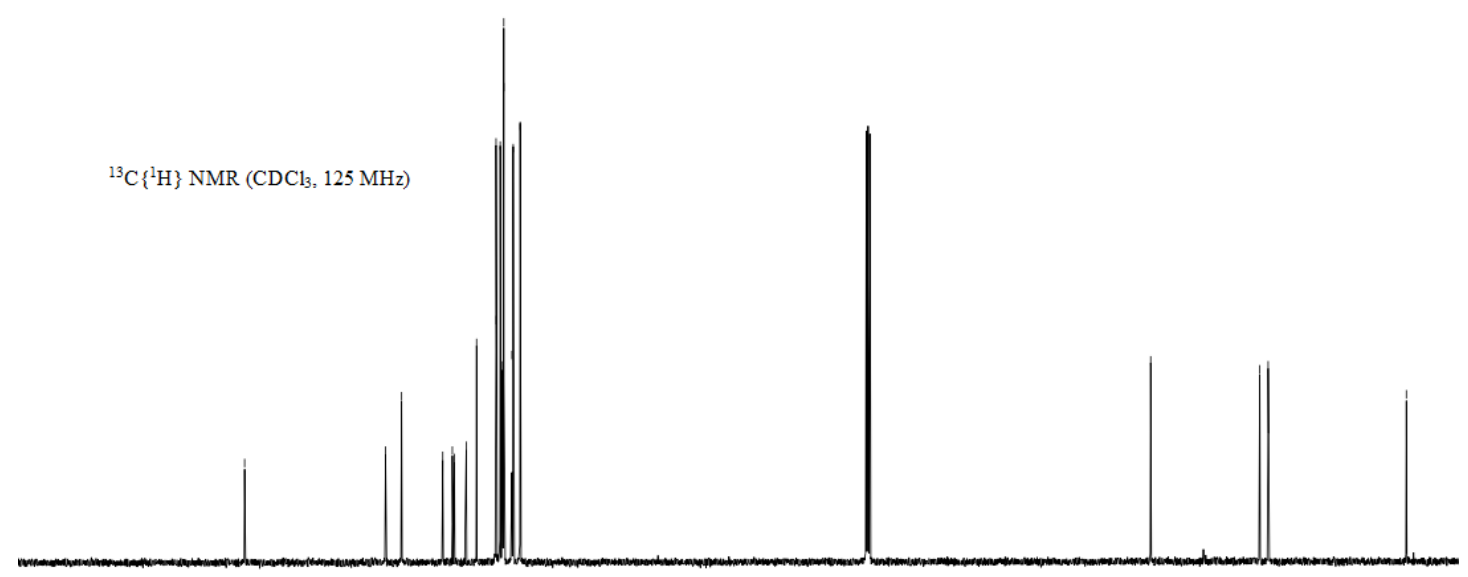

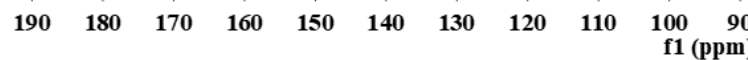


<smiles>CC(C=Cc1ccccc1)C=C(C(=O)N[In])c1ccc(F)cc1</smiles>

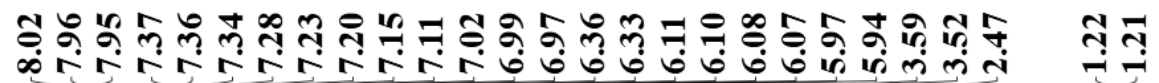

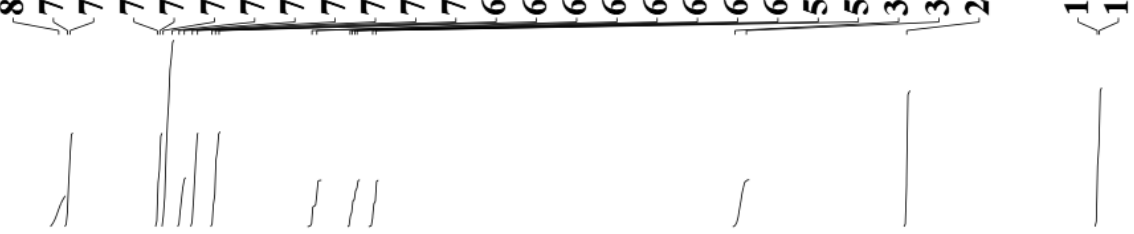

${ }^{1} \mathrm{H}$ NMR $\left(\mathrm{CDCl}_{3}, 500 \mathrm{MHz}\right)$

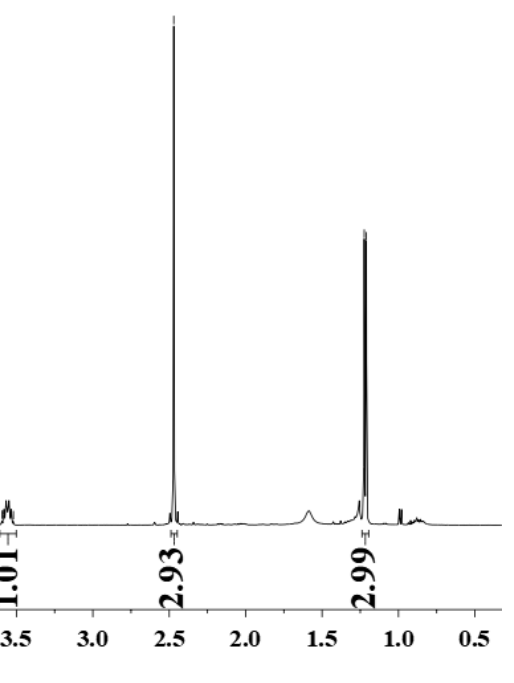

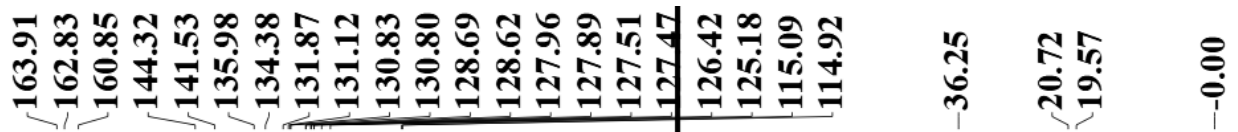

${ }^{13} \mathrm{C}\left\{{ }^{1} \mathrm{H}\right\}$ NMR $\left(\mathrm{CDCl}_{3}, 125 \mathrm{MHz}\right)$

$\begin{array}{lllllllllll}190 & 180 & 170 & 160 & 150 & 140 & 130 & 120 & 110 & \begin{array}{l}100 \\ \text { f1 (ppm) }\end{array}\end{array}$ 
<smiles>CC(/C=C(\C(=O)N[In])c1ccc(C(F)(F)F)cc1)/C=C/c1ccccc1</smiles>

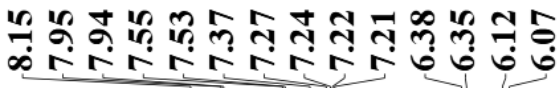

${ }^{1} \mathrm{H} \mathrm{NMR}\left(\mathrm{CDCl}_{3}, 500 \mathrm{MHz}\right)$

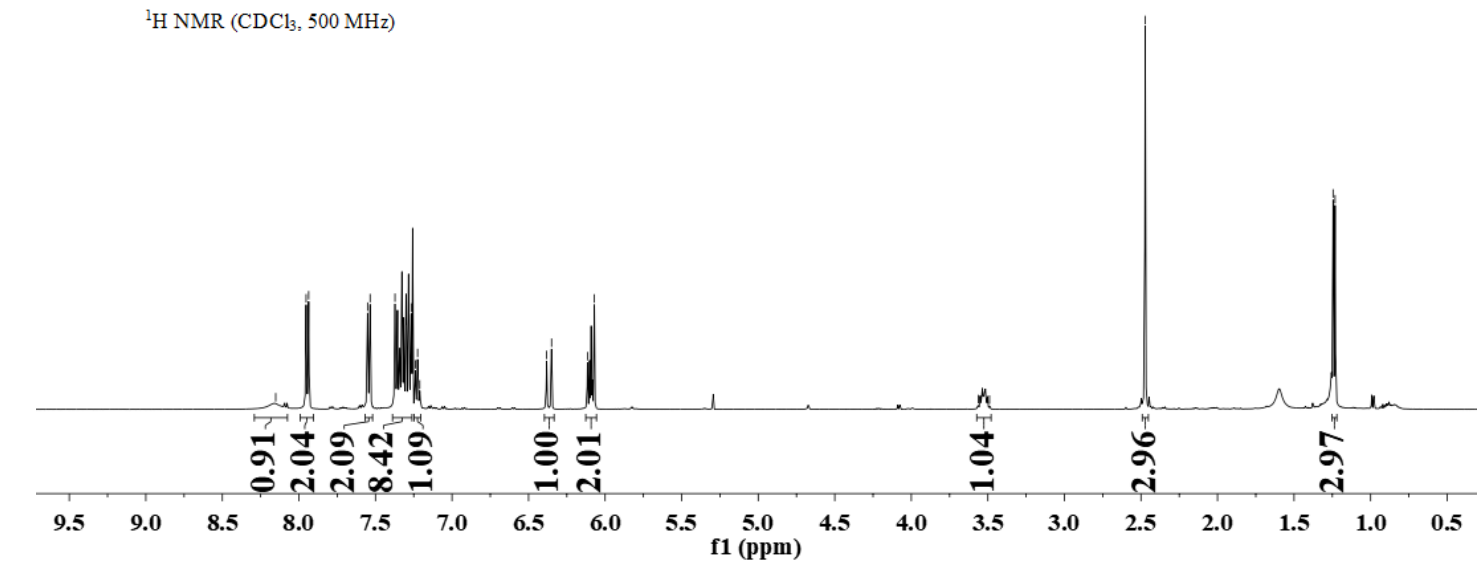

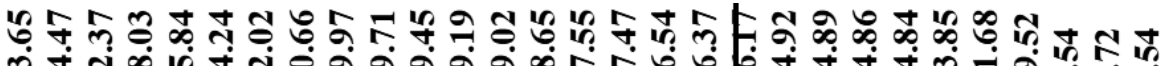

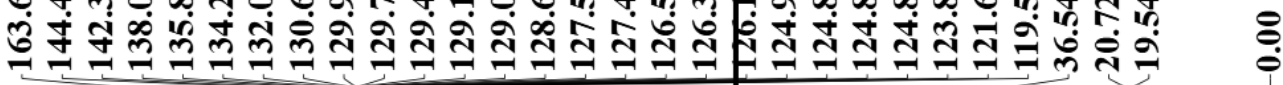

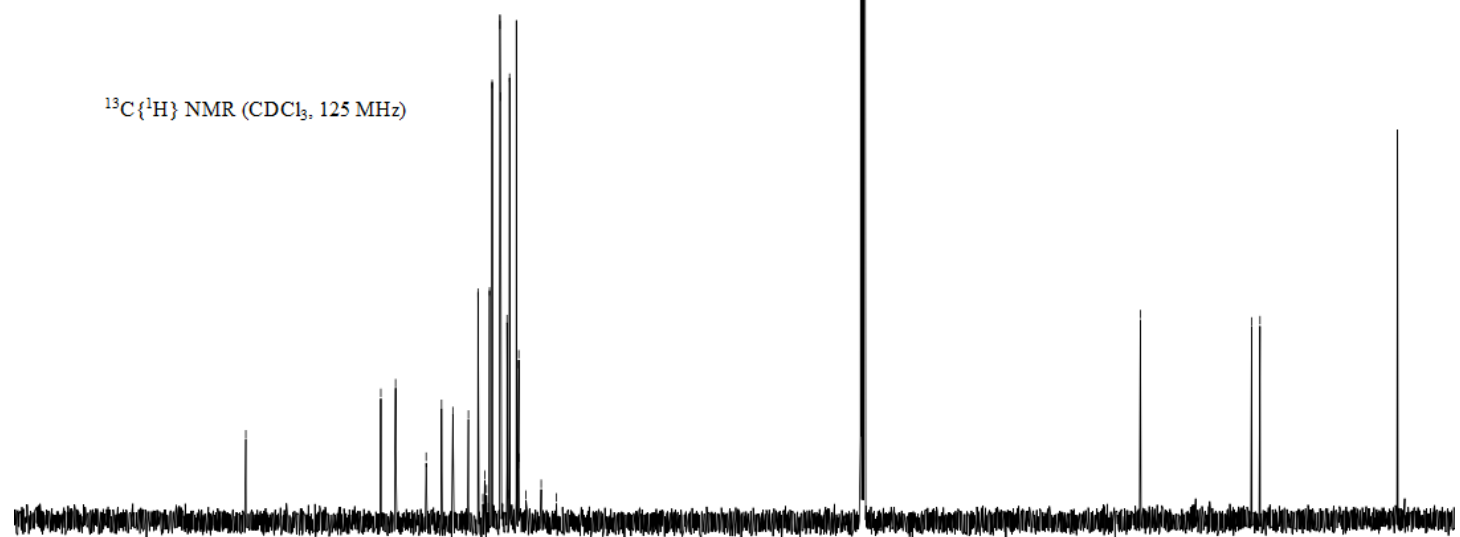

$\begin{array}{lllllllllll}190 & 180 & 170 & 160 & 150 & 140 & 130 & 120 & 110 & 100 & 90\end{array}$ $\begin{array}{lllllllll}80 & 70 & 60 & 50 & 40 & 30 & 20 & 10 & 0\end{array}$ 
<smiles>Cc1ccc(C(=CC(C)C)C(=O)NC(F)(F)F)cc1</smiles>

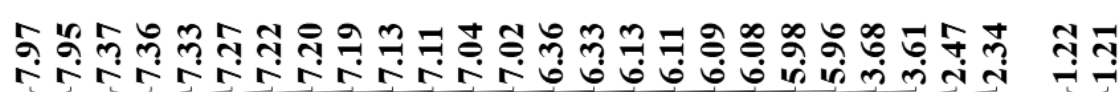

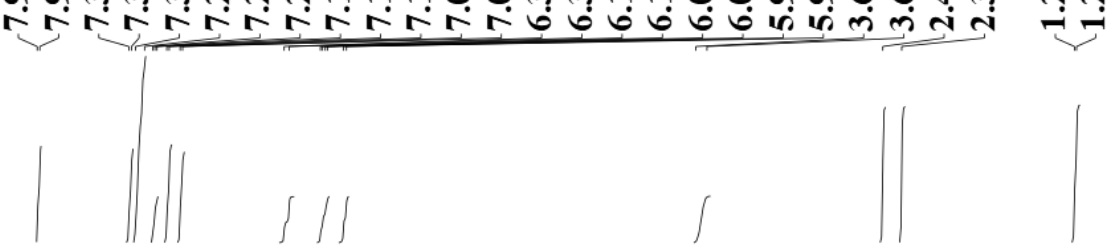

${ }^{1} \mathrm{H}$ NMR $\left(\mathrm{CDCl}_{3}, 500 \mathrm{MHz}\right)$

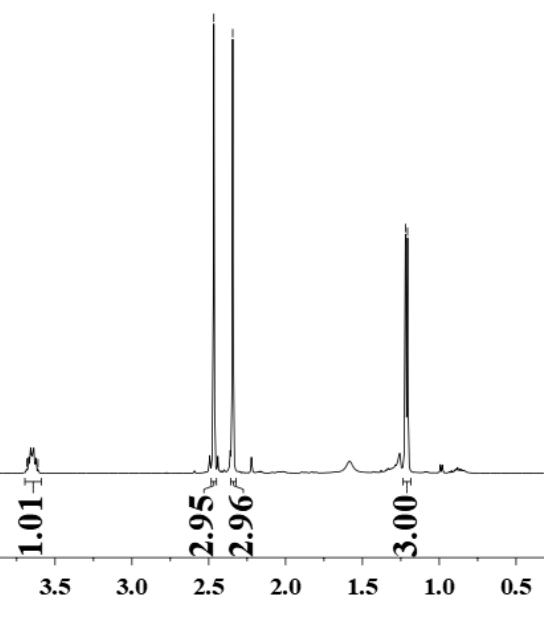

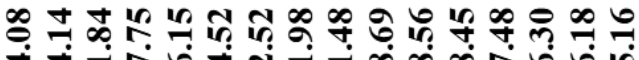

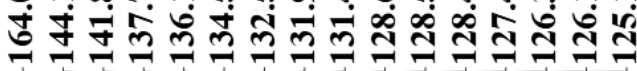

苍

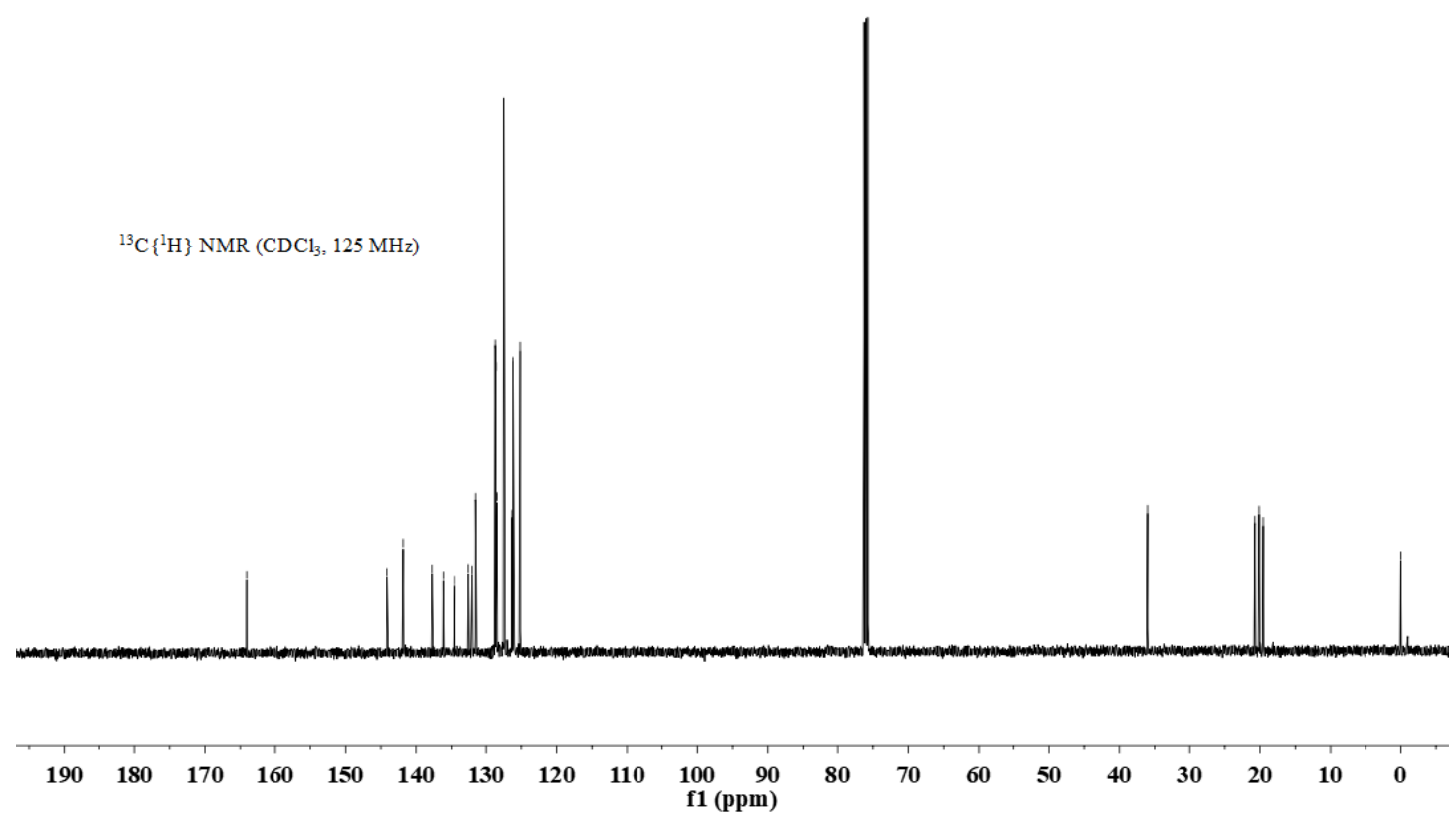


<smiles>COc1ccc(/C(=C/C(C)([18OH])C=Cc2ccccc2)C(=O)NC(F)(F)F)cc1</smiles>

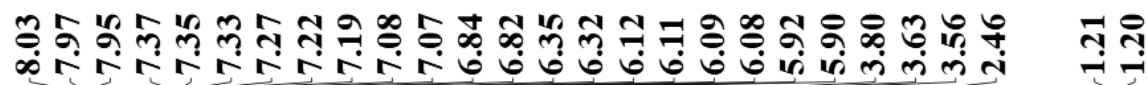

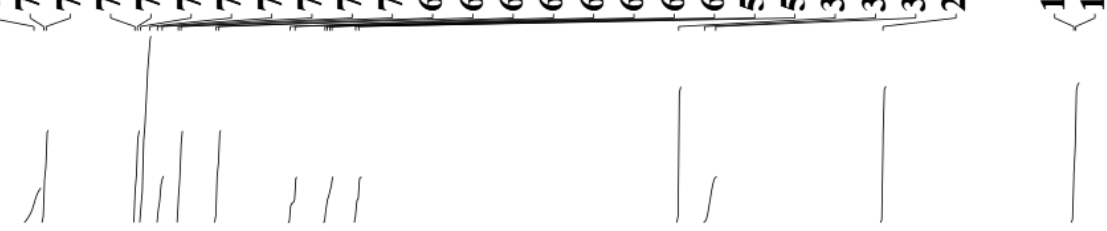

${ }^{1} \mathrm{H} \mathrm{NMR}\left(\mathrm{CDCl}_{3}, 500 \mathrm{MHz}\right)$

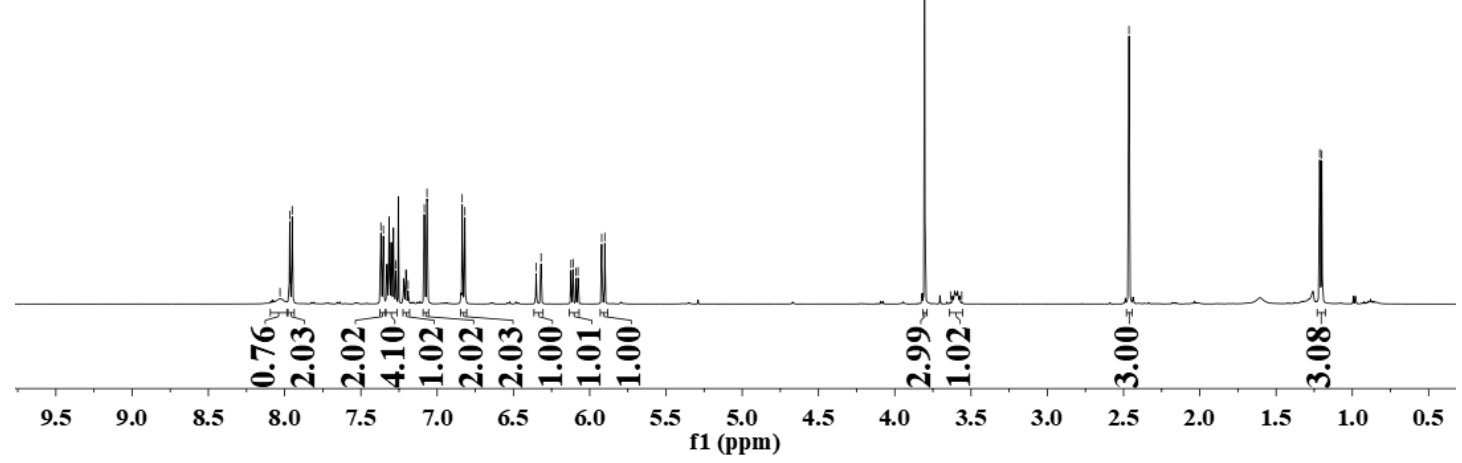

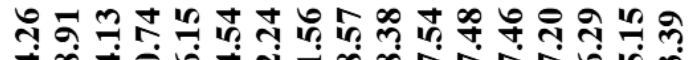

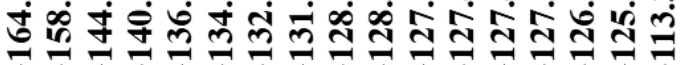

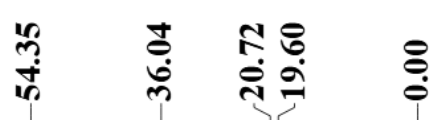

${ }^{13} \mathrm{C}\left\{{ }^{1} \mathrm{H}\right\}$ NMR $\left(\mathrm{CDCl}_{3}, 125 \mathrm{MHz}\right)$

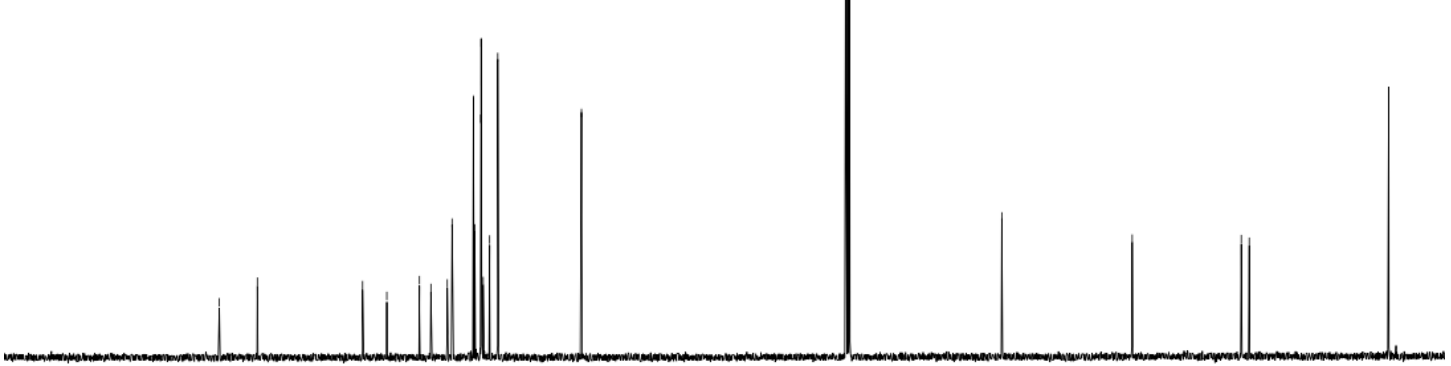

$\begin{array}{llllllllll}190 & 180 & 170 & 160 & 150 & 140 & 130 & 120 & 110 & 100 \\ \text { f1 }(\mathrm{ppm}) & 90\end{array}$ 


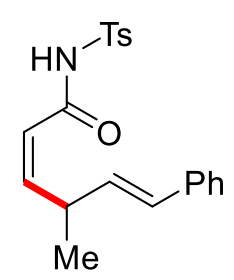

3ga

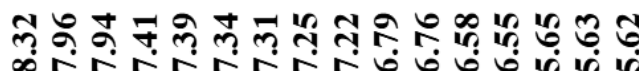

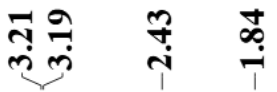

${ }^{1} \mathrm{H}$ NMR $\left(\mathrm{CDCl}_{3}, 500 \mathrm{MHz}\right)$
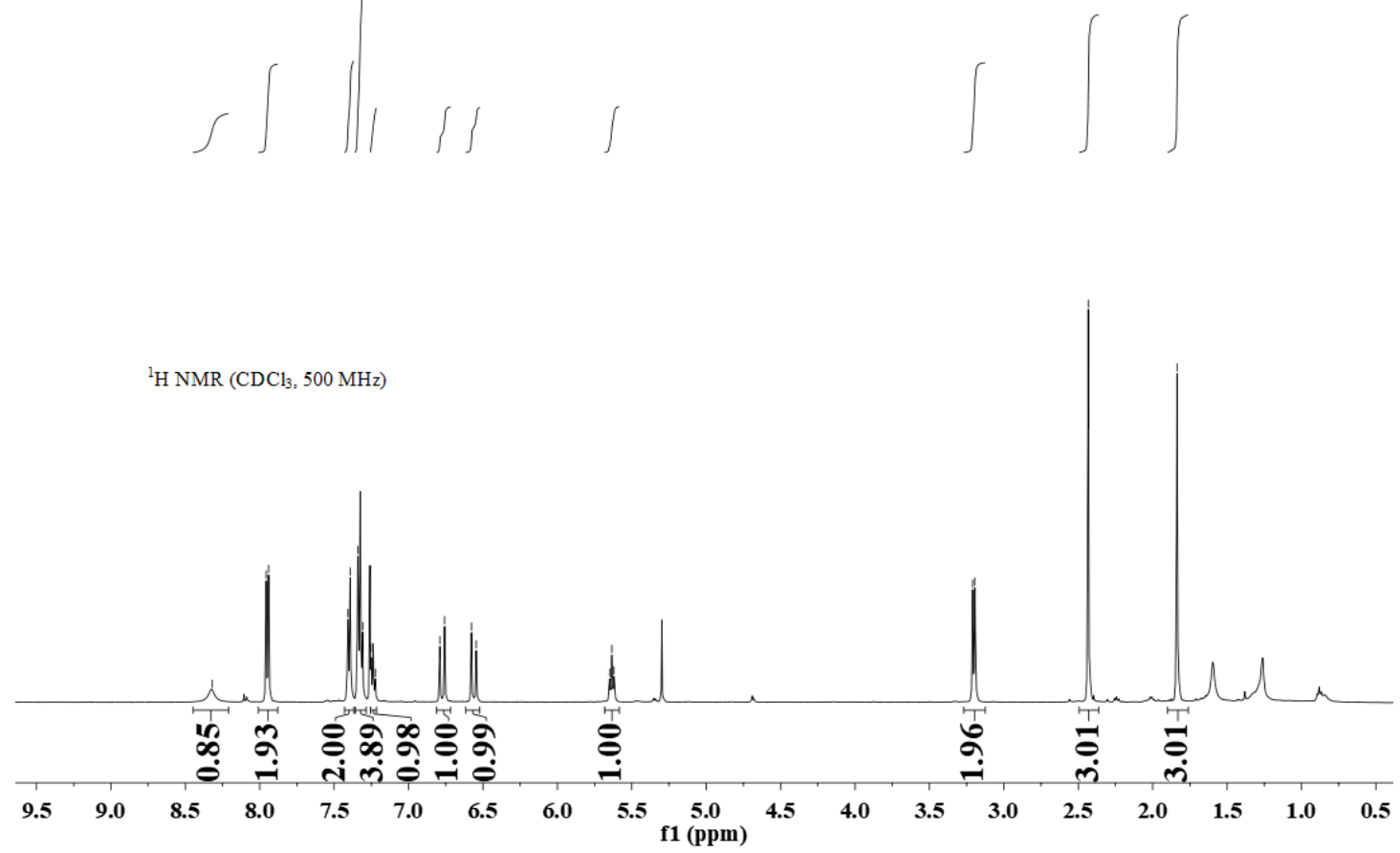

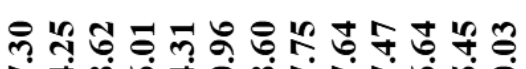

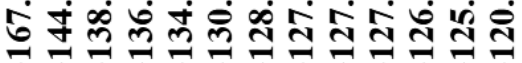

${ }^{13} \mathrm{C}\left\{{ }^{1} \mathrm{H}\right\} \mathrm{NMR}\left(\mathrm{CDCl}_{3}, 125 \mathrm{MHz}\right)$

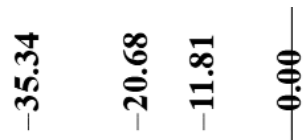

$\begin{array}{lll}180 & 170 & 160\end{array}$

150

140130

120

10

f1 $\stackrel{90}{(\mathrm{ppm})} 80$

$\begin{array}{lll}60 & 50 & 40\end{array}$

$\begin{array}{llll}30 & 20 & 10 & 0\end{array}$ 
<smiles>CC(/C=C/c1ccccc1)c1ccccc1C(=O)NC(F)(F)F</smiles>

3ha

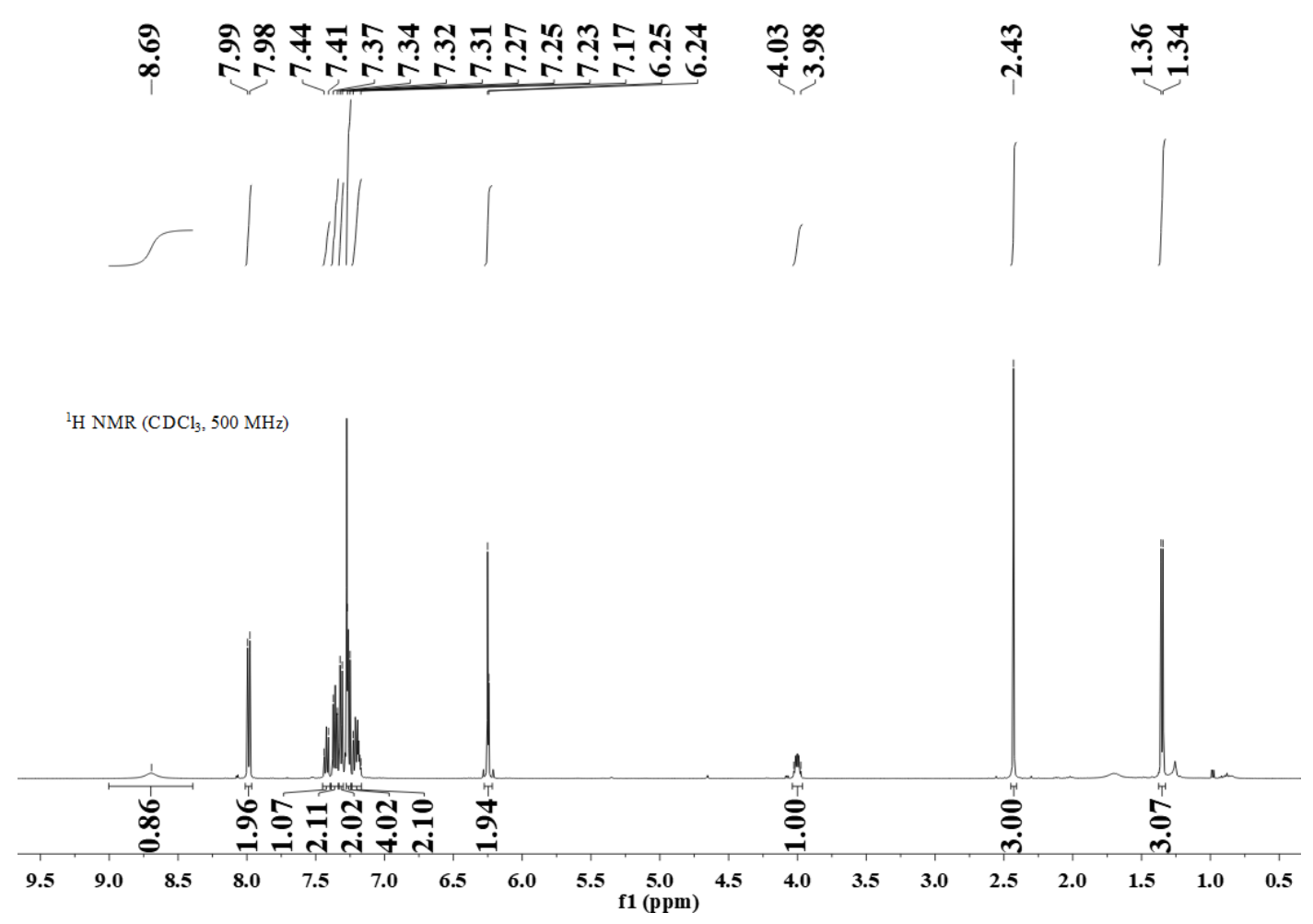

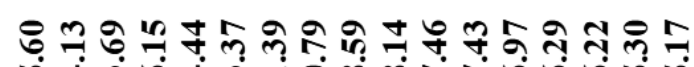

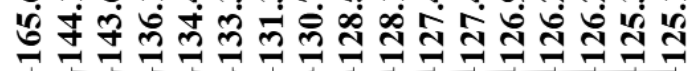

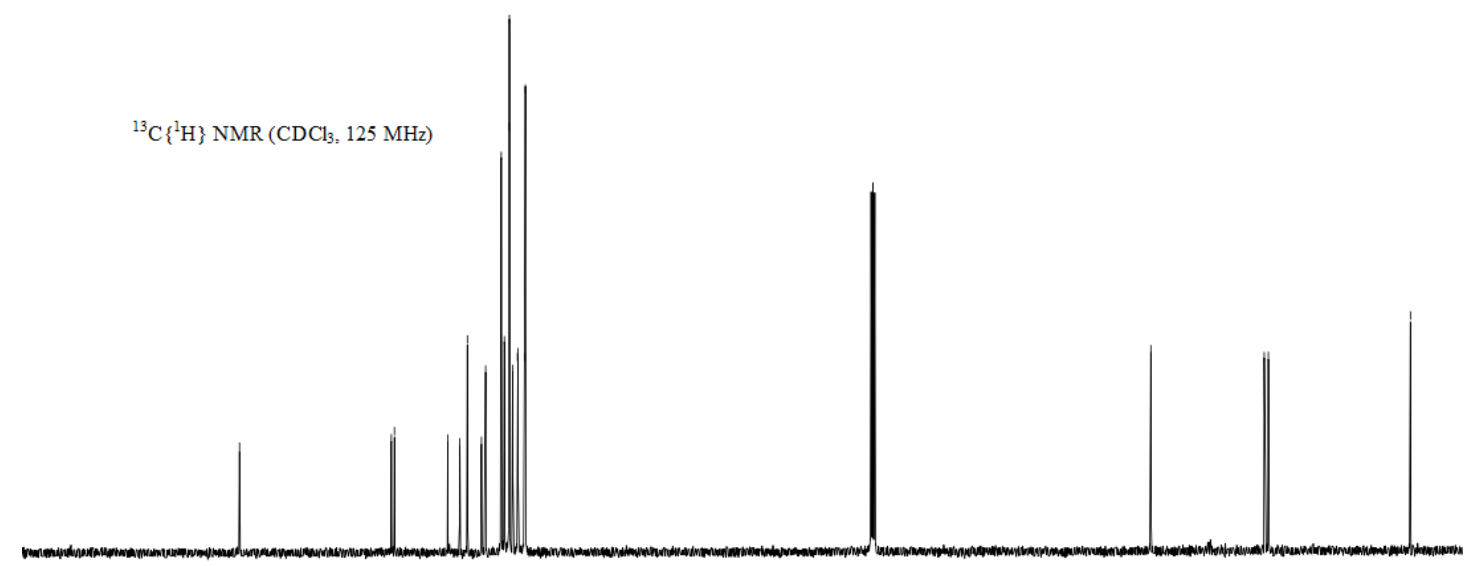

$\begin{array}{lllllllllll}190 & 180 & 170 & 160 & 150 & 140 & 130 & 120 & 110 & 100 & 90\end{array}$ f1 (ppm) 

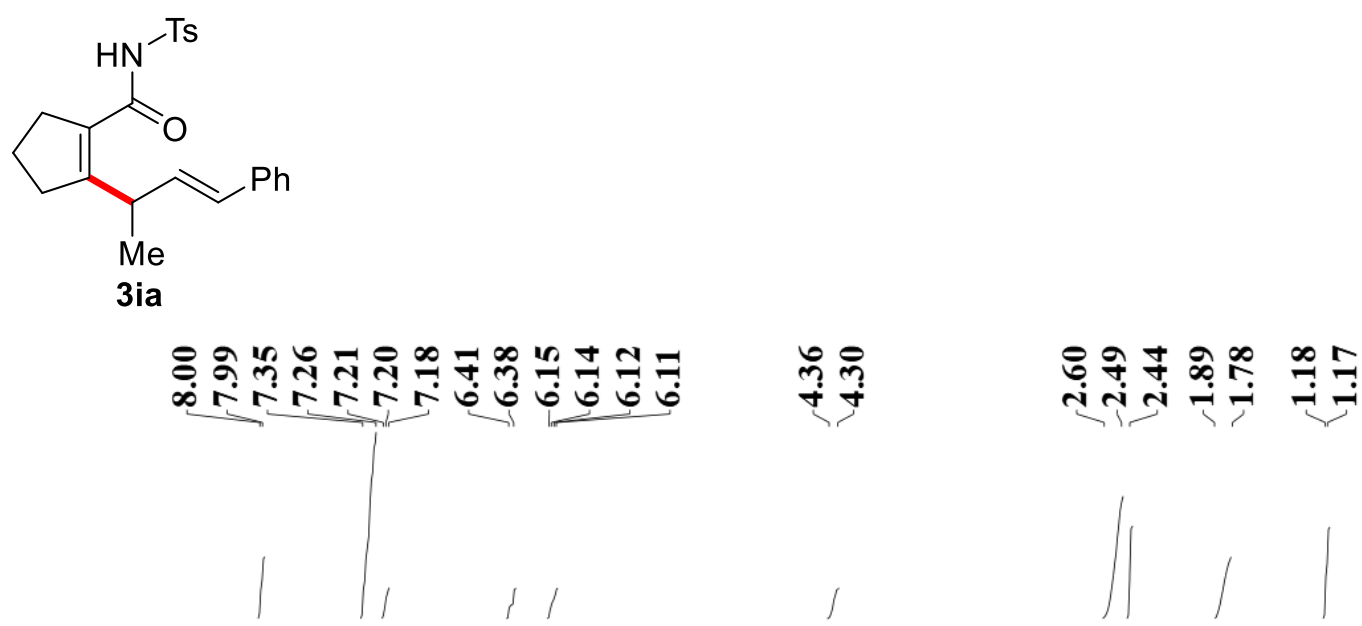

${ }^{1} \mathrm{H} \mathrm{NMR}\left(\mathrm{CDCl}_{3}, 500 \mathrm{MHz}\right)$

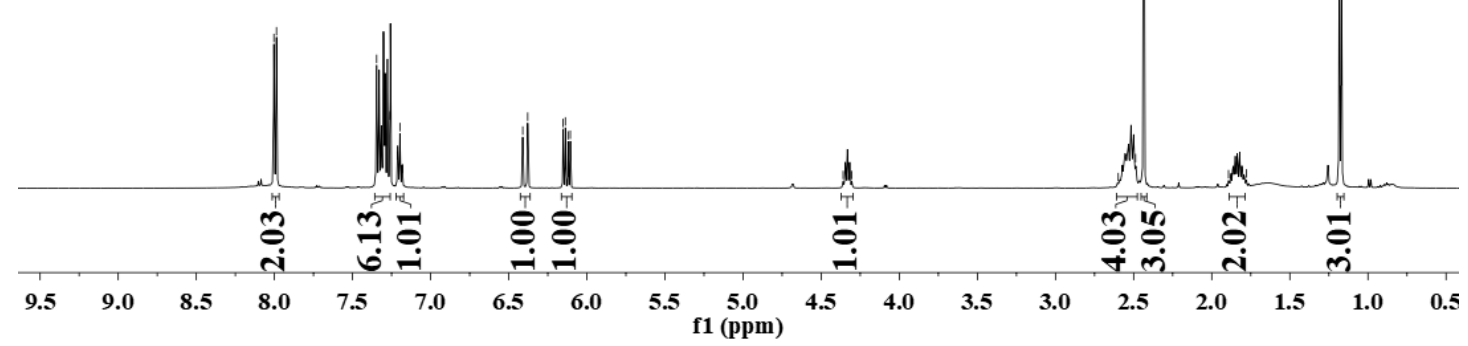

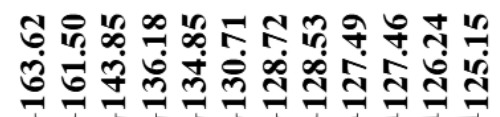

พัฒ

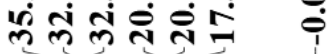

${ }^{13} \mathrm{C}\left\{{ }^{1} \mathrm{H}\right\}$ NMR $\left(\mathrm{CDCl}_{3}, 125 \mathrm{MHz}\right)$

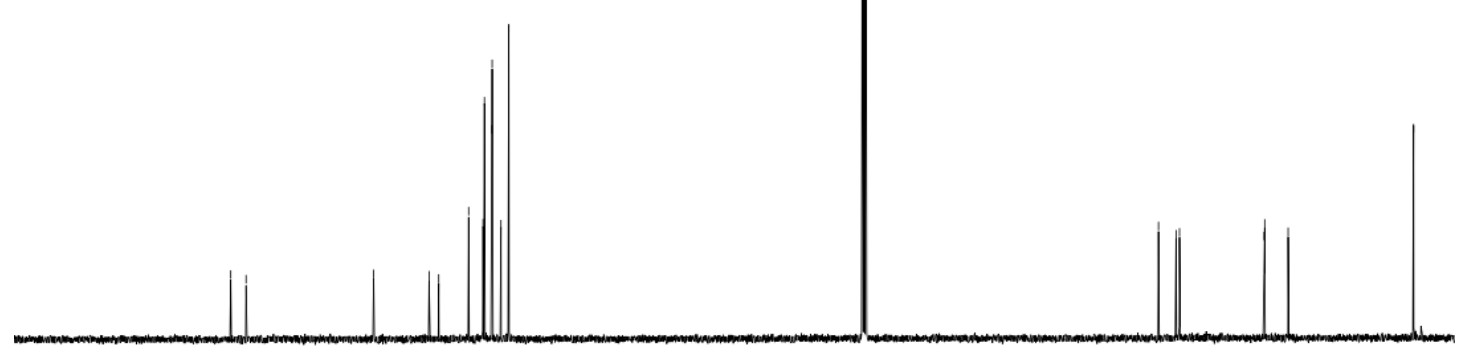

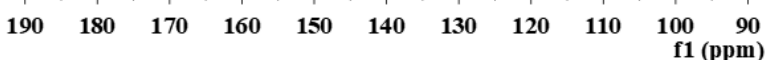




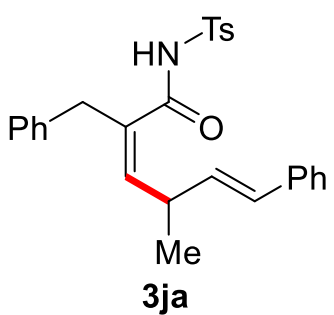

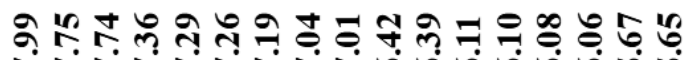

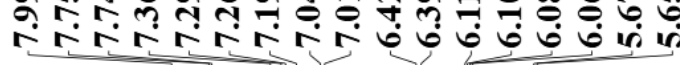

芦导

$\stackrel{\text { i }}{\text { i }}$

${ }^{1} \mathrm{H} \mathrm{NMR}\left(\mathrm{CDCl}_{3}, 500 \mathrm{MHz}\right)$
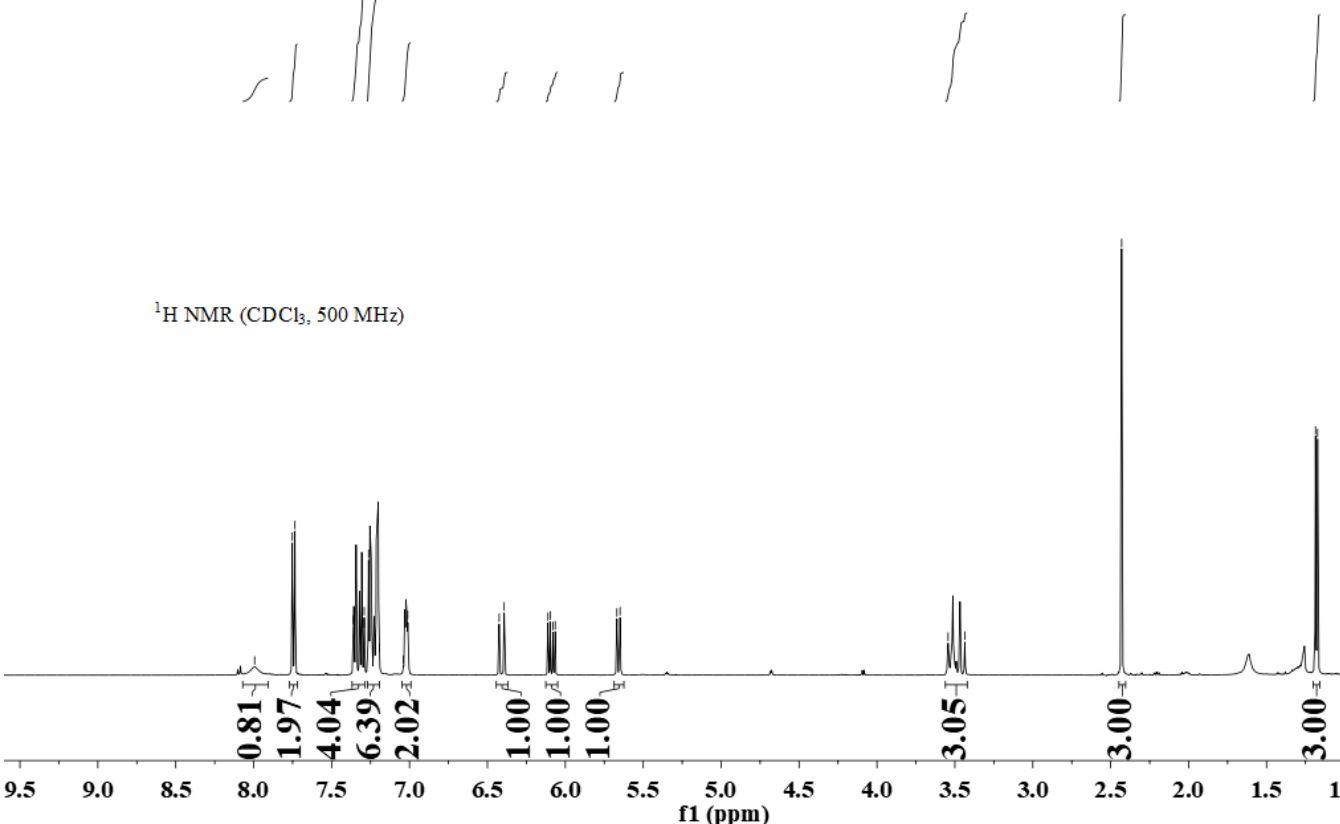

$8.07 .5 \quad 7.0$

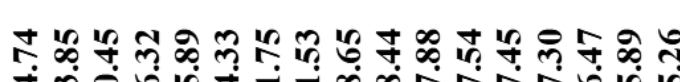

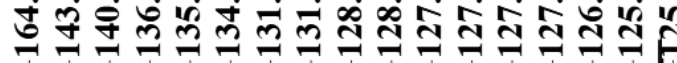
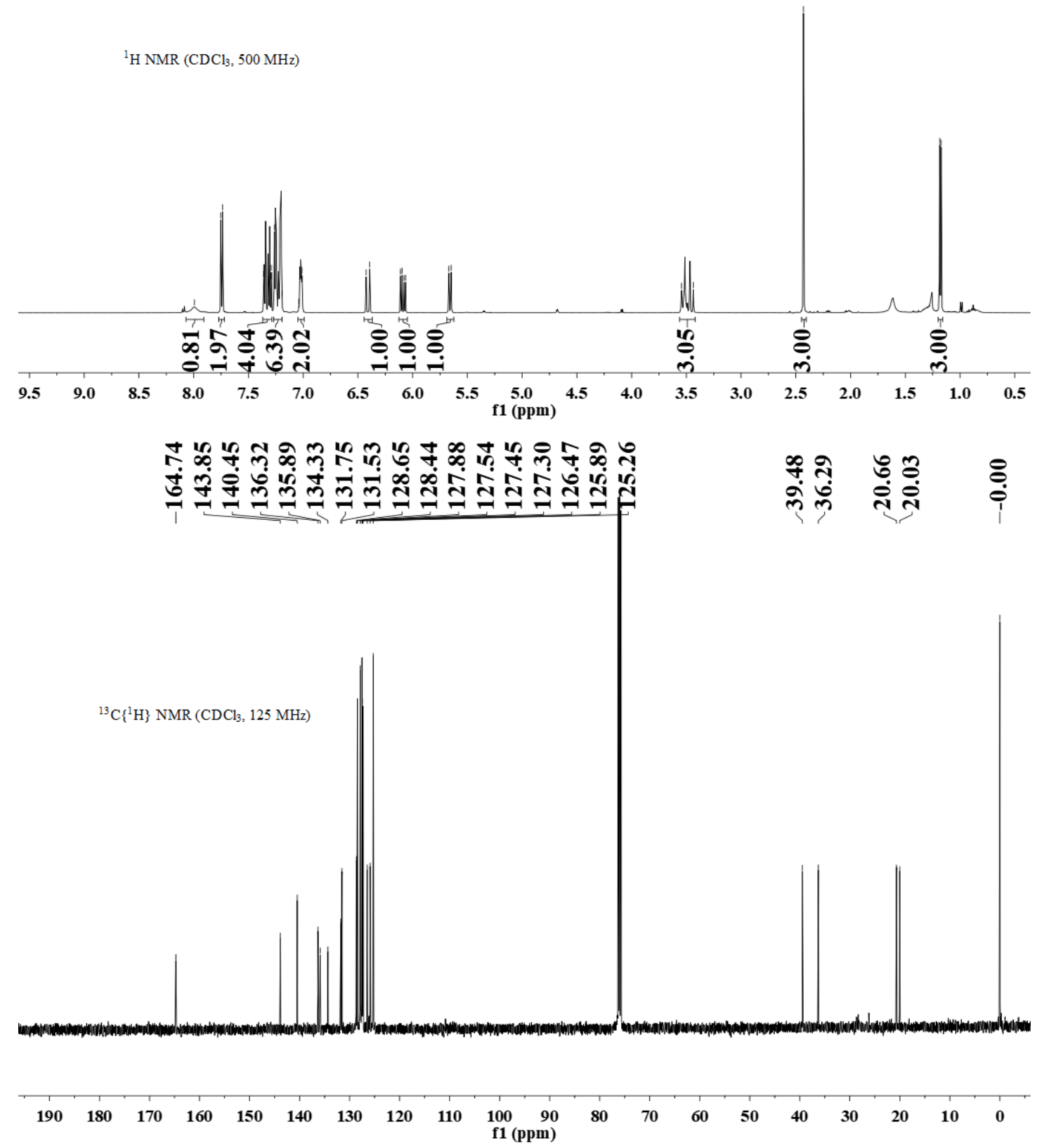
<smiles>CCCCC(=CC(C)C)C(=O)NC(=O)c1ccccc1</smiles>

3ka

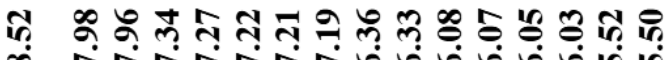

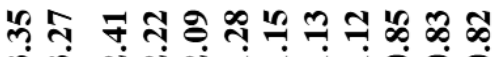

क

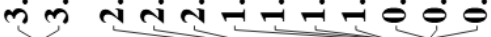

$\mathrm{H} \operatorname{NMR}\left(\mathrm{CDCl}_{3}, 500 \mathrm{MHz}\right)$

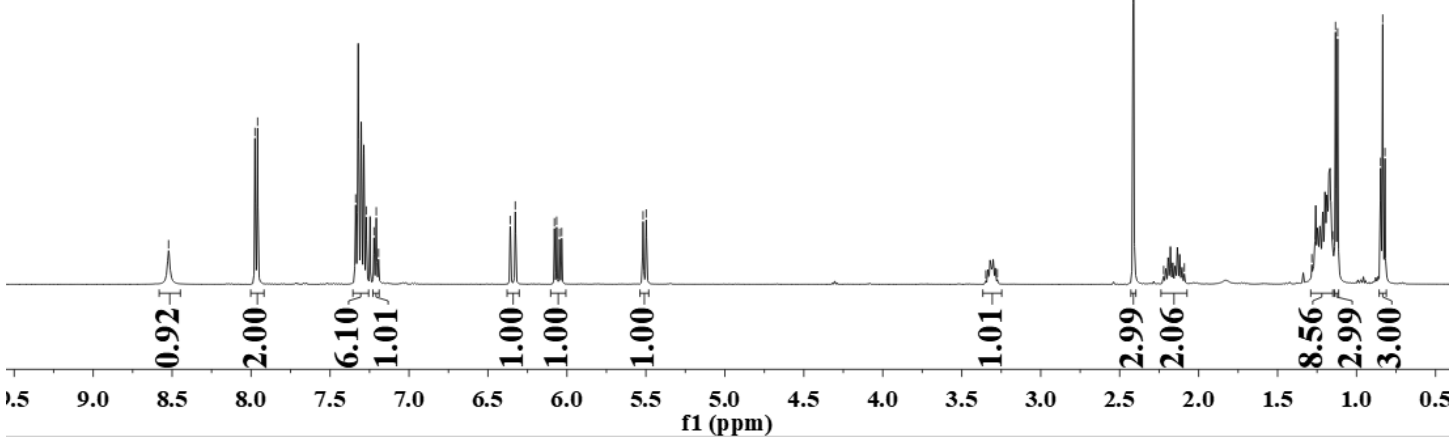

6
6
6
0

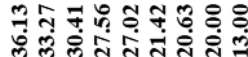

${ }^{13} \mathrm{C}\left\{{ }^{1} \mathrm{H}\right\} \mathrm{NMR}\left(\mathrm{CDCl}_{3}, 125 \mathrm{MHz}\right)$

$\begin{array}{lllllllllll}190 & 180 & 170 & 160 & 150 & 140 & 130 & 120 & 110 & 100 \begin{array}{r}90 \\ \text { f1 (ppm) }\end{array}\end{array}$ 
<smiles>[3H]NC(=O)C(=CC(C)C)CCCC</smiles>

3la

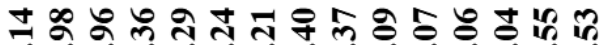
क

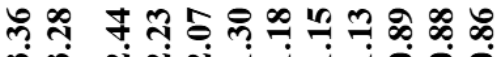
ले نंतi-i-i远 ${ }^{1} \mathrm{H} \mathrm{NMR}\left(\mathrm{CDCl}_{3}, 500 \mathrm{MHz}\right)$

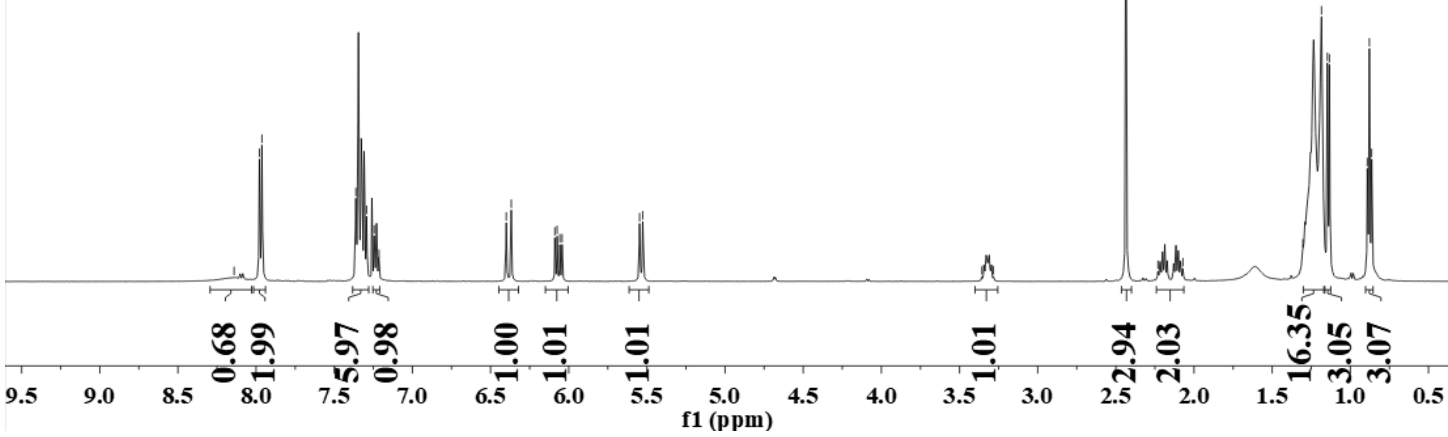

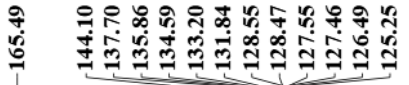

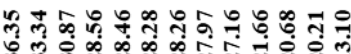

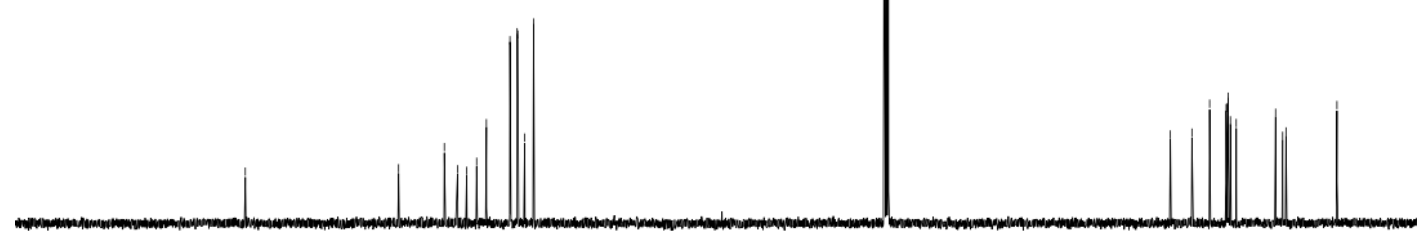

$\begin{array}{llllllllllllllllll}190 & 180 & 170 & 160 & 150 & 140 & 130 & 120 & 110 \underset{f 1}{100}(\mathrm{ppm}) & 90 & 80 & 70 & 60 & 50 & 40 & 30 & 20 & 10\end{array}$ 
<smiles>C/C(=C/C(C)/C=C/c1ccccc1)C(=O)NS(C)(=O)=O</smiles>

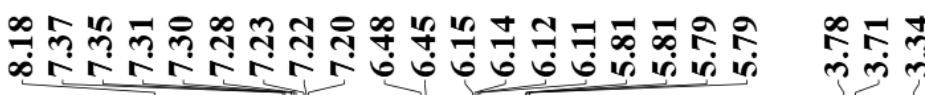

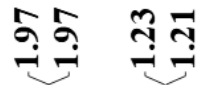
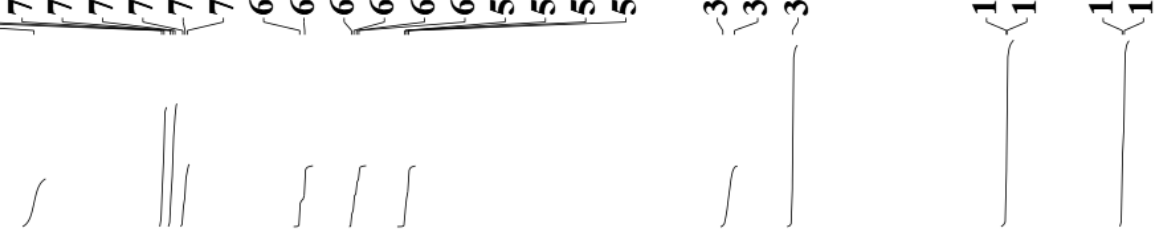

${ }^{1} \mathrm{H} \mathrm{NMR}\left(\mathrm{CDCl}_{3}, 500 \mathrm{MHz}\right)$
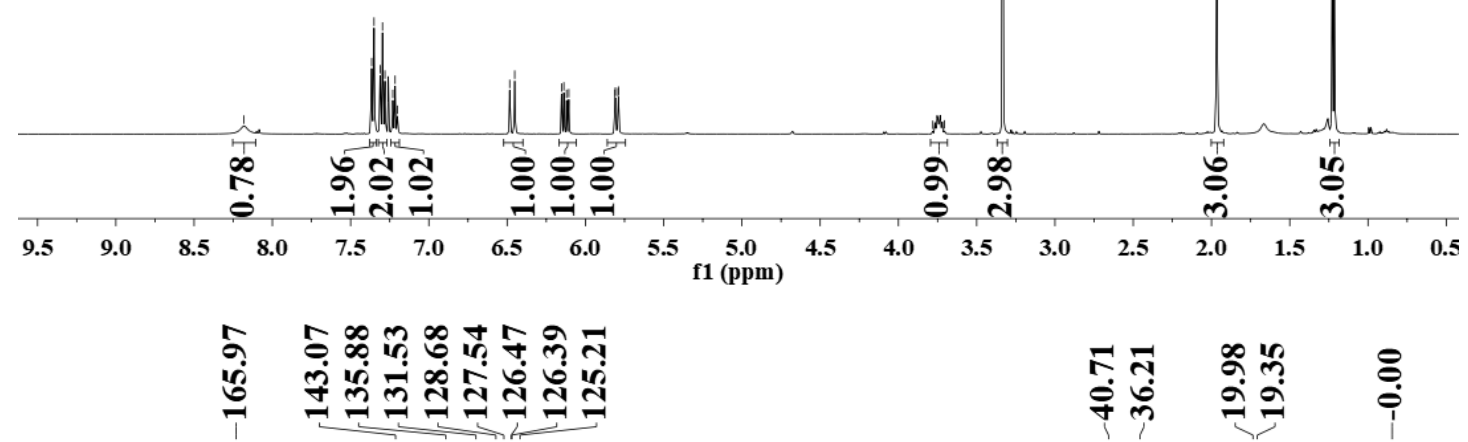

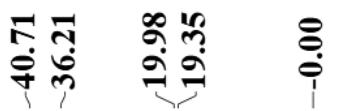

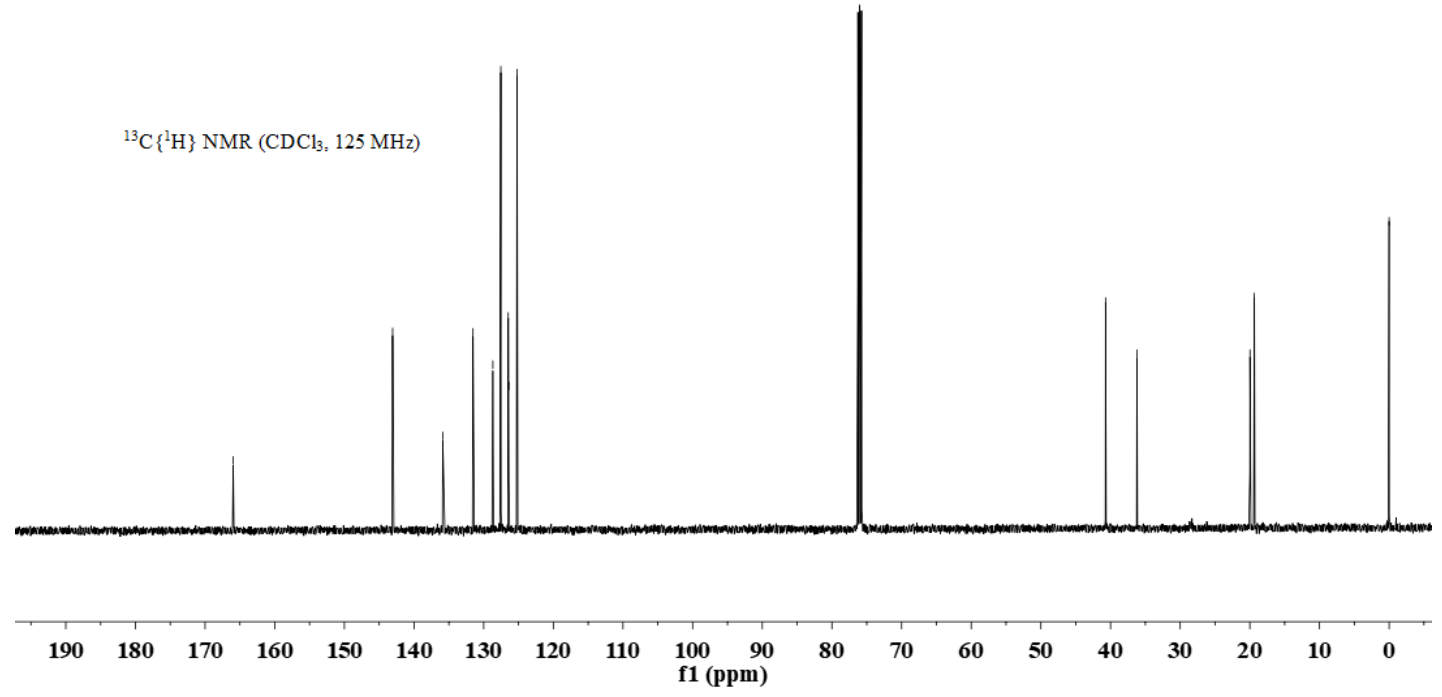



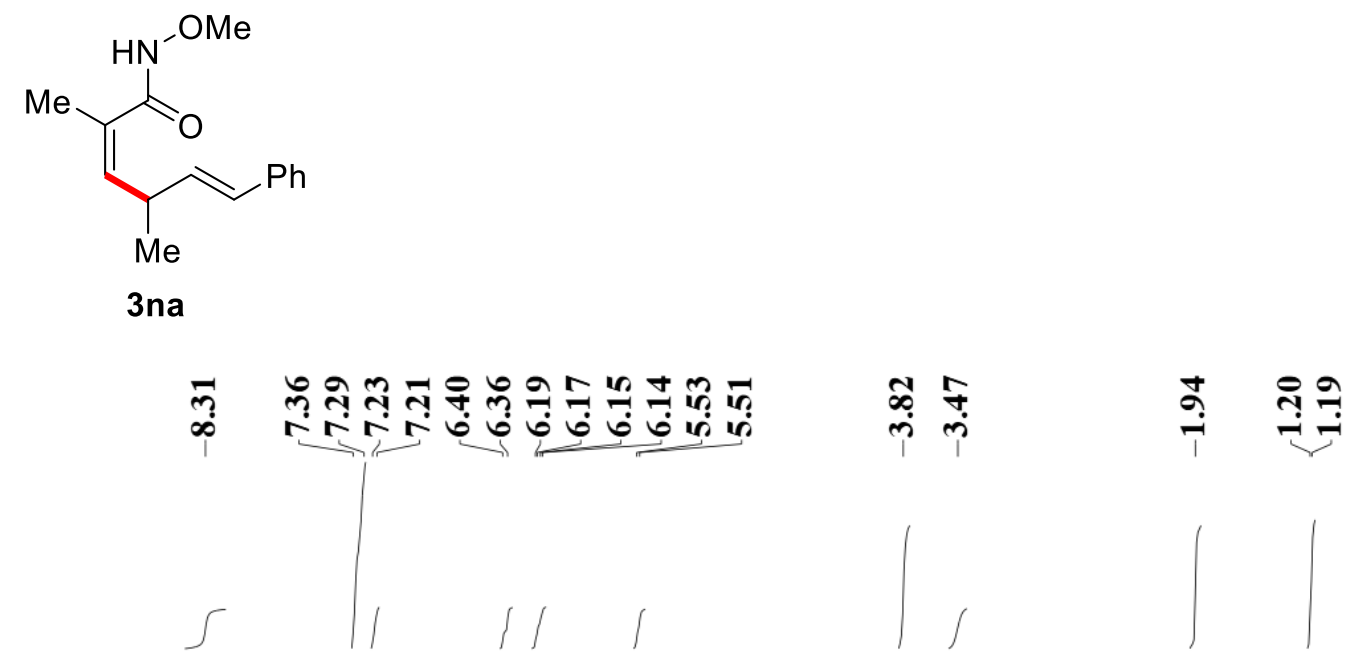

${ }^{1} \mathrm{H} \mathrm{NMR}\left(\mathrm{CDCl}_{3}, 500 \mathrm{MHz}\right)$
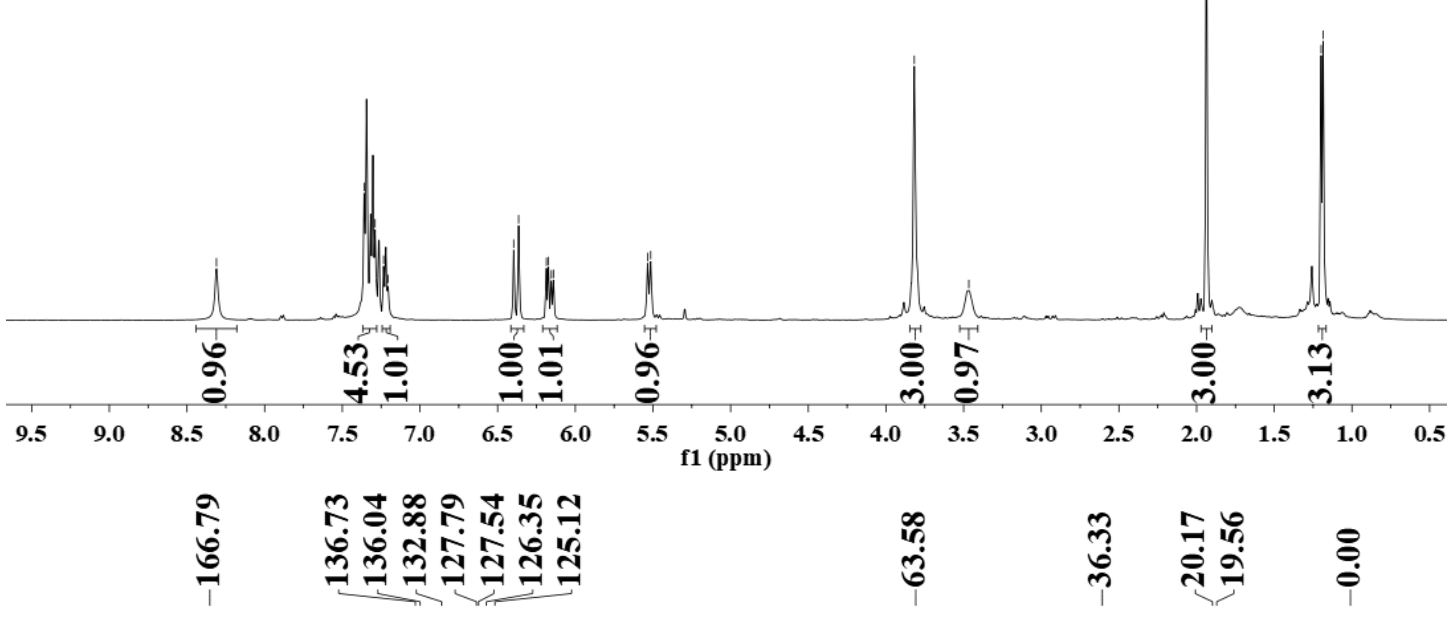

${ }^{13} \mathrm{C}\left\{{ }^{1} \mathrm{H}\right\}$ NMR $\left(\mathrm{CDCl}_{3}, 125 \mathrm{MHz}\right)$

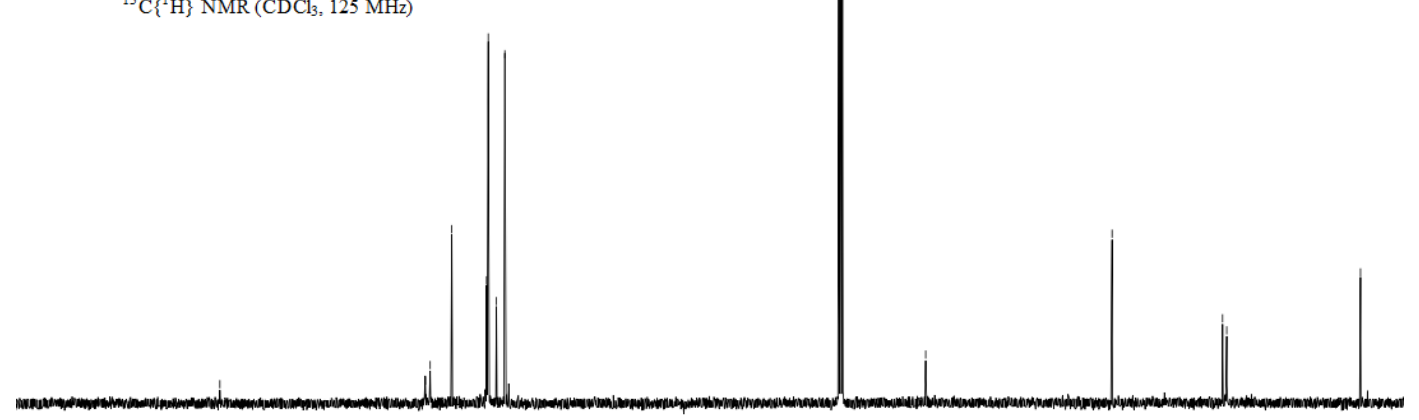

$\begin{array}{lllllllllll}190 & 180 & 170 & 160 & 150 & 140 & 130 & 120 & 110 & 100 & 90\end{array}$ 
<smiles>CONC(=O)/C(=C\C(C)/C=C/c1ccccc1)c1ccccc1</smiles>

3oa

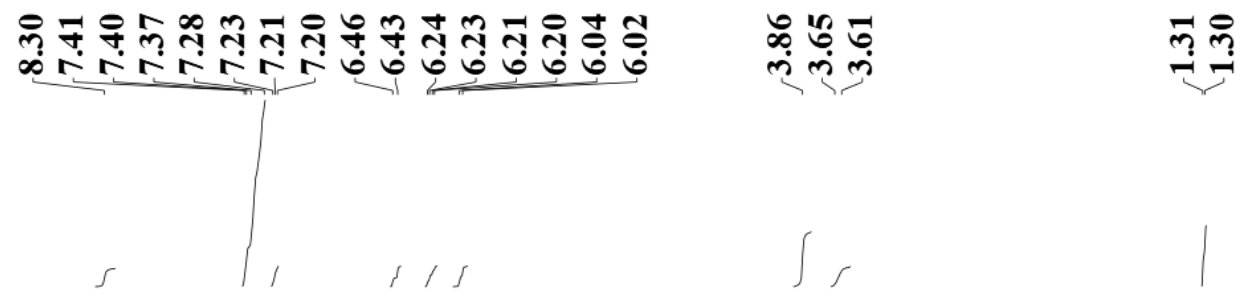

${ }^{1} \mathrm{H} \mathrm{NMR}\left(\mathrm{CDCl}_{3}, 500 \mathrm{MHz}\right)$

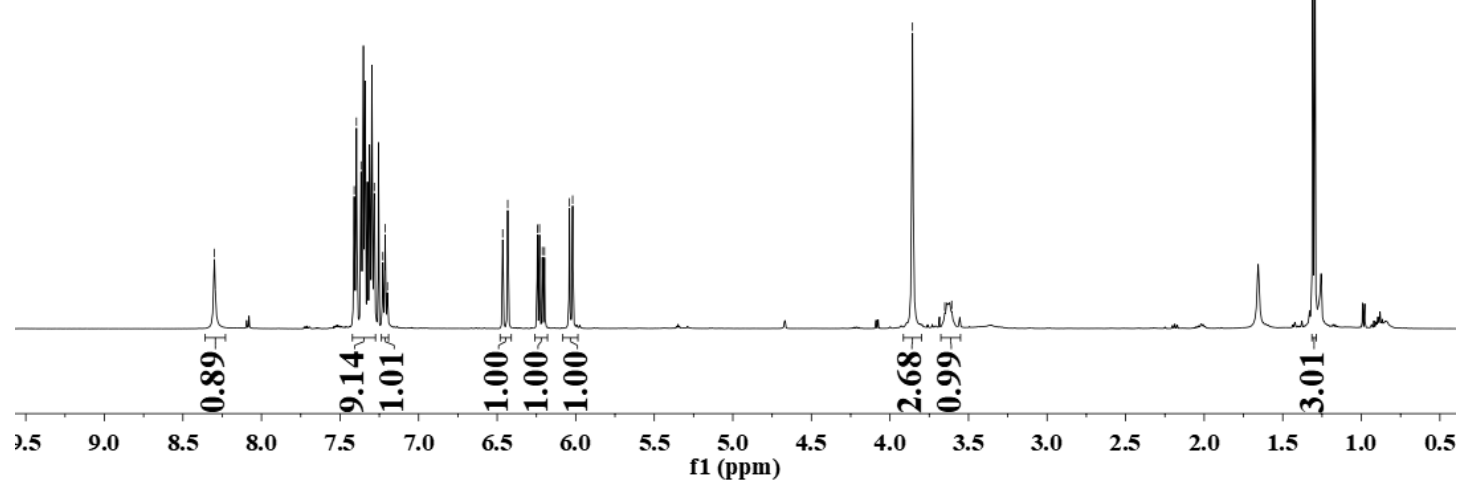

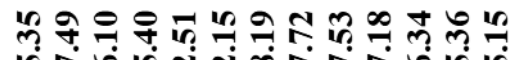

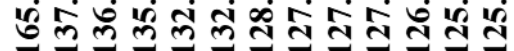

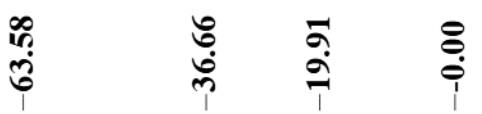

${ }^{13} \mathrm{C}\left\{{ }^{1} \mathrm{H}\right\}$ NMR $\left(\mathrm{CDCl}_{3}, 125 \mathrm{MHz}\right)$

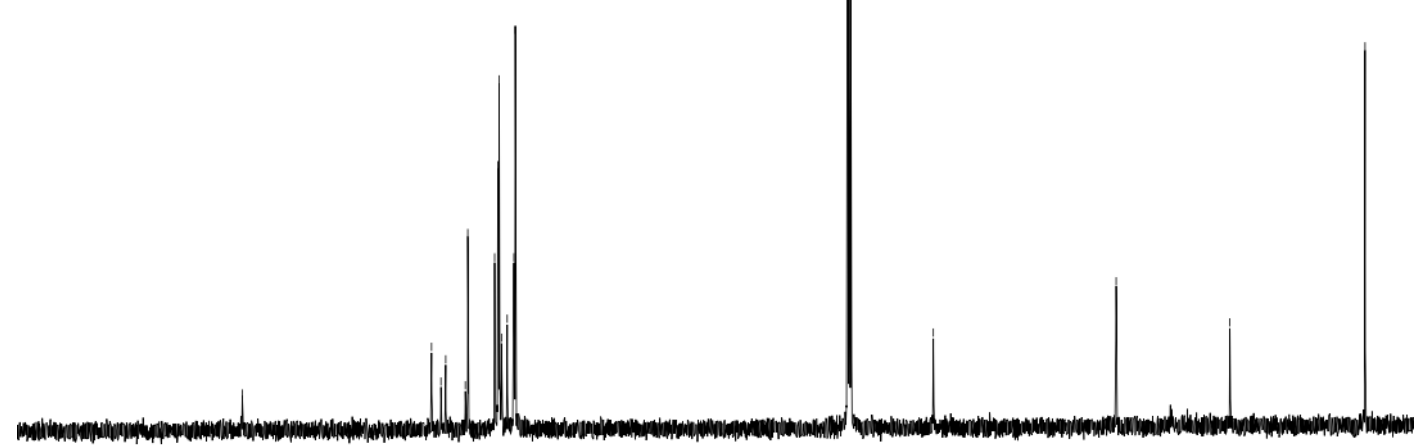

$\begin{array}{llllllllllllllllllll}190 & 180 & 170 & 160 & 150 & 140 & 130 & 120 & 110 & \begin{array}{l}100 \\ \text { f1 }(\mathrm{ppm})\end{array} & 80 & 70 & 60 & 50 & 40 & 30 & 20 & 10 & 0\end{array}$ 
<smiles>[3H]NC(=O)C(C)=C/C(=C\c1ccccc1)c1ccccc1</smiles>

$5 a a$

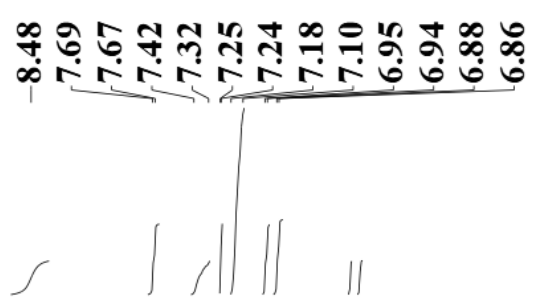

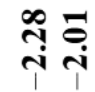

${ }^{1} \mathrm{H} \mathrm{NMR}\left(\mathrm{CDCl}_{3}, 500 \mathrm{MHz}\right)$

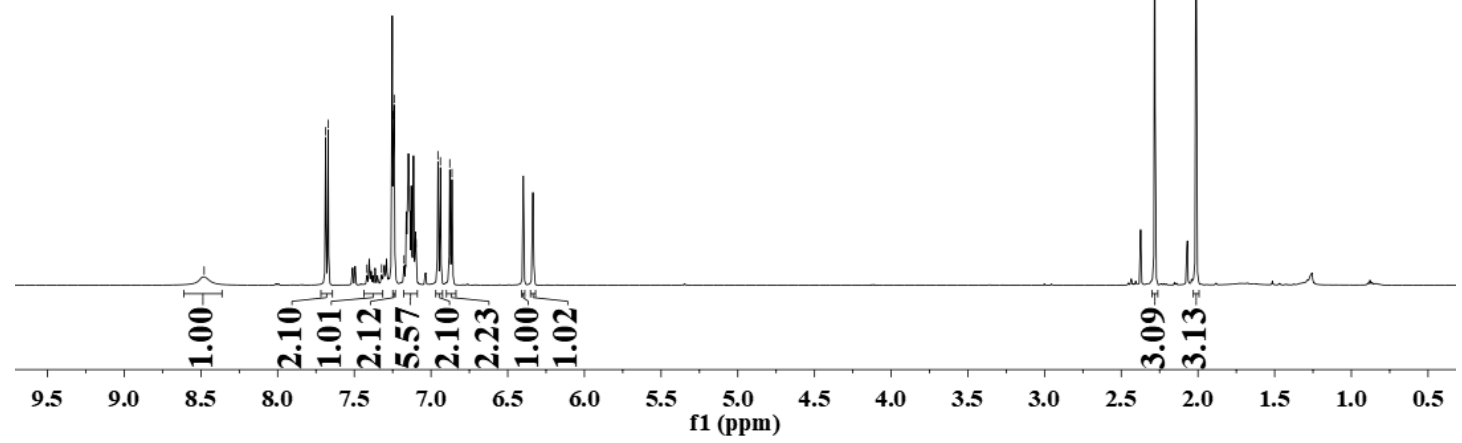

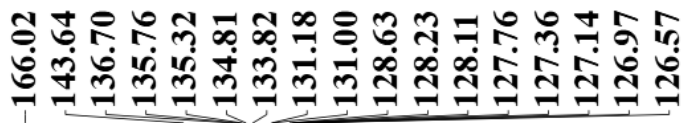

تே:

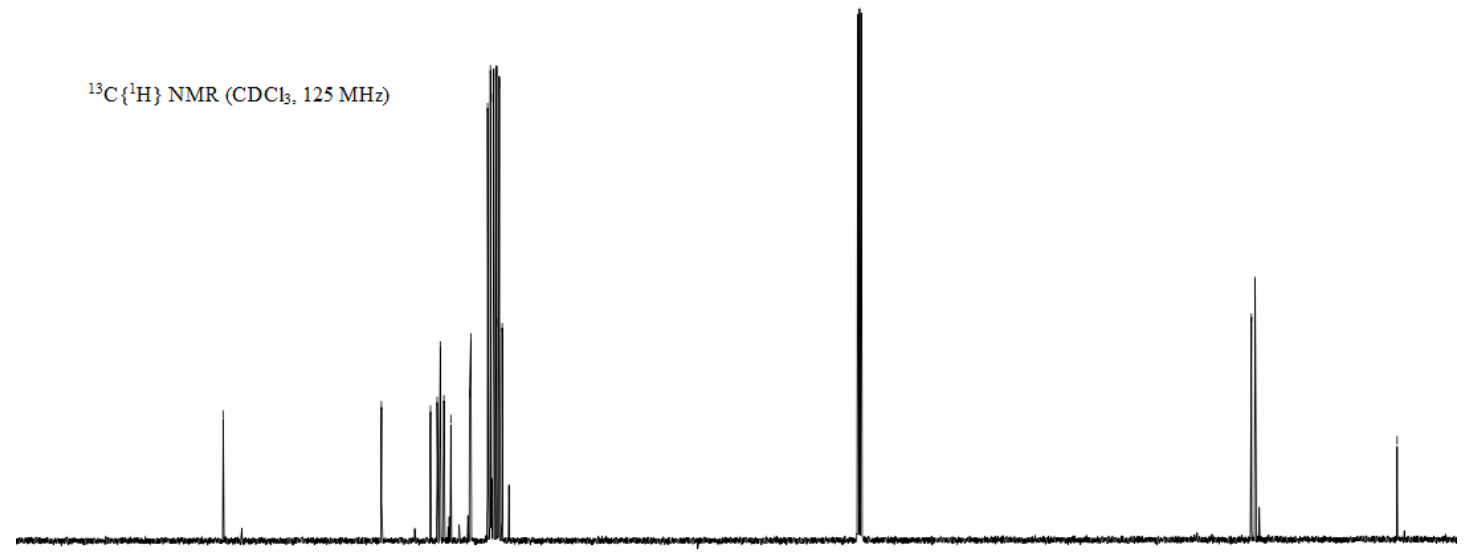

$\begin{array}{lllllllllll}190 & 180 & 170 & 160 & 150 & 140 & 130 & 120 & 110 & 100 & 90 \\ \mathrm{f} 1(\mathrm{ppm})\end{array}$ 
<smiles>[3H]NC(=O)/C(=C\C(=C/c1ccccc1)c1ccccc1)c1ccccc1</smiles>

$5 \mathrm{ba}$

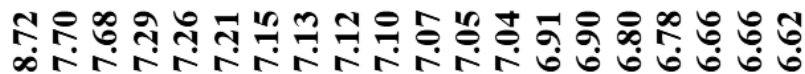

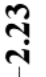

${ }^{2} \mathrm{H} \mathrm{NMR}\left(\mathrm{CDCl}_{3}, 500 \mathrm{MHz}\right)$

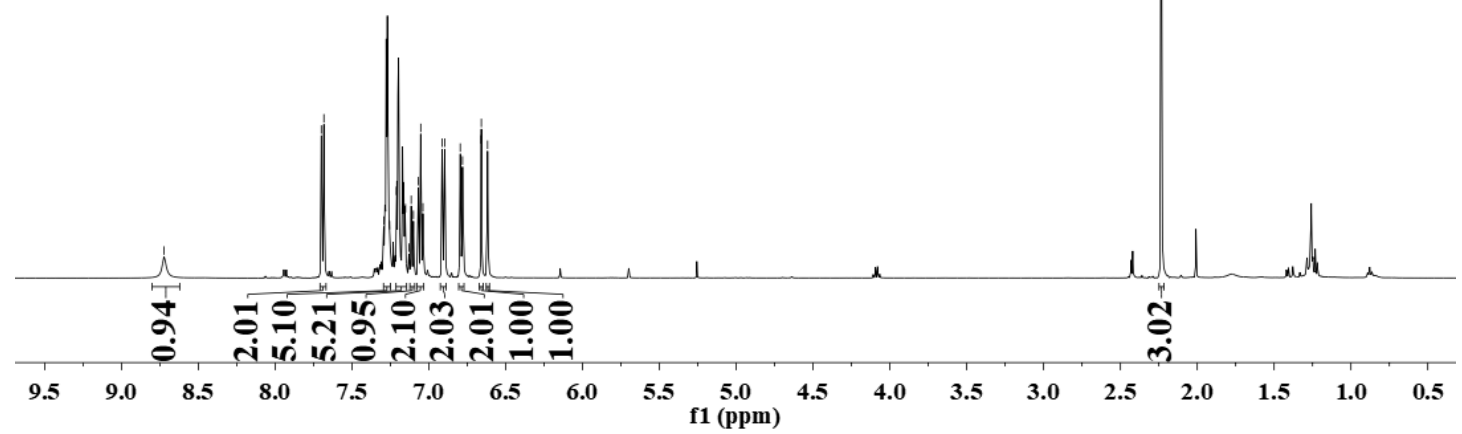

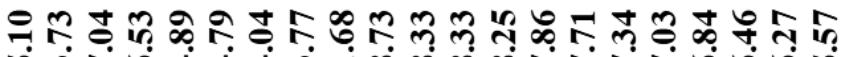

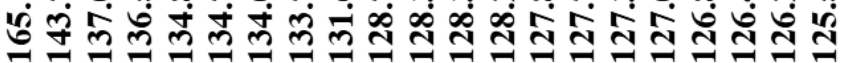

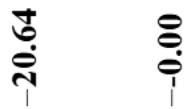

${ }^{13} \mathrm{C}\left\{{ }^{1} \mathrm{H}\right\}$ NMR $\left(\mathrm{CDCl}_{3}, 125 \mathrm{MHz}\right)$

$\begin{array}{lllllllllll}190 & 180 & 170 & 160 & 150 & 140 & 130 & 120 & 110 & \begin{array}{l}100 \\ \text { f1 }(\mathrm{ppm})\end{array}\end{array}$ 
<smiles>NNC(=O)/C(=C\C(=C/c1ccccc1)c1ccc(C(F)(F)F)cc1)c1ccccc1</smiles>

$5 \mathrm{ca}$

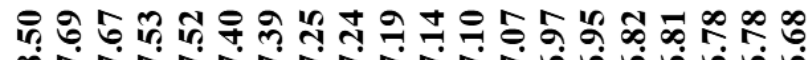

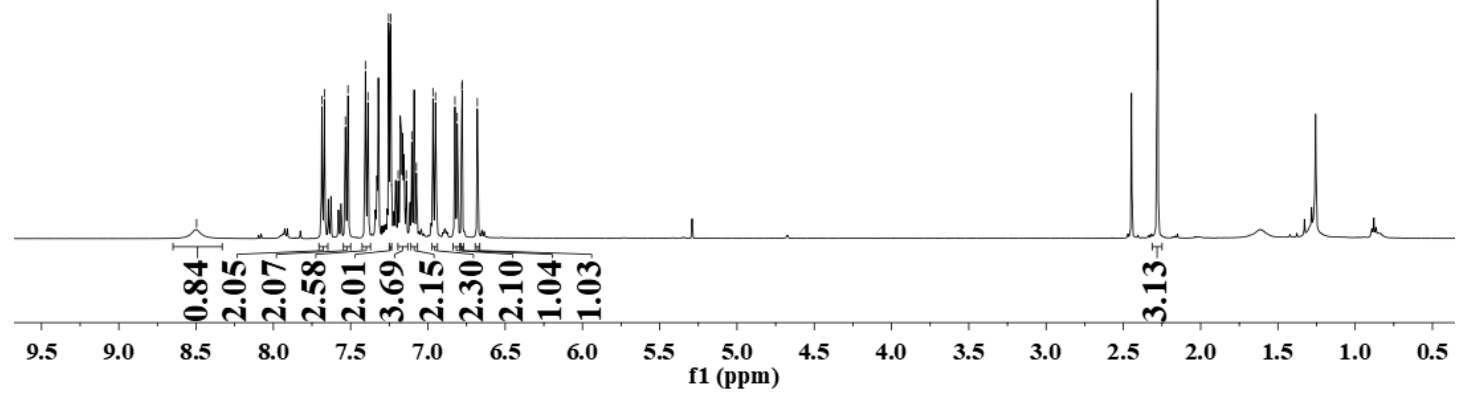

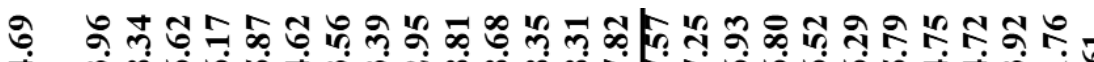

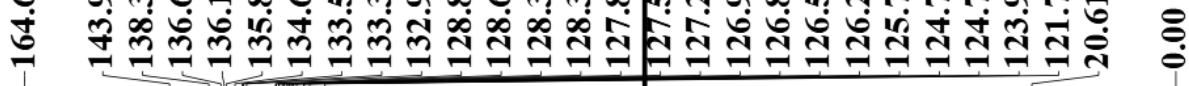

C $\left.{ }^{\mathrm{H}}\right\}$ NMR $\left(\mathrm{CDCl}_{3}, 125 \mathrm{MHz}\right)$

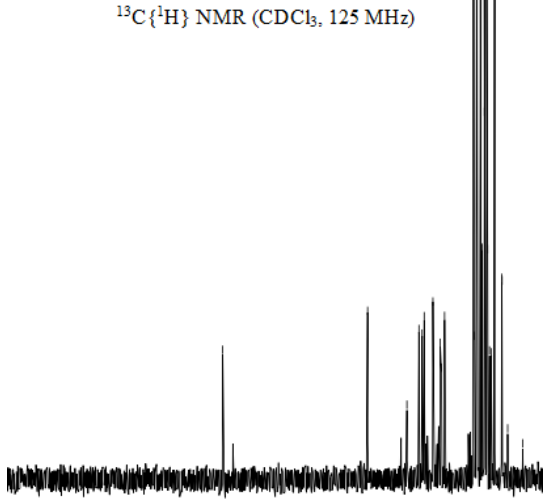

$\begin{array}{llllllllll}190 & 180 & 170 & 160 & 150 & 140 & 130 & 120 & 110 & 100 \\ \text { f1 }(\text { ppm })\end{array}$ 


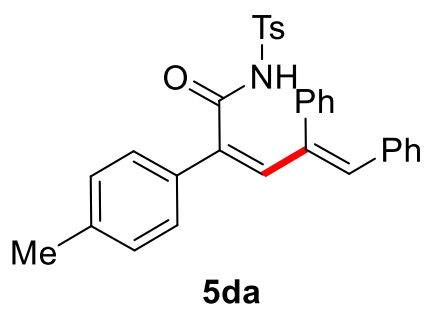

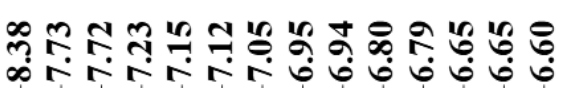

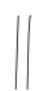

${ }^{1} \mathrm{H}$ NMR $\left(\mathrm{CDCl}_{3}, 500 \mathrm{MHz}\right)$

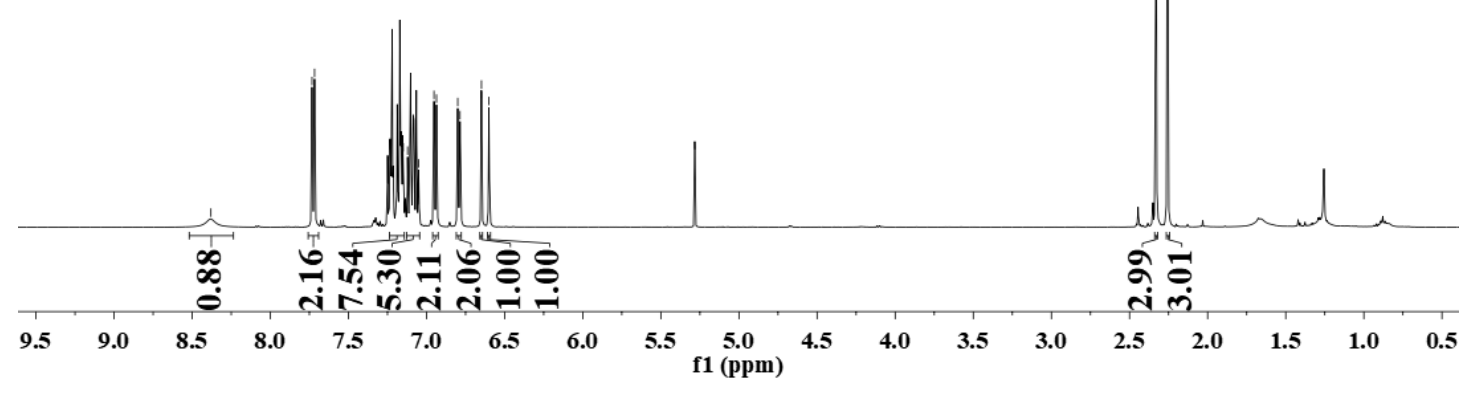

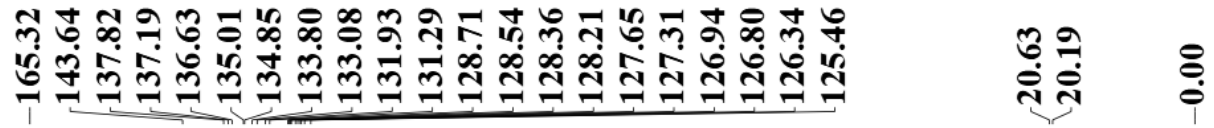
${ }^{13} \mathrm{C}\left\{{ }^{1} \mathrm{H}\right\}$ NMR $\left(\mathrm{CDCl}_{3}, 125 \mathrm{MHz}\right)$

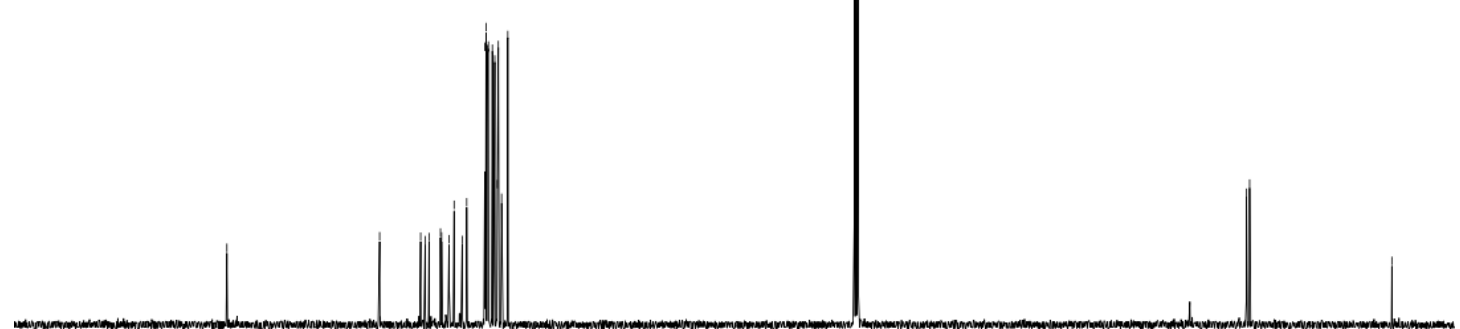

$\begin{array}{llllllllll}190 & 180 & 170 & 160 & 150 & 140 & 130 & 120 & 110 & 100 \\ \mathrm{f} 1(\mathrm{ppm})\end{array}$ 
<smiles>CNC(=O)C(=CC(=Cc1ccccc1)c1ccccc1)c1ccc(OC)cc1</smiles>

5 ea

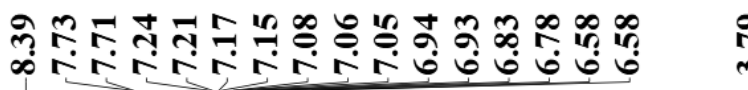

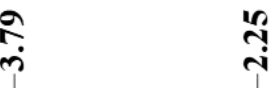

${ }^{1} \mathrm{H} \mathrm{NMR}\left(\mathrm{CDCl}_{3}, 500 \mathrm{MHz}\right)$

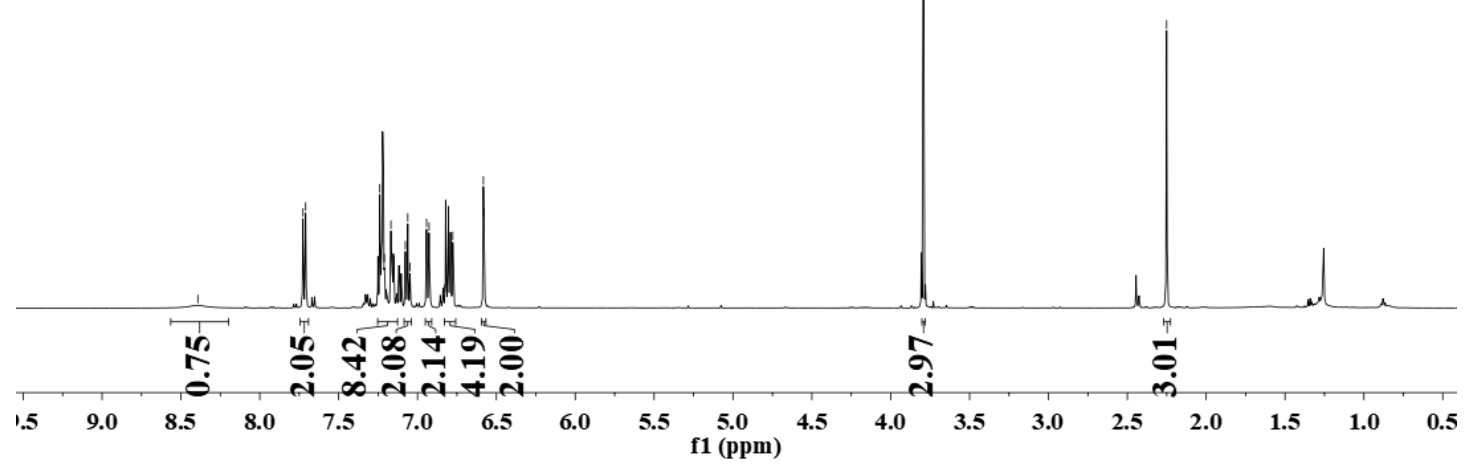

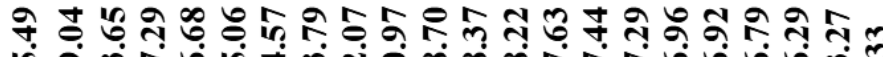

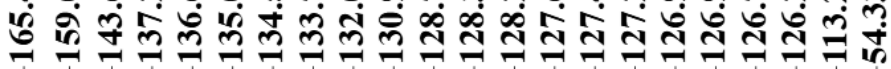

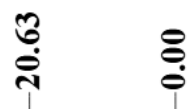

${ }^{13} \mathrm{C}\left\{{ }^{1} \mathrm{H}\right\}$ NMR $\left(\mathrm{CDCl}_{3}, 125 \mathrm{MHz}\right)$

$\begin{array}{llllllllll}190 & 180 & 170 & 160 & 150 & 140 & 130 & 120 & 110 & \begin{array}{r}100 \\ \text { f1 (ppm) }\end{array}\end{array}$ 
<smiles>[3H]NC(=O)/C(=C\C(=C/c1ccccc1)c1ccccc1)C(=O)NC</smiles>

$5 f a$

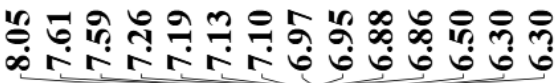

ஸ़े

${ }^{1} \mathrm{H} \mathrm{NMR}\left(\mathrm{CDCl}_{3}, 500 \mathrm{MHz}\right)$

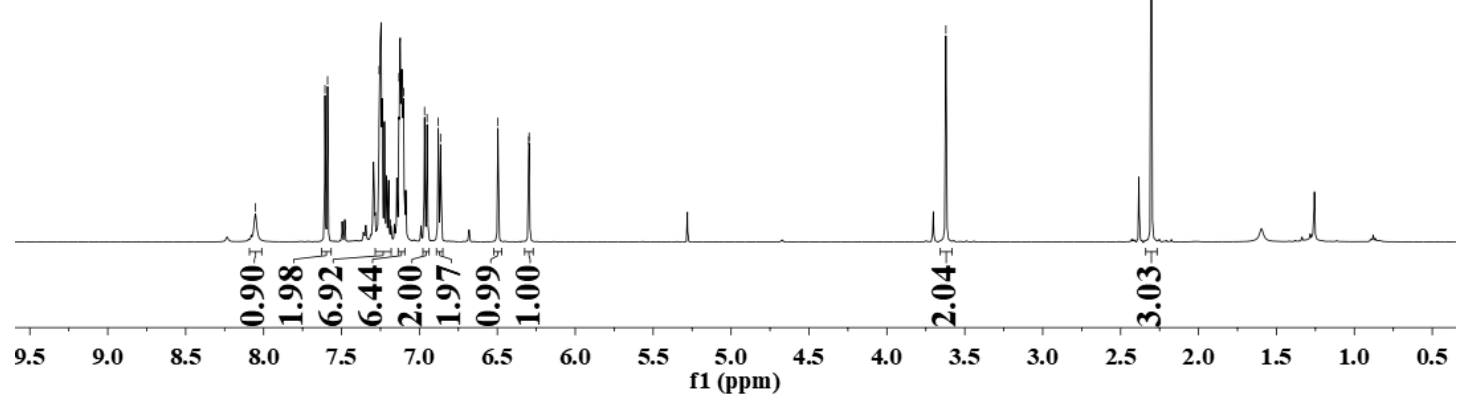

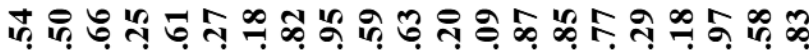

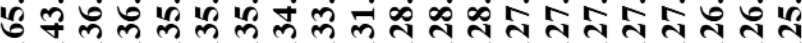
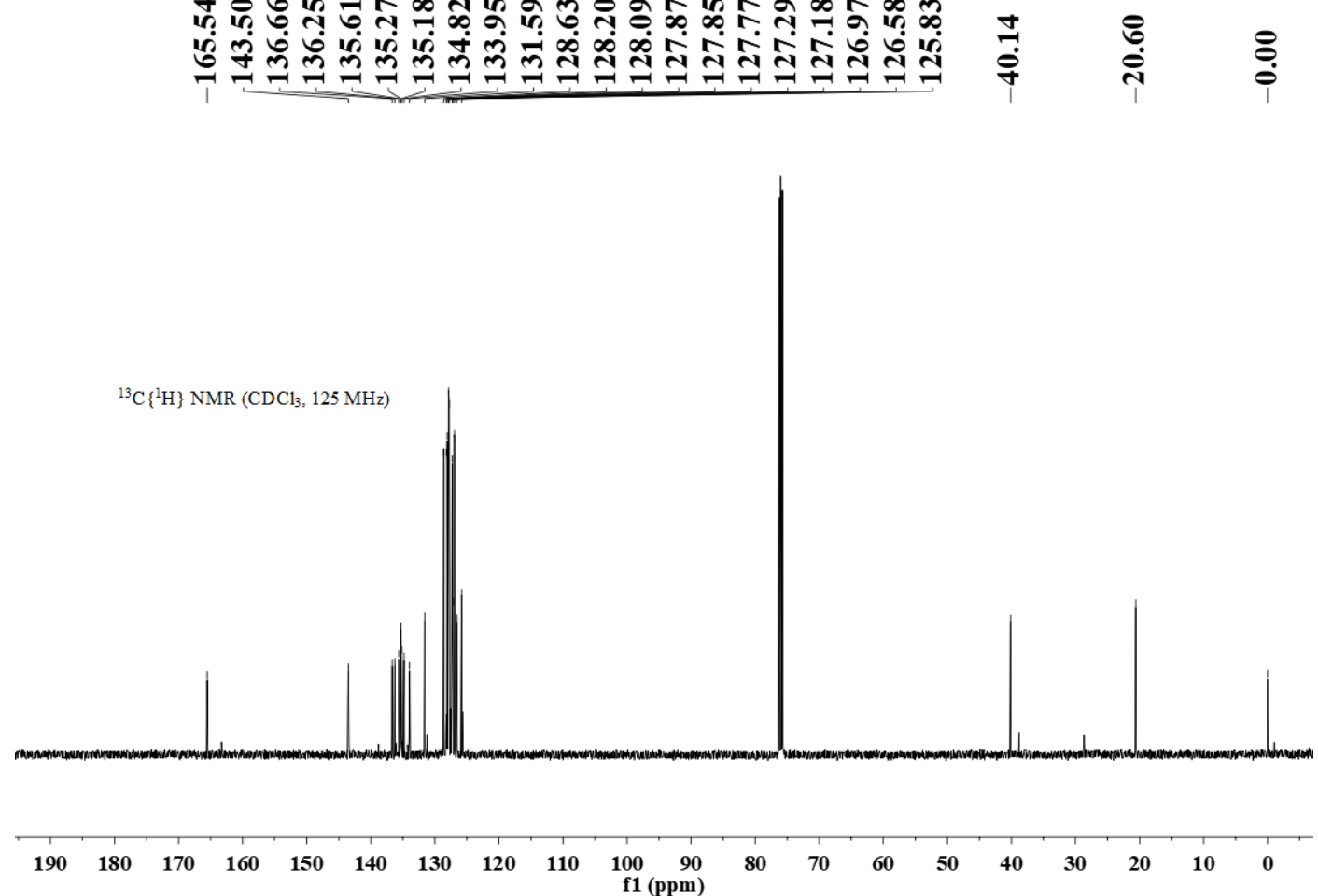


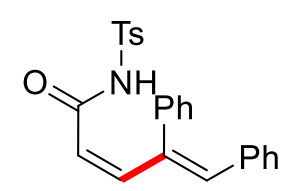

5 ga

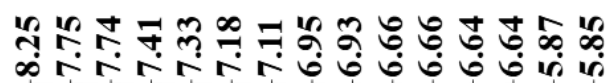

กับ

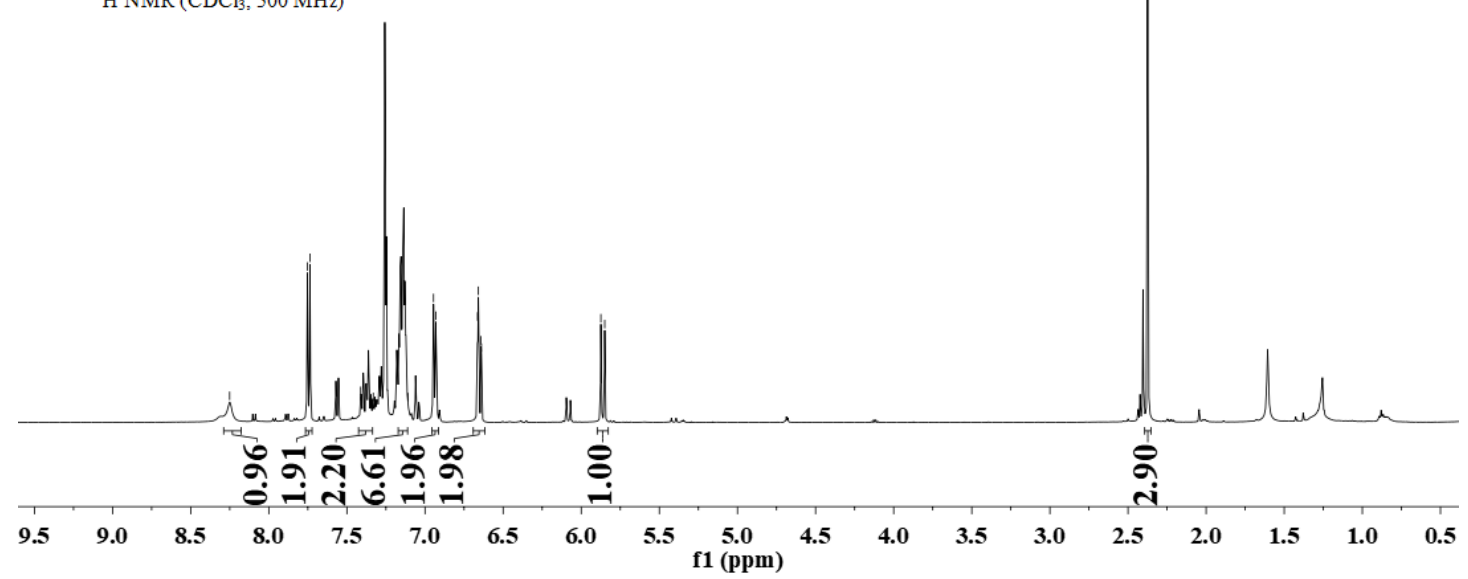

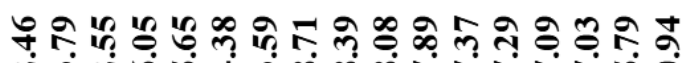

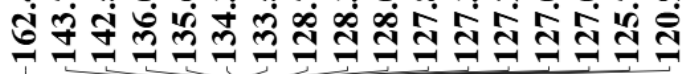

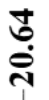

${ }^{13} \mathrm{C}\left\{{ }^{1} \mathrm{H}\right\} \operatorname{NMR}\left(\mathrm{CDCl}_{3}, 125 \mathrm{MHz}\right)$

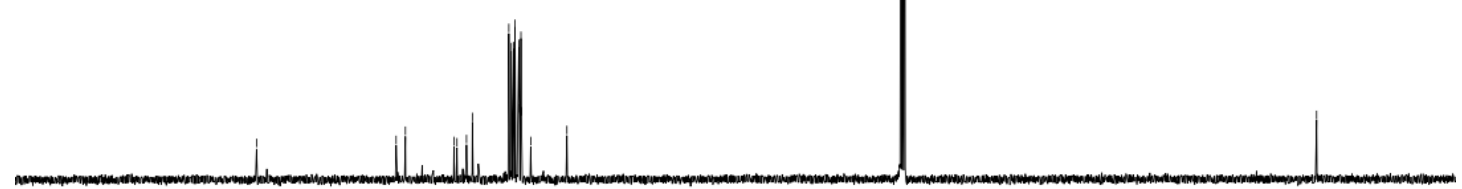

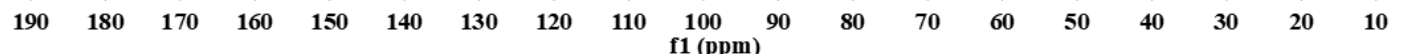




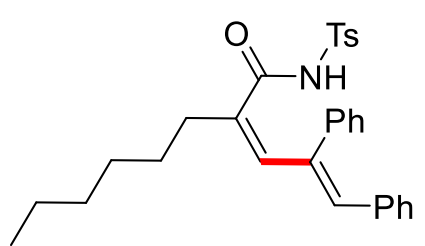

5ha

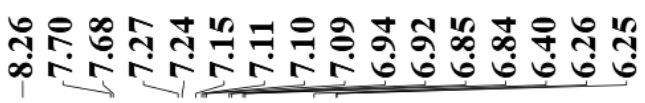

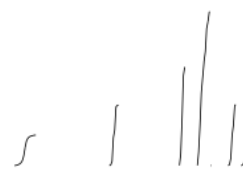

${ }^{1} \mathrm{H} \mathrm{NMR}\left(\mathrm{CDCl}_{3}, 500 \mathrm{MHz}\right)$

${ }^{13} \mathrm{C}\left\{{ }^{1} \mathrm{H}\right\} \mathrm{NMR}\left(\mathrm{CDCl}_{3}, 125 \mathrm{MHz}\right)$

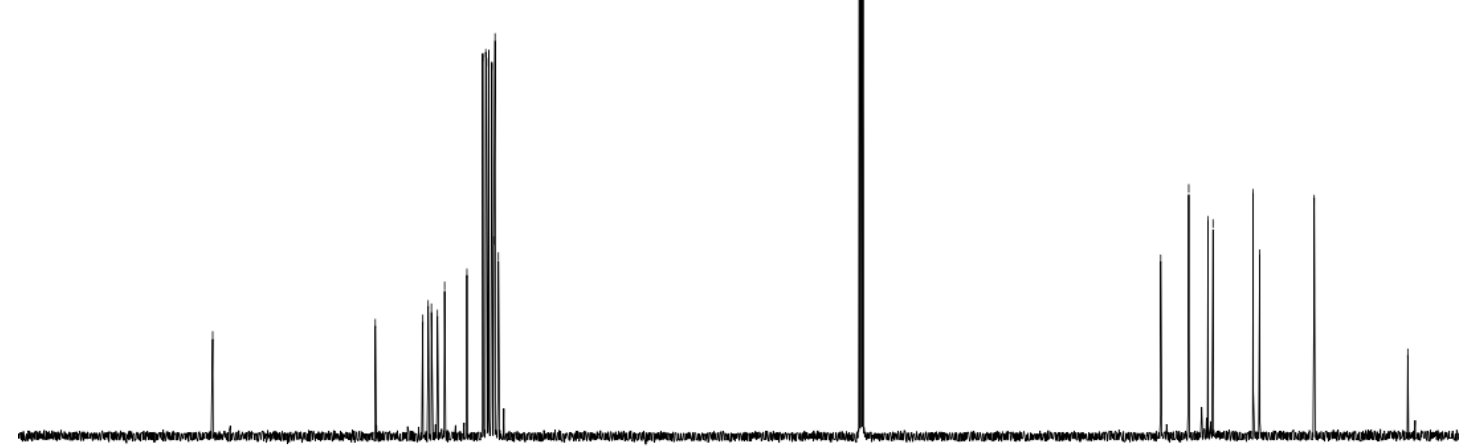

190180

$\begin{array}{llllllllll}170 & 160 & 150 & 140 & 130 & 120 & 110 & 100 & 90 \\ \mathrm{f} 1(\mathrm{ppm})\end{array}$

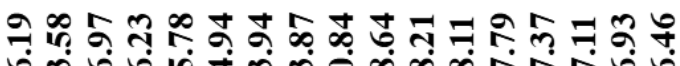

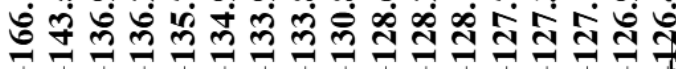

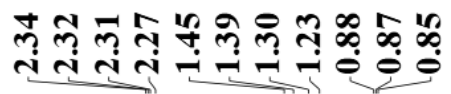
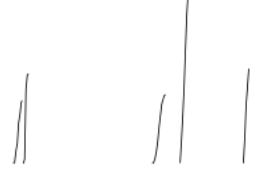

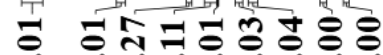

- imis i i i

$\begin{array}{lllllllllllllllllll}9.5 & 9.0 & 8.5 & 8.0 & 7.5 & 7.0 & 6.5 & 6.0 & 5.5 & \underset{\mathrm{f1}}{\mathbf{5}(\mathrm{ppm})} \mathbf{4 0} & 4.5 & 4.0 & 3.5 & 3.0 & 2.5 & 2.0 & 1.5 & 1.0 & 0.5\end{array}$

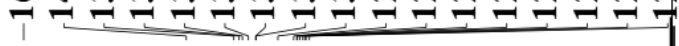

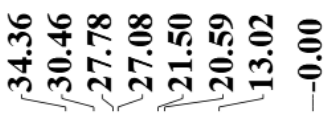


<smiles>[3H]NC(=O)/C(C)=C/C(=C\CC)CC</smiles>

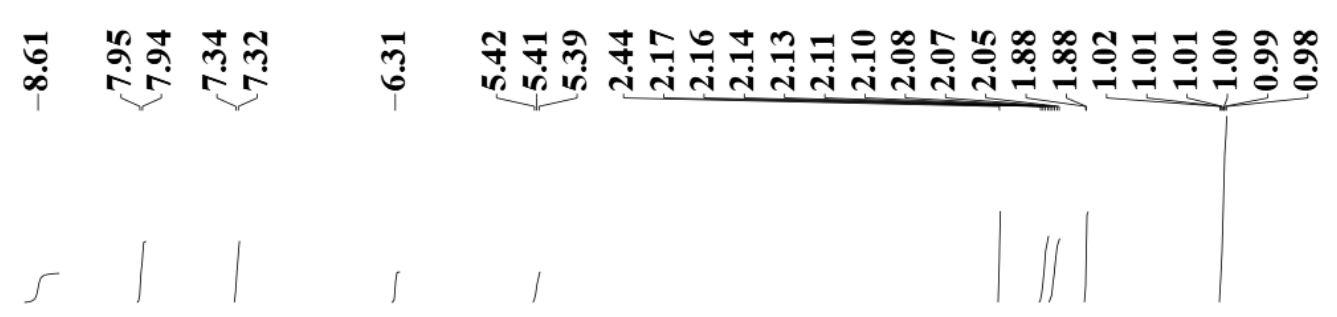

${ }^{1} \mathrm{H} \mathrm{NMR}\left(\mathrm{CDCl}_{3}, 500 \mathrm{MHz}\right)$

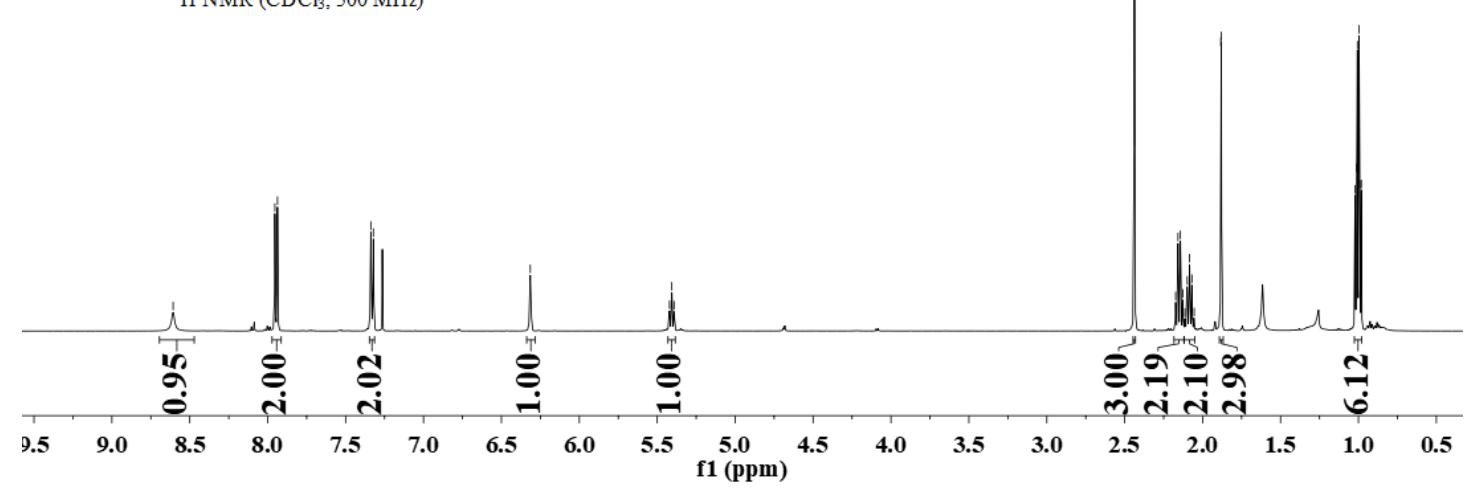

\section{5 $5578 \times 54$ \\ 본}

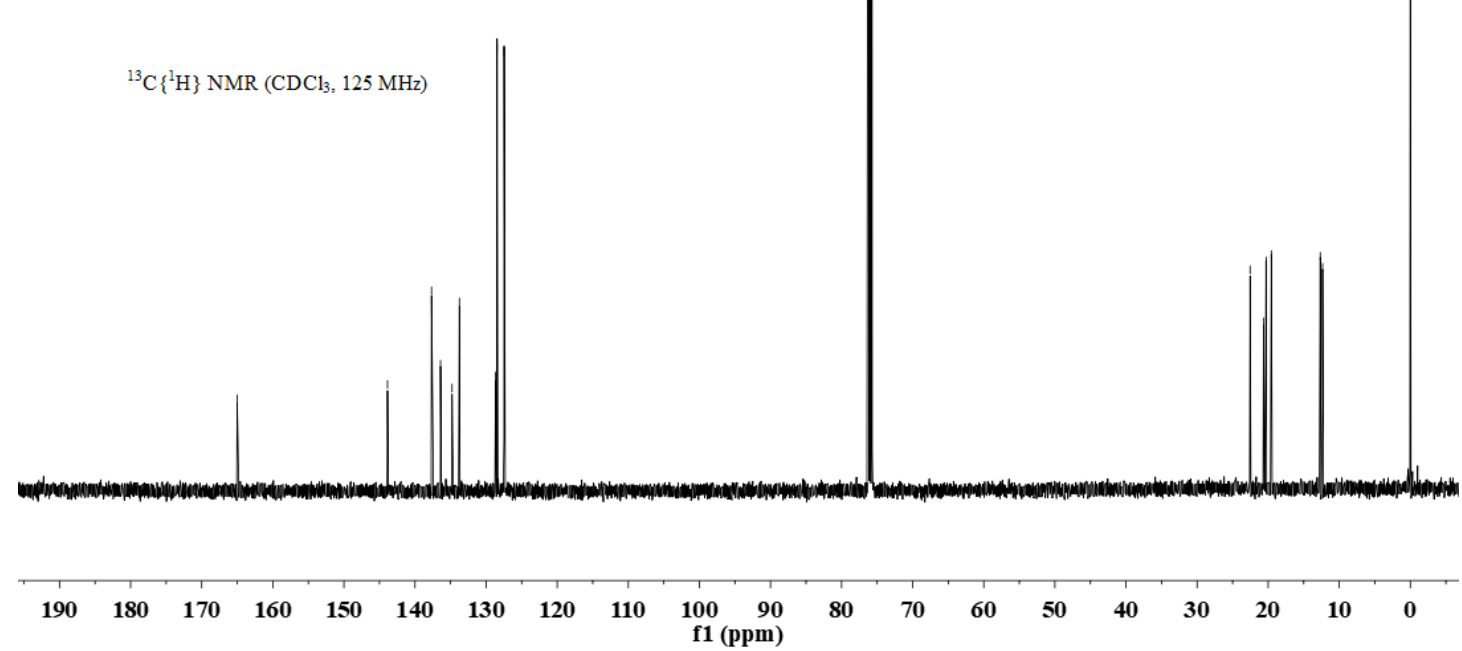


<smiles>[3H]NC(=O)C(C=C(C)C)=CC</smiles>

$5 a c$
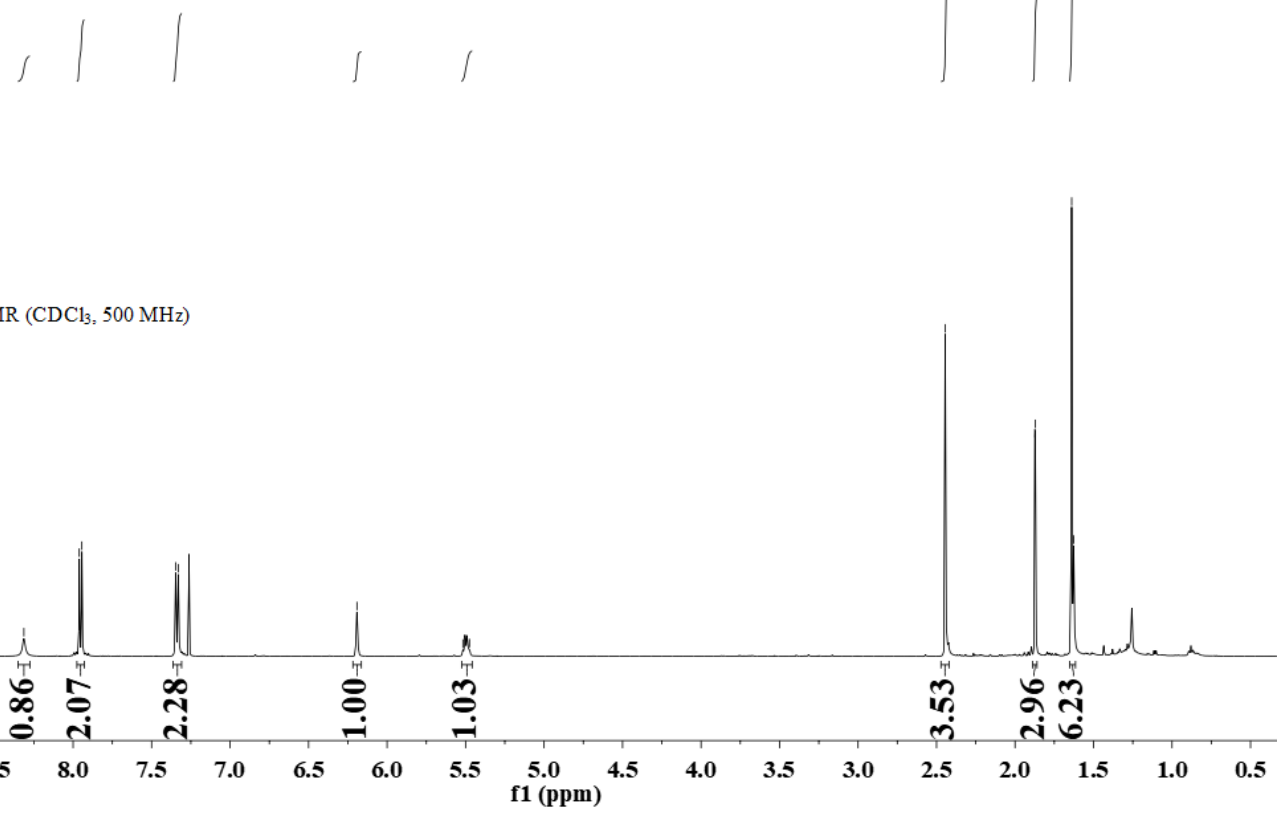

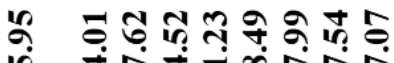

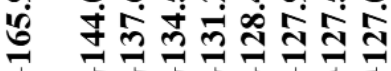

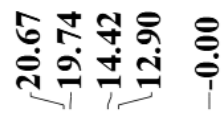

${ }^{13} \mathrm{C}\left\{{ }^{1} \mathrm{H}\right\}$ NMR $\left(\mathrm{CDCl}_{3}, 125 \mathrm{MHz}\right)$

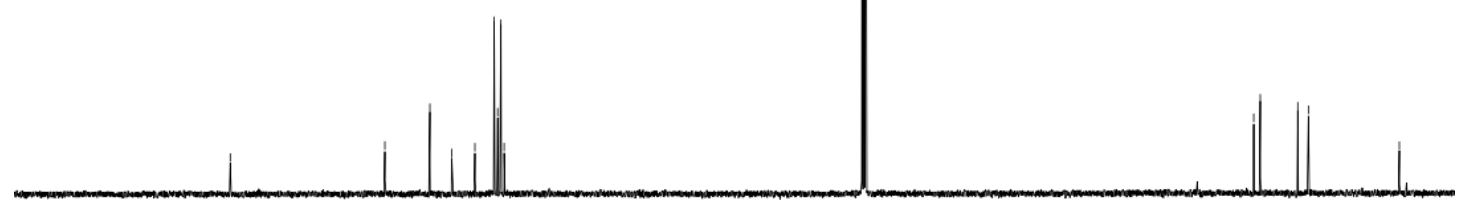

$\begin{array}{lllllllllll}190 & 180 & 170 & 160 & 150 & 140 & 130 & 120 & 110 & \begin{array}{r}100 \\ \text { f1 (ppm) }\end{array}\end{array}$ 
<smiles>[3H]NC(=O)C(C)=CC(=Cc1cccc(Br)c1)c1ccc(Br)cc1</smiles>

$5 \mathrm{ad}$

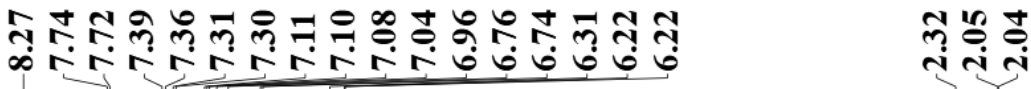

${ }^{1} \mathrm{H}$ NMR $\left(\mathrm{CDCl}_{3}, 500 \mathrm{MHz}\right)$

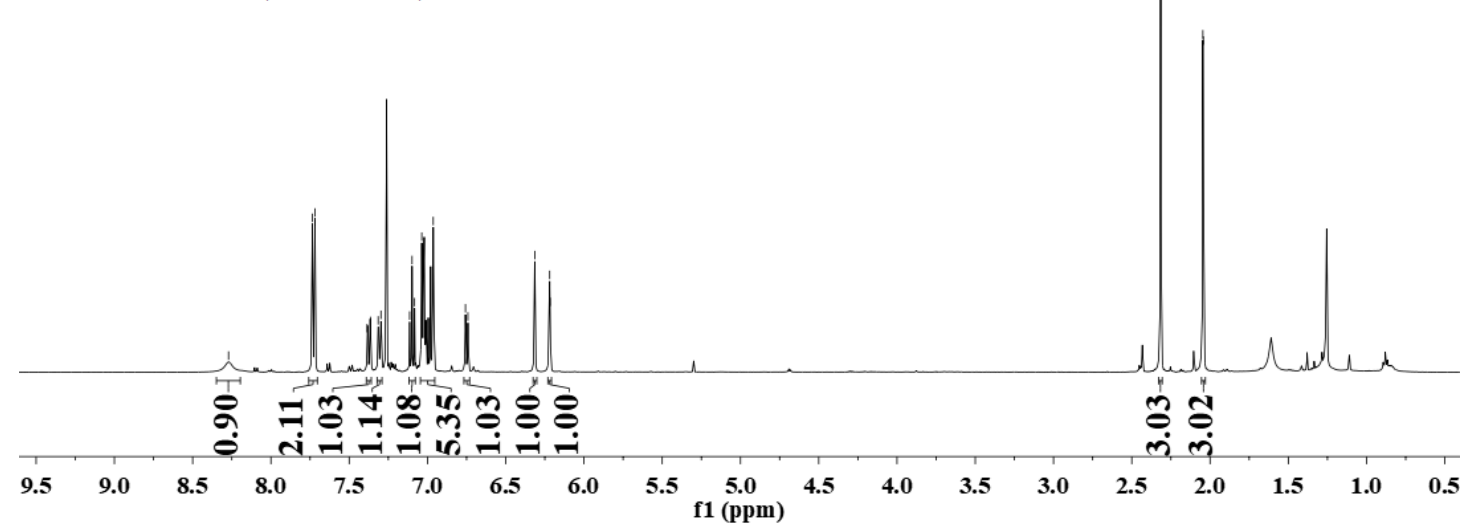

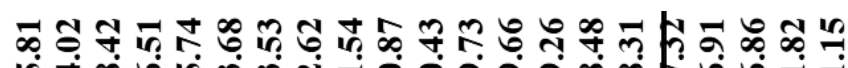

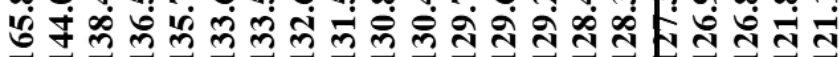

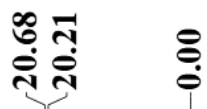

${ }^{13} \mathrm{C}\left\{{ }^{1} \mathrm{H}\right\}$ NMR $\left(\mathrm{CDCl}_{3}, 125 \mathrm{MHz}\right)$

$\begin{array}{lllllllllll}190 & 180 & 170 & 160 & 150 & 140 & 130 & 120 & 110 & \begin{array}{r}100 \\ \text { f1 (ppm) }\end{array}\end{array}$ 
<smiles>[CH2]NC(=O)/C(C)=C\C(=C\CCCCC)CCCCC</smiles>

5 af

${ }^{1} \mathrm{H} \mathrm{NMR}\left(\mathrm{CDCl}_{3}, 500 \mathrm{MHz}\right)$

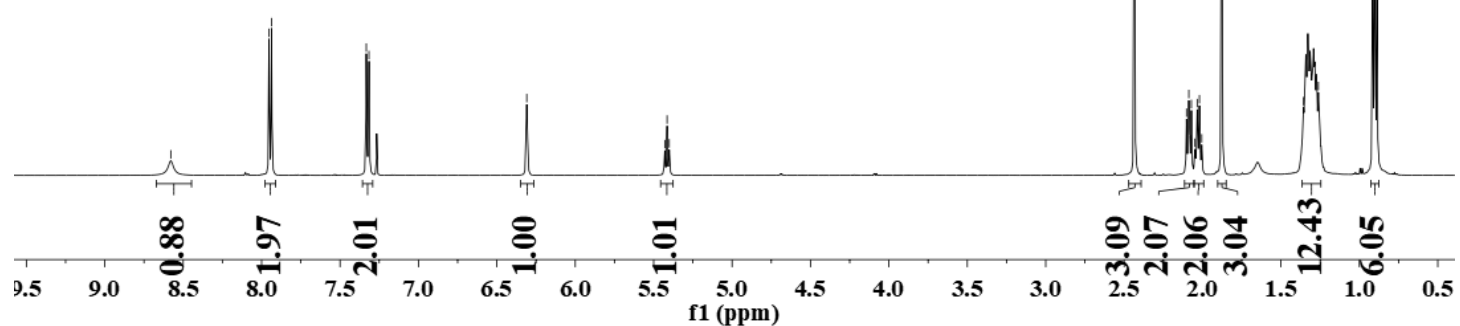

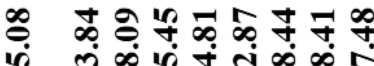

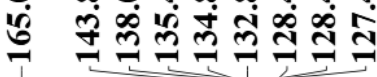

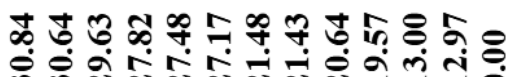

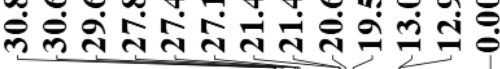

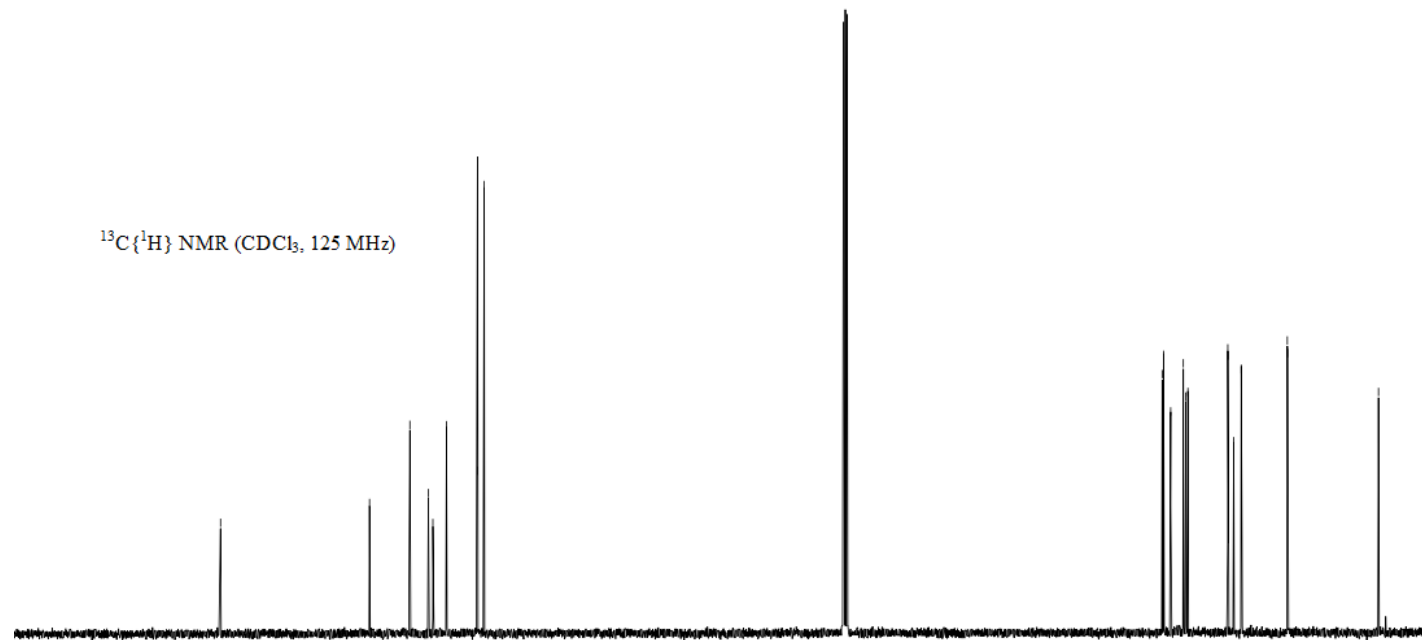

$\begin{array}{lllllllllll}190 & 180 & 170 & 160 & 150 & 140 & 130 & 120 & 110 & 100 & 90 \\ \text { f1 (ppm })\end{array}$ 


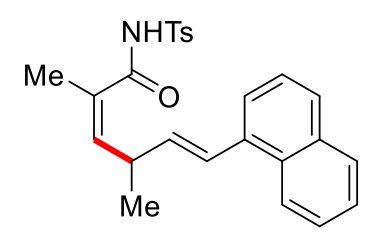

$3 a h$

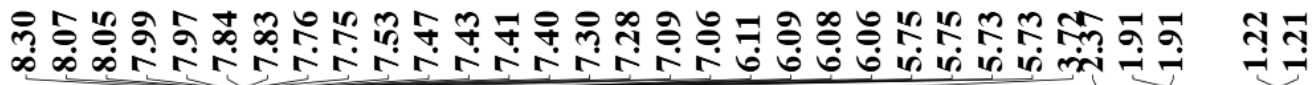

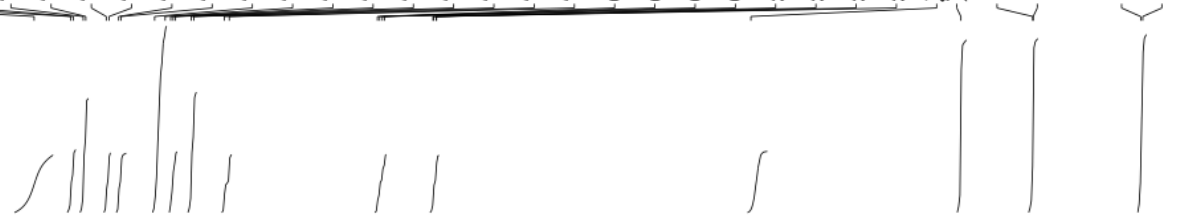

${ }^{1} \mathrm{H}$ NMR $\left(\mathrm{CDCl}_{3}, 500 \mathrm{MHz}\right)$

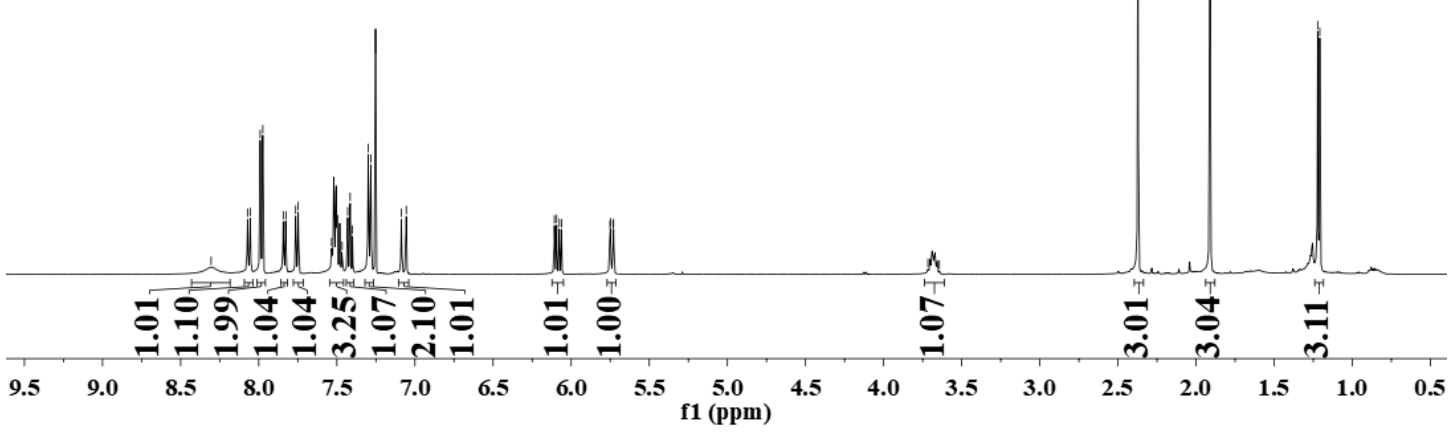

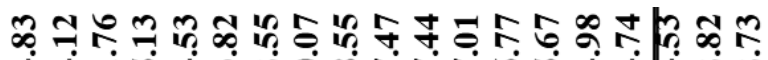

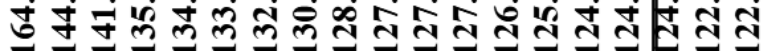

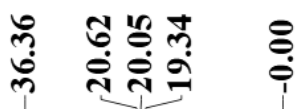

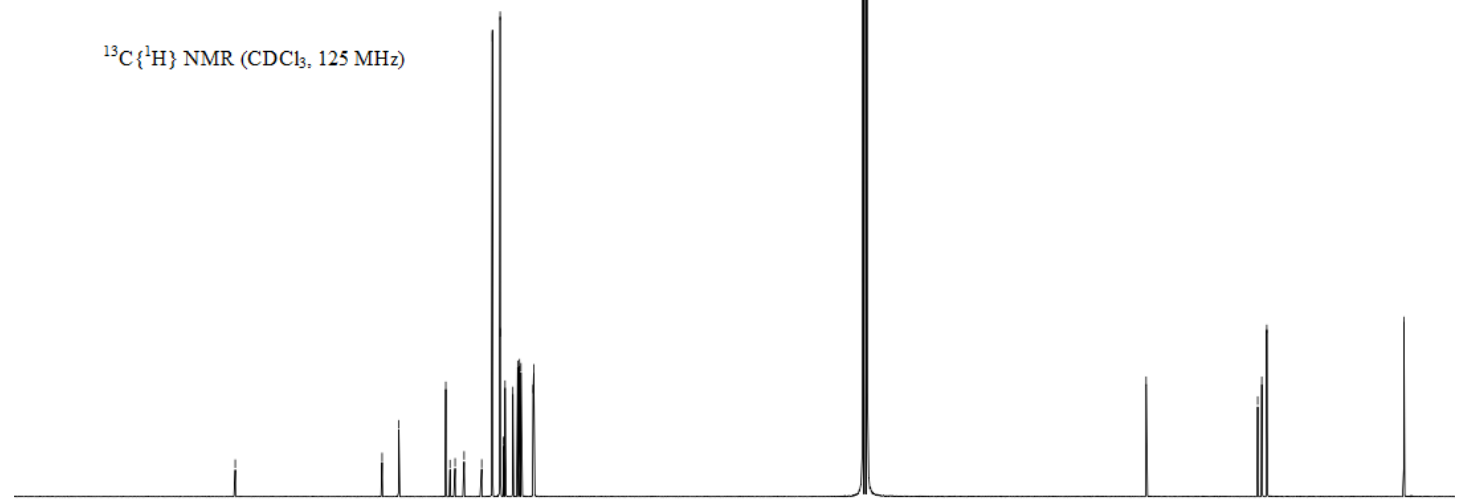

$\begin{array}{lllllllllll}190 & 180 & 170 & 160 & 150 & 140 & 130 & 120 & 110 & \begin{array}{r}100 \\ \text { f1 (ppm) }\end{array}\end{array}$ 